\title{
Nondestructive Inspection of Thin Plasma-Sprayed Ceramic and Cermet Protective Coatings for Coal Conversion and Utilization Equipment
}
K. V. Cook
G. W. Scott
E. V. Davis
W. J. Mason
R. W. McClung
C. V. Dodd
W. A. Simpson, Jr.
B. E. Foster
S. D. Snyder 


\section{DISCLAIMER}

This report was prepared as an account of work sponsored by an agency of the United States Government. Neither the United States Government nor any agency Thereof, nor any of their employees, makes any warranty, express or implied, or assumes any legal liability or responsibility for the accuracy, completeness, or usefulness of any information, apparatus, product, or process disclosed, or represents that its use would not infringe privately owned rights. Reference herein to any specific commercial product, process, or service by trade name, trademark, manufacturer, or otherwise does not necessarily constitute or imply its endorsement, recommendation, or favoring by the United States Government or any agency thereof. The views and opinions of authors expressed herein do not necessarily state or reflect those of the United States Government or any agency thereof. 


\section{DISCLAIMER}

Portions of this document may be illegible in electronic image products. Images are produced from the best available original document. 
Printed in the United States of America Available from National I echnical Intormation Service

U.S. Department of Commerce

5285 Port Royal Road, Springfield, Virginia 22161

Price: Printed Copy $\$ 6.00$; Microfiche $\$ 3.00$

This report was prepared as an account of work sponsored by an agency of the United States Government. Neither the United States Government nor any agency thereof, nor any of their employees, contractors, subcontractors, or their employees, makes any warranty, express or implied, nor assumes any legal liability or responsibility for any third party's use or the results of such use of any information, apparatus, product or process disclosed in this report, nor represents that its use by such third party would not infringe privately owned rights. 
Contract No. W-7405-eng-26

METALS AND CERAMICS DIVISON

\section{NONDESTRUCTIVE INSPECTION OF THIN PLASMA-SPRAYED CERAMIC AND CERMET PROTECTIVE COATINGS FOR COAL CONVERSION \\ AND UTILIZATION EQUTPMENT}

\section{G. W. Scott}
K. V. Cook
W. J. Mason
E. V. Davis
R. W. McClung
C. V. Dodd
W. A. Simpson, Jr.
B. E. Foster
S. D. Snyder

Date Published: April 1978

OAK RIDGE NATIONAL LABORATORY

Oak Ridge, Tennessee 37830

operated by

UNION CARBIDE CORPORATION

for the

DEPARTMENT OF ENERGY

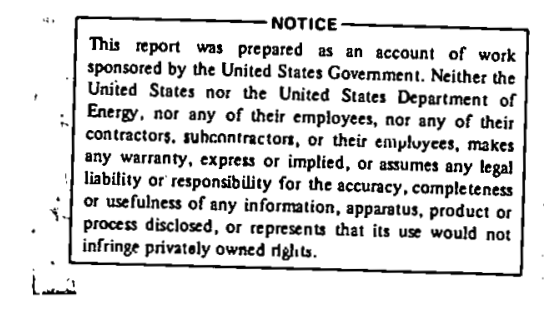




\section{THIS PAGE}

\section{WAS INTENTIONALLY LEFT BLANK}


CONTENTS

ABSTRACT . . . . . . . . . . . . . . . . . . . . 1

INTRODUCTION . . . . . . . . . . . . . . . . . . . . 1

1. USES OF COATINGS, SERVICE REQUIREMENTS, MATERIALS, AND

FAILURE . . . . . . . . . . . . . . . . . . . . . . 3

1.1 PLASMA-SPRAY-COATED COMPONENTS IN COAL SYSTEMS . . . . . 3

1.2 THE SERVICE ENVIRONMENT IN COAL GASIFIER SYSTEMS . . . . 4

1.3 REQUIREMENTS FOR PROTECTION BY COATINGS . . . . . . . . 6

1.3.1 Properties of Composite Layer Structures . . . . 6

1.3.2 Special Requirements for Coatings . . . . . . 6

1.4 COATING MATERIALS AND STRUCTURES . . . . . . . . . . . . 7

1.5 FAILURES AND PRECURSORS OF FAILURE . . . . . . . . . . . 9

1.5.1 Definitions . . . . . . . . . . . . . 9

1.5.2 Inspection Requirements . . . . . . . . . 10

1.5.3 Abnormal Conditions in Coatings . . . . . . 10

2. THE APPLICATION OF NONDESTRUCTIVE TESTING TO PLASMA-SPRAYED-

COATING INSPECTION PROBLEMS . . . . . . . . . . . . 11

2.1 INSPECTION OF COATINGS IN THE COAL PLANT DESIGN-

FABRICATION-OPERATION CYCLE . . . . . . . . . . . . . il

2.1.1 Development and Engineering . . . . . . . . 11

2.1.2 Component Fabrication . . . . . . . . . . . 11

2.1.3 The In-Si.tu Condition . . . . . . . . . . . 13

2.2 GENERAL PROBLEMS RELATED TO INSPECTION OF PLASMA-SPRAYED

COATINGS ON COAL SYSTEM COMPONENTS . . . . . . . . . 13

2.2.1 Coating Surfaces . . . . . . . . . . . . 14

2.2.2 Workpiece Geometry . . . . . . . . . . . . 14

2.2.3 Environment . . . . . . . . . . . . . 14

2.3. APPLICATION OF NDT DEVELOPMENT METHODS TO COATING

INSPECTION PROBLEMS . . . . . . . . . . . . 15

2.4 BIBLIOGRAPHY . . . . . . . . . . . . . . . . 16

3. PENETRATING AND BACKSCATTER RADIATION METHODS . • . • . . 17

3.1 APPLICATIONS TO COATING INSPECTION . . . . . . . . . 17

3.1.1 Transmission Radiography and Gaging . . . . . . 17

3.1.2 Backscatter Radiography . . . . . . . . . 18

3.1.3 Beta-Ray Backscatter . . . . . . . . . . . 18 
3.1 .4 X-Ray Fluorescence (XRF) . . . . . . . . . . 19

3.2. EXPERIMENTAL WORK . . . . . . . . . . . . . . . 19

3.2.1 Transmission Radiography ........... 19

3.2.2 Backscatter Radiography . . . . . . . 20

3.2.3 Beta-Ray Backscatter . . . . . . . . . 20

3.2 .4 X-Ray Fluorescence . . . . . . . . . . . . 21

3.3 BIBLIOGRAPHY . . . . . . . . . . . . . 23

4.. SURFACE INSPECTION MATERIALS . . . . . . . . . . . 24

4.1 APPLICATIONS TO COATING INSPECTION . . . . . . . . 24

4.i.1 Liquid Penetrants . . . . . . . . . . . 24

1.1.2 Filtered Particles.... . . . . . . . . 25

4.1.3 Electrified Particles :............ 26

4.2 EXIERIMTPSTAL WORK............... 20

4.2.1 Specimen Fabrication . . . . . . . . . 26

4.2 .2 Ceramic Coatings . . . . . . . . . . . 28

4.2.3 Cermet Coatings . . . . . . . . . . . . 30

4.3 BIBLIOGRAPHY . . . . . . . . . . . . . 31

5. DIELECTRIC INSPECTION METHODS . . . . . . . . . . . 33

5.1. APPLICATIONS TO COATING INSPECTION . . . . . . . . 33

5.1.1 Capac1cance Gaging . . . . . . . . . . . 33

5.1.2 Microwave Measurements ........... 35

5.1.3 Arc Dlscharge Tests . . . . . . . . . . 36

5.2 exterimental hotuK . . . . . . . . . . . . . jl

5.2.1 Response of a Dimensional Capacitance Gage . . . 37

5.2.2 Microwave Development . . . . . . . . . . 38

5.2 .3 Arc Discharge Testing . . . . . . . . . 38

5.3 BIBLIOGRAPHY ... . . . . . . . . . . . . 44

6. ELECTROCHEMICAL METHODS .............. . . 45

6.1 APYLICATIONS TO COATING INSPECTION ......... 45

6.1.1 Galvanic Methods........... 45

6.1 .2 Differential Electrode Capacitance (DEC)
Methods . . . . . . . . . . . 46

6.2 EXPFRTMFNTAT, WORK . . . . . . . . . . . . . . 47

6.2.1 Galvanic Potential . . . . . . . . . . . 47

6.2.2 Differential Electrode Capacitance....... 47 
6.3 BIBLIOGRAPHY . . . . . . . . . . . . . . . 48

7. EDDY-CURRENT METHODS . . . . . . . . . . . . . 53

7.1 APPLICATIONS TO COATING INSPECTION . . . . . . . . 53

7.1.1 Through-Transmission Methods . . . . . . . 54

7.1.2 Reflection Methods ............ 55

7.2 EXPERIMENTAL WORK ................ 56

7.2.1 Ceramic Coatings . . . . . . . . . . 56

7.2 .2 Cermet coatings . . . . . . . . . . . 58

8. THERMAL INSPECTION METHODS . . . . . . . . . . . . 59

8.1 APPLICATIONS TO COATING INSPECTION . . . . . . . . 59

8.1.1 Material Characterization . . . . . . . . . 59

8.1.2 Mathematical Modeling ............ 60

8.1.3 Scanning Thermometric Inspection . . . . . 61

8.2 EXPERIMENTAL WORK ... . . . . ........ 61

8.2.1 Thermal Modeling . . . . . . . . . . . 61

8.2.2 Video Thermographic Tests ......... 62

8.3 BIBLIOGRAPHY . . . . . . . . . . . . . . . 66

9. ULTRASONIC INSPECTION METHODS ............... 67

9.1 APPLICATIONS TO COATING INSPECTION . . . . . . . . 68

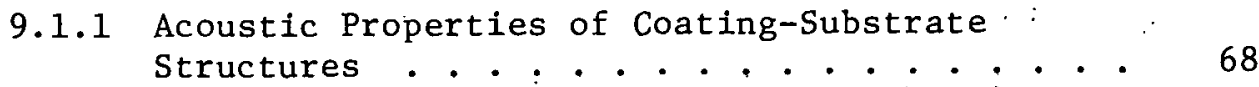

9.1.2 Design of Coating Inspection ........ . 68

9.2 EXPFRIMENTAL WORK . . . . . . . . . . 69

9.2.1 Thickness Gaging . . . . . . . . . . . 69

9.2.2 Critical Angle and Surface Wave Studies... . 69

9.2.3 Norma1-Incidence Pulse-Echo Unbond Detection . 70

9.3 BTRLTOGRAPHY . . . . . . . . . . . . . 72

10. SUMMARY AND TECHNICAL ASSESSMENT OF INSPECTION . . . . . . 73

10.1 LIMITATIONS OF CURRENT WORK . . . . . . . . . . . 73

10.2 ASSESSMENT OF CURRENTLY AVAILABLE INSPECTION CAPABILITY 73

10.2.1 Thickness Measurement . . . . . . . . . 73

10.2.2. Detection of Cracks and Holes........ . 74

10.2.3 Detection of Unbonds and Delaminations . . . . 74

10.2.4 Detection or Measurement of Inhomogeneity . . 75

10.3 RECOMMENDATIONS . . . . . . . . . . . . 75 ACINOHLEDGMENTS . . . . . . . . . . . . . . . 76 


\title{
NONDESTRUCTIVE INSPECTION OF THIN PLASMA-SPRAYED CERAMIC AND CERMET PROTECTIVE COATINGS FOR COAL CONVERSION AND UTILIZATION EQUIPMENT
}

G. W. Scott
K. V. Cook
W. J. Mason
E. V. Davis
R. W. McClung
C. V. Dodd
W. A. Simpson, Jr.
B. E. Foster
S. D. Snyder

\begin{abstract}
This report describes the results of a project to develop nondestructive inspection techniques for ceramic and cermet wear- and process-resistant coatings used in coal system components. The general inspection problem has been analyzed and the difficulties peculiar to plasma-sprayed coatings are discussed. Physical properties, especially porosity, and the nominal $0.25 \mathrm{~mm}$ (0.010 in.) thickness make the inspection of these coatings difficult. The literature has been reviewed for inspection methods and technology adaptable to coating inspection. Several inspection methods have been evaluated for feasibility by laboratory experiments. The basic coating defect. conditions considered are cracks or holes, variations in thickness, lamellar separations, and inhomogeneities. Assessment of current technology indicates that a few nondestructive methods can be applied directly to the inspertion of coatings with very lit.t.le development; in most cases, however, considerable development is required.
\end{abstract}

\section{INTRODUCTION}

Since January 1, 1976, the Nondestructive Testing (NDT) Group at ORNL has studied inspection techniques for wear- and process-resistant coatings for the Fossil Energy area of the Energy Research and Development Administration (now absorbed by the Department of Energy). Our initial task was the inspection of coatings applied in coal gasifiers, but the developments can benefit other conversion and utilization equipment. Available materials for pressure boundaries 
and internal parts of coal equipment frequently do not adequately resist erosion and corrosion caused by exposure to process streams. The use of protective coatings produces a composite structure with each layer tailored to its specific function; fabrication of components this way reduces cost and the need for scarce materials. Adequate inspection assures the functional capability of coated parts and materials.

Coal conversion process equipment operates under harsh conditions and offers correspondingly important and challenging inspection situations. Other projects in the Coal Technology Program are developing protective coatingo or testing their aplicatiul.

Nondestructive inspection methods are needed for protective coatings because many coated items cannot be easily sampled destructively to evaluate or control coating quality. Corrosion-resistant coating materials and application methods have increased in scope over the years; they include plated metals, brushed or sprayed organics and elastomers, and, more recently, flame- or plasma-sprayed metals and ceramics. Erosion-resistant coatings are newer, having awaited the development of abrasion-resistant materials and ways to apply them.

A useful inspection technique must be able to detect failures in the coating protection that exist in a manufactured component or an operating system, either on line or shut down. The maintenance program of an operating plant could be helped by techniques that detect conditions preceding failure and warn of failure.

The emphasis has been on plasma-sprayed ceramic and cermet coatings. We reviewed published documente from the ERDA coal programs to follow materials selection, methods of applying coatings, studies nf failure modes or abnormal conditions in coatings, and any inspection requirements that appear. We reviewed the open technical literature and Government reports to identify existing technology that has been applied or could be adapted to the inspection of plasma-sprayed coatings. We also looked for characterization data on the coatings to input to the design of inspection methods. 
We developed prototype systems of inspection equipment by identifying and assembling suitable commercial items or by designing and fabricating equipment. We have designed and fabricated a number of specimens and standards for laboratory use.

Because of the many testing disciplines involved, space does not permit explaining the principles of each in detail. Therefore, the" significant characteristics of each method that apply to coating inspection are sketched, and bibliographic references to further explanations are provided. The footnoted references are keyed to earlier reports of experimental work at ORNL or to other information bearing directly on the experimental problems.

1. USES OF COATINGS, SERVICE REQUIREMENTS, MATERIALS, AND FAILURE

\subsection{PLASMA-SPRAY-COATED COMPONENTS IN COAL SYSTEMS}

Direct utilization systems use the coal as mined, with minor physical changes such as crushing or grinding. Conversion systems derive other types of fuels, such as oils and gases, from the coal, leaving a combustible char as the residue. Conversion processes may. remove a large fraction of undesirable components, such as sulfur, from the coal and produce a solid, carbonaceous material that burns with diminished pollution.

Examples of coating applications include:

1. At least one stage of many refining and conversion processes requires handling pulverized coal in an oil slurry and transferring or pressurizing it by pumping. Coatings are being tested on valve plungers, seats, and disks in reciprocating slurry pumps. Wear plates, casings, and impellers in centrifugal pumps are being tested; ${ }^{1}$

${ }^{1}$ E. J. Miles and E. G. Halleck, Evaluation of Process Pumps for CRESAF Testing, The Fluor Corporation, FE-1517.31 (March 1976). 
2. Heat transfer tubing used in combustion units, such as boilers or fluidized-bed combuster's, may be coated to resist corrosive attack from combustion gas and ash. ${ }^{2,3}$

3. Coatings are being tested on nozzles, buckets, and shrouds of gas turbines. ${ }^{4}$ Gas turbines are being developed for use in topping cycle systems burning oịl or low-Btu gas derived from coal.

4. Conversion. and other process systems use experimental coated components such as cyclone, separators, baffles, and hopper parts.

\subsection{THE SERVICE ENVIRONMENT IN COAL GASIFIER SYS'IEMS}

operating conditiong vary somewliat. Uetween gasleying processes.

Illinois Institute of Technology Research Institute (IITRI) has designed a test matrix for gasifier materials ${ }^{5}$ and it reflects current estimates of service conditions. Tables 1.1 through 1.3 , adapted from IITRI reports, describe the test conditions used to simulate gasifier operation.

${ }^{2}$ E. D. Montrone, "Design of Jmproved Materials Systems for CoalFired Boiler Superheater and Reheater Tubes," presented at ERDA-EPRI-AGA Conference on Materials for Coal Conversion and Utilization, September 1976.

${ }^{3} R$, G. Frank, "Inveotigation of Corrosiull Performance of boiler and Gas Turbine Alloys in "Fluidized Bed Combustion Systems," presented at ERDA-EPRI-AGA Conference on Materials for Coal Conversion and Utilizatinn, September $19 / 6$.

${ }^{4}$ F. V. Flynt, High Temperature Gas Turbine Engine Component Materials Testing Program Quart. Prog. Rep. 1, FE-1765-4 (Oct. 15, 1975).

${ }^{5}$ A. 0. Schaefer et al., A Program to Discover Materials Suitable for Service Under Hostile Conditions obtaining in Equipment for the Gasification of Coal and Other Solid Fuels Annix. Prng. Rep. DBc. 31, 1975, The Metal properties Council, Inc., FE-1784-12.

Table 1.1. Gas Atmosphere for MPC-IITRI-ERDA Gaseous Corrosion Screening Tests

\begin{tabular}{lcccccccc}
\hline Component & $\cdots$ & $\mathrm{H}_{2}$ & $\mathrm{CO}$ & $\mathrm{CO}_{2}$ & $\mathrm{CH}_{4}$ & $\mathrm{NH}_{3}$ & $\mathrm{H}_{2} \mathrm{~S}$ & $\mathrm{H}_{2} \mathrm{O}$ \\
Content, vol \% & 24 & 18 & 12 & 5 & 1 & $0-1.0^{\mathrm{a}}$ & $39-40$
\end{tabular}

${ }^{a}$ Adjusted in steps for various experiments, according to Tables 1.2 and 1.3 . 
Table 1.2. Test Matrix for High-Temperature Oxidation-Sulfidation Corrosion Tests in Process Gas.

\begin{tabular}{ll}
\hline \multicolumn{1}{c}{ Variable } \\
\hline $\mathrm{H}_{2} \mathrm{~S}$ concentration, vol $\%$ & \multicolumn{1}{c}{ Values in Test } \\
Gas temperature, ${ }^{\circ} \mathrm{C}\left({ }^{\circ} \mathrm{F}\right)$ & $482(900), 816(1500), 982(1800)$ \\
Pressure, $\mathrm{MPa}(\mathrm{psi})$ & $1.03(150), 6.89(1000)$ \\
Exposure time, $\mathrm{hr}$ & $100,1000,5000.5$.
\end{tabular}

Table 1.3. Test Matrix for High-Temperature CorrosionErosion Tests in Simulated Process stream

\begin{tabular}{ll}
\hline \multicolumn{1}{c}{ Variable } & \multicolumn{1}{c}{ Values in Test } \\
\hline $\mathrm{H}_{2} \mathrm{~S}$ concentration, vol \% & $0.1,0.5,1.0$ \\
Gas temperature, ${ }^{\circ} \mathrm{C}\left({ }^{\circ} \mathrm{F}\right)$ & $816(1500), 982(1800)$ \\
Pressure, MPa (psi) & $0.10(15), 6.89(1000), 10.3(1500)$ \\
Particle type & Char, ash, dolomite \\
Particle size & Coarse, ${ }^{a}$ fine \\
Jet velocity, $\mathrm{m} / \mathrm{s}$ (fps) & $7.6(25), 30.5(100)$ \\
Exposure time, hr & $50,100,1000$
\end{tabular}

${ }^{a}$ Selected values representing two segments of a range between 40 and $1000 \mu \mathrm{m}$.

The gas composition in Table 1.1 results from the high-temperature, high-pressure reaction between the components, which occurs during the process. The particle sizes, compositions, and velocities are based on analyses performed at pilot plants. The gas stream is usually chemically reducing and contains $\mathrm{H}_{2} \mathrm{~S}$, and diffusion-controlled processes are generally important at high temperatures. The ash and dolomite particles, in particular, are at least as hard as many of the substrate materials. 


\subsection{REQUIREMENTS FOR PROTECTION BY COATINGS}

\subsubsection{Properties of Composite Layer Structures}

In a coated structure, each material layer has designated functions. The substrate should provide mechanical strength to sustain the required weight and pressure loads. It must retain adequate properties at operating temperatures and stress levels and tolerate the thermal stress transients caused by heat-up and cool-down of the system.

The coating add" propertics that the substrate frequenily lacks: resistance to abrasion and erosion from particle impingement and corrosion resistance to contain the tlowing gas mixture. Materiais having suitable properties for coatings are usually scarce, expensive, and difficult to fabricate. Concentrating them in the relatively thin coating layer is more cost effective than incorporating them in the bulk of the substrate.

\subsubsection{Special Requirements for Coatings}

To be useful, a coating must bond to the substrate and remain in place throughout the service life, including the thermal and stress transients occurring in normal operation. The thermal expansion coefficient should be fairly well matched to that of the substrate to minimize stresses.

In addition to resisting its own corrosion, the coating must block the diffusion of species that could react with or alter the properties of the substrate material. Hydrogen embrittlement is an example of a common problem arising from uncontrolled diffusion. 


\subsection{COATING MATERIALS AND STRUCTURES}

Table 1.4 is the list of materials that we have compiled from a review of reports ${ }^{1-9}$ from laboratories participating in coal-related materials programs. Exact information on compositions and commercial sources has generally not been available. We have chosen simple representative materials whose compositions are not likely to vary significantly between suppliers.

Figure 1.1 shows three of the coating layer structures examined thus far in the coating selection program; structures with two intermediate-composition layers have also been investigated. ${ }^{9}$ Another

${ }^{6}$ R. Swaroop, Materials Science Division Coal Technology Fourth Quarterly Report, July-September 1975, ANL-76-7, Task B. Task B.

${ }^{7}$ Ibid. Fifth Quarterly Report, October-December 1975, ANL-76-22,

${ }^{8}$ Ibid. Sixth Quarterly Report, January-March 1976, ANL-76-60, Task B.

${ }^{9}$ D. Stahl, Materials Science Division Coal Technology Seventh Quarterly Report, April-June 1976, ANL-76-111, Task B.

Table 1.4. Protective Coating Materials Applied to Coal System Components by Plasma Spraying

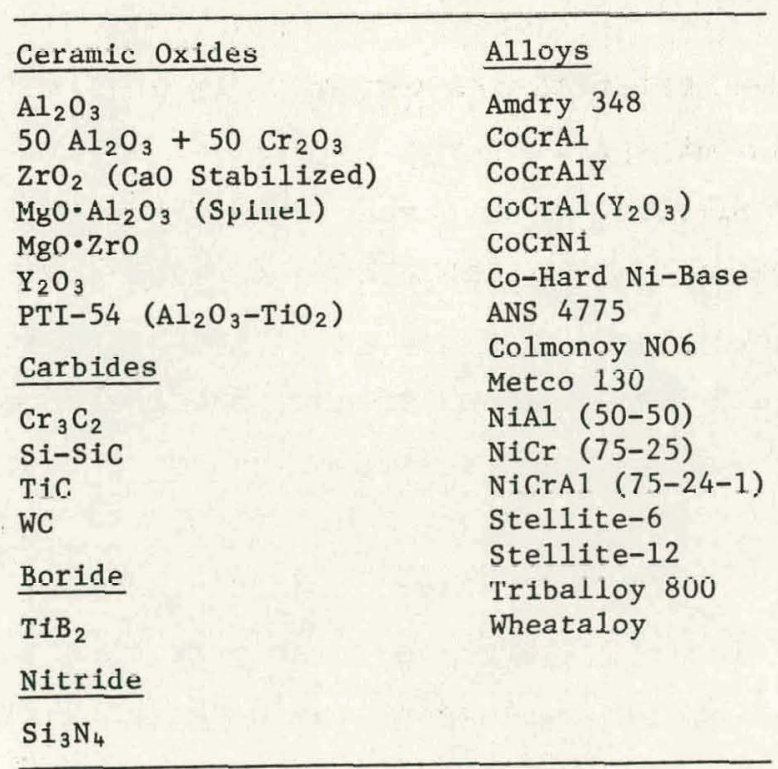



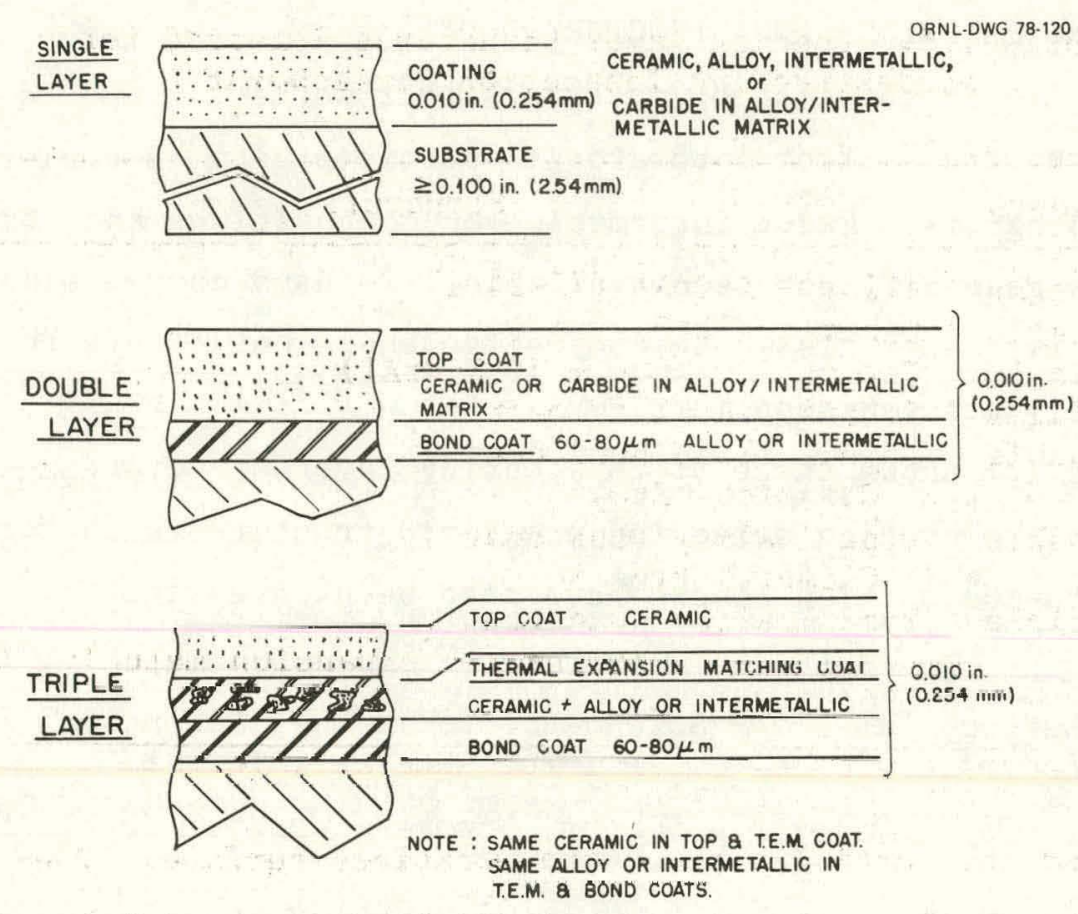

Fig. 1.1. One-, Two-, and Three-Layer Plasma Sprayed Coating Structures.

option would be an intermediate layer with continuously graduated composition. The bond coat layer improves adhesion between the coating and substrate. Intermediate layers compensate for differences in thermal expansion of the coating material and the substrate, to help prevent spalling.

We used single- and double-layer coatings of fixed composition. Table 1.5 lists the layer structures we planned to examine and those materials chosen for them; we have specimens of types $1,2,3$, and 5 .

We have worked exclusively on plasma-sprayed coatings. Some information on other types was found in literature searches. Some work on ion plating has been done ${ }^{6}$ at ANL, hi1t the efforts were small; the process was reported as slower and more cuslly Llian plasma spraying.

The plasma torch transports powder particles through an electric arc in a stream of ionized inert gas. The particles melt in the arc and solidify on the cooler surface of the workpiece. The "non-transferredarc" (NTA) process confines the arc to the torch head; only the ionized 
Table 1.5. Coating Layer Structures Selected for Nondestructive Inspection Development

\begin{tabular}{|c|c|c|}
\hline Type & Layers & Structure \\
\hline 1 & Single & Alloy - NiCrAl $(75-24-1)$ \\
\hline 2 & Single & Ceramic $-\mathrm{ZrO}_{2}$ \\
\hline 3 & Single & Cermet $\left(50 \mathrm{ZrO}_{2}+50 \mathrm{NiCrA1}\right)$ \\
\hline 4 & Single & Carbide in alloy matrix \\
\hline 5 & Double & $\begin{array}{l}\text { Type } 1 \text { alloy bond coat } \\
\text { Ceramic }-\mathrm{ZrO}_{2}\end{array}$ \\
\hline 6 & Double & $\begin{array}{l}\text { Type } 1 \text { alloy bond coat } \\
\text { Cermet - type } 3\end{array}$ \\
\hline 7 & Triple & $\begin{array}{l}\text { Type } 1 \text { alloy bond coat } \\
\text { Type } 3 \text { cermet thermal expansion matching layer } \\
\text { Ceramic }-\mathrm{ZrO}_{2}\end{array}$ \\
\hline
\end{tabular}

gas stream and the particles reach the workpiece surface. The "transferred-arc" (TA) process uses an arc between the torch head and the workpiece and generally melts the workpiece surface. The NTA process keeps the workpiece temperature below melting at the cost of lowered deposition rates. The TA process requires an extra gas stream to shield the arc. The TA process bonds the coating by fusion of both substrate and coating material; the NTA process depends on mechanical bonding produced by deposition of molten coating particles on a solid, roughened substrate. Spraying by TA severely distorted 3.2-mm-thick (0.125-in.) coupons and was discontinued.

\subsection{FAILURES AND PRECURSORS OF FAILURE}

\subsubsection{Definitions}

"Failure" of a protective coating is defined as any loss of its ability to protect the substrate. Because measurement techniques cannot be made Infinitesimally sensitive, there is a lower limit to the size or degree of fallure that can be detected. (As a practical matter, fallure can be defined as a "significant" loss of protective capability, and the problem then becomes that of deciding what is significant). A "precursor" to failure is any detectable condition that warns of inctpient tallure. The concept is useful when one deals with 
catastrophic coating failures, such as large-area spalling. In situations such as gradual wear or thinning of the coating, a precursor and a failure may be distinguished by a threshold: some maximum, measurable loss of coating thickness may be defined as a failure condition.

\subsubsection{Inspection Requirements}

Useful inspection techniques must detect failures with a known degree of confidence. The threshold and the degree of confidence are set: by the user. A viable quality assurance (QA) program needs techniques that can detect existing fallure with the required sensitivity and sonfidence. Inopcction techniques lu detect precurisory conditions become options to the QA program. Their dcoirability is deletullued by a trade-off between additional inspection cost and the consequences of unpredicted failures.

\subsubsection{Abnorma1 Conditions in Coatings}

We identified a list of abnormal conditions that are likely to be detectable by nondestructive techniques and significant in many applications. They are: cracks, holes, delaminations, unbonds, inhomogeneities, and thickness variations.

"Delámination" denotes a general lamellar defect, whose length and width greatly exceed its height and. which results from adhesive failure between coating layers or cohesive failure within a layer: The term "unbond" has been reserved for lamellar defects caused by adhesive failure between the coating and the substrate.

"Inhomogeneity" denotes an unintentional variation in composition or some property of the coating with position, measured in a direction either parallel or perpendicular to the substrate surface. Detectable inhomogeneities in plasma-sprayed coatings might include density, porosity, and alloy element concentration.

There is no special terminology to cover the case of a large area of spalled or removed coating. We tacitly assume that tcchniques for detecting such areas would be similar to those for detecting unbonds or delaminations. 
2. THE APPLICATION OF NONDESTRUCTIVE TESTING TO PLASMASPRAYED-COATING INSPECTION PROBLEMS

Nondestructive examination methods produce no irreversible changes of significance in the workpiece and no net change in its serviceability. Inspection implies the examination of a passive object for comparison with its own earlier condition or with an established standard. Nondestructive inspections use some form of energy that is reflected, transmitted, or scattered from a workpiece, or else a material that interacts with the surface of the workpiece to produce a useful indication. Dimensional. inspection methods are included.

2.1 INSPECTION OF COATINGS IN THE COAL PLANT DESIGN-FABRICATION-OPERATION CYCLE

Inspection techniques, nondestructive or otherwise, form the technological basis for any quality assurance program and are necessary to ensure the performance and reliability of the finished plant.

Figure 2.1 summarizes some of the coating inspection activities applicable to coal facilities.

i.

\subsubsection{Development and Engineering}

Laboratory-based nondestructive techniques can assist the selection of coating materials by evaluating the quality of specimens and prototype components and by verifying the condition of used or failed components. They are useful to extract information while leaving the specimen intact for other uses.

\subsubsection{Component Fabrication}

Nondestructive techniques developed to the stage of industrial reliability can be used to control the quality of coatings applied to components for plant assembly. Appropriate inspections will ensure the quality of finished units, assist in the rework of nonaccepted units, and help detect problem areas in the fabrication process. 


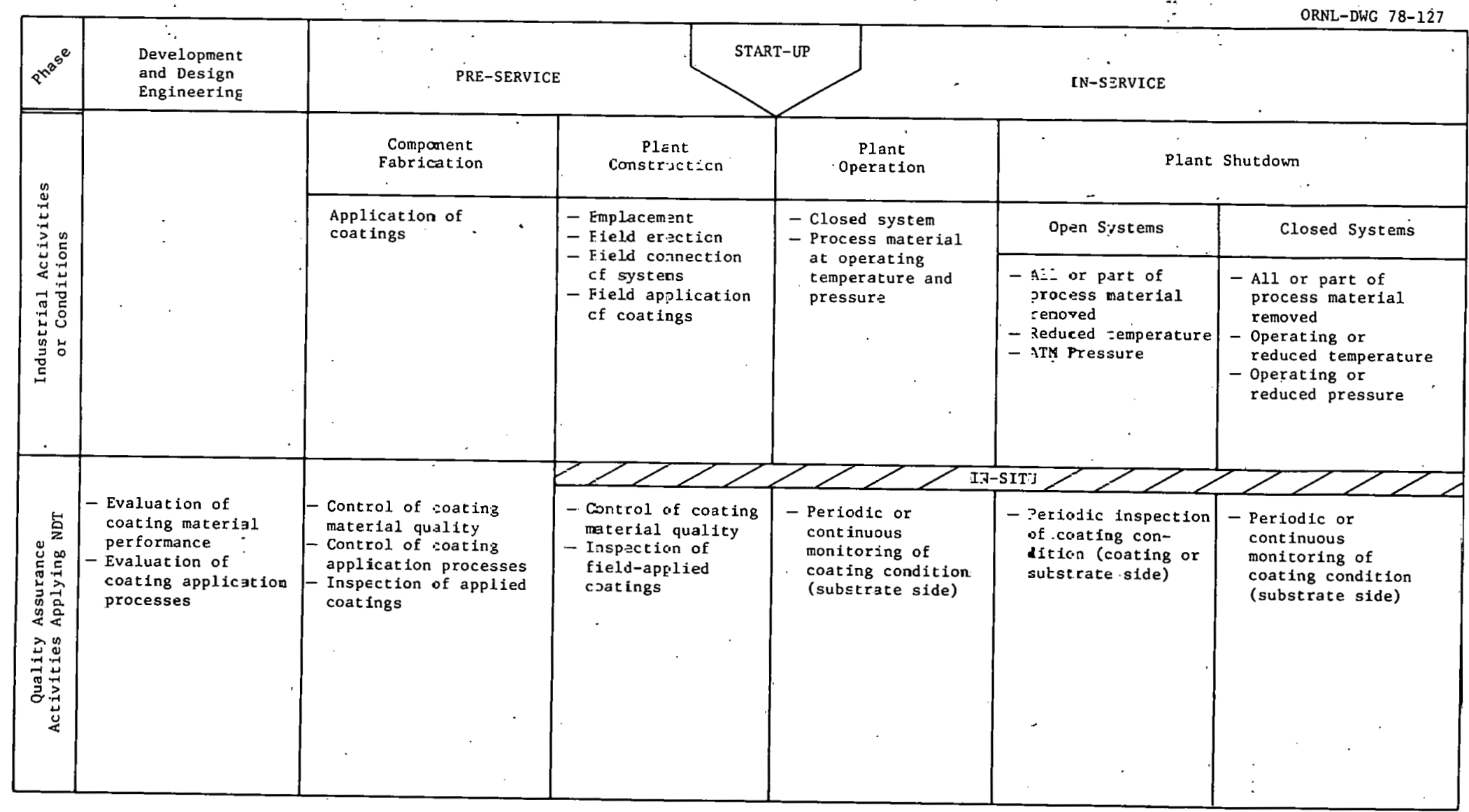

Fig. 2.1. Summary of Protective Coating Inspection Activities in the Design-Construction-operation Cycle of a Coal Use or Processing Facility. 


\subsubsection{The In-Situ Condition}

The in-situ, or in-place, inspection of a unit or component occurs

in the latter stages of construction and under the operating and shutdown conditions of the finished plant.

Coated components may require inspection after shipment and handling for emplacement. There will be field operations, such as welding, to connect and seal the operating systems, and some sensitive areas may require coating after the joining and assembly operations are finished.

Plant operation will require any inspections to be performed on the completely closed system, filled with process materials at operating temperatures, pressures, and flow rates and possibly some contents resulting from abnormal operation. Inspections may use devices kept completely outside the system, permanently mounted inside the system, or temporarily insertable through special access fittings. The planned use of permanent or insertable devices will require coordination between. engineering and inspection personnel in the design phase. Inspection intervals will likely be determined by the criticality of the component or feature involved and the failure experience accumulated. Critical i.tems may need continuous monitoring; most items can be inspected periodically.

Preventive maintenance schemes require planned shutdowns, and some unplanned ones occur. The system may be open or closed, depending on . the nature and purpose of the shutdown, all or part of the process material may be removed, and the system may have temperatures and pressures reduced. The inspection plan should make use of the directaccess opportunities offered by opening of the system. A11 applicable inspections performed on the operating system should be performed during shutdown to cross-compare results of direct-access inspection with those obtained during operation.

\subsection{GENERAL PROBLEMS RELATED TO INSPECTION OF PLASMA-SPRAYED COATINGS ON COAL SYSTEM COMPONENTS}

The problems discussed below have significant impacts on the inspection of plasma-sprayed coatings and many of them relate to the inspection of any type of coating in a coal system. Some relate to inspections in general. 


\subsubsection{Coating Surfaces}

The plasma-spraying operation produces a rough, porous finish for most materials sprayed. Because the ceramics are hard, their sprayed surfaces are also highly abrasive. Inspection devices designed for moving contact with these surfaces must use either rolling contactors or sliding.contactors made of wear-resistant materials. Nondestructive methods that can operate with noncontacting devices are highly desirable.

The porous sprayed surfaces can entrap matter that may contaminate materials applied to aid surface inspection and thus interfere with the inspection: Liquid or finely divided solit inspection materials used on the surface may also become entrapped and require removal before other production (fabrication) steps.

The as-milled finish on most plate and pipe stock and some forgings will not hurt most NDT probes if they are protected by commercially available wear-facing attachments.

\subsubsection{Workpiece Geometry}

There may be as many geometrical problems as there are distinct part shapes. We list some of the possibilities:

1.- Lack of rotational symmetry may require hand-scanning methods or expensive dedicated positioning machines.

2. Confined spaces or limited access may prevent the introduction or limit the maneuverability of an inspection device.

3. Abrupt features, such as short-radius bends and curves, sharp edges, and inside corners, can limit the use of probes or techniques that respond to their presence. The result may be an uninspectable area; a requirement to use an additional or more complex technique, or a loss of sensitivity.

Proper coneideration of "ịspectability" at Llit devlgn level can reduce or eliminate many geometrical problems.

\subsubsection{Environment}

The component manufacturing facility and the operating plant present a heavy industrial environment, to which the inspection process, 
equipment, and personnel must be adapted. This environment may include extremes of and variations in temperature and humidity, airborne dust and fumes, mechanical vibration, and electrical noise on power supply lines. The electronic equipment used for many inspections may require "ruggedized" construction and special protective cases or cabinets. The liquids used for many surface inspection methods (e.g., penetrants) are sensitive to chemical contamination by dust and fumes and may require a sheltered clean area. Vibration affects unprotected or inadequately designed positioning devices. Many inspections depend on the alertness of the operator and hence can be degraded by distracting influences such as weather exposure and noise.

Permanently installed inspection devices in an operating system may experience an especially harsh environment. These devices usually require careful design and extremely rugged construction and will probably use expensive materials and fabrication methods.

\subsection{APPLICATION OF NDT DEVELOPMENT METHODS TO COATING INSPECTION PROBT.EMS}

Development of an NDT method must establish a positive, reliable correlation between the response of the inspection instrument and the condition of interest within the workpiece. The instrument may respond directly to the property of interest or to a second property having a strong correlation with the actual property of interest.

Establishing the correlation between instrument response and workpiece condition requires a comparison between the instrument. response and a specimen that contains a known condition. The most desirable specimen type contains a natural (i.e, made by the process of interest) or synthetic defect or condition that is deliberately introduced and whose characteristics are either carefully controlled or accuratcly measurable.

Only the controlled characteristics of the specimen may be used for comparison or correlation. For example, dimensional control and machining can produce a ceramic coating layer of well-defined thickness. Thjs layer can he used as a thickness calibration standard for a 
technique that senses only the distance between the coating surface and the substrate interface (e.g., eddy current) but it cannot be used as a standard.for a technique that senses the mass per unit area (e.g., $x$-ray fluorescence) unless the porosity (density) of the coating is also controlled.

If fabrication of a controlled synthetic specimen or characterization of a natural specimen is not practicable, one can study pairs of natural specimens. In this scheme, specimens are sorted into groups of at least two that yield the same inspection response. One of the group is analyzed destructively to characterize the defect or ronditinn of interest. Then it is assumed that the remaining specimen(s) in the group have characteristics identical to those of the destroyed one. If there are interfering parameters, such as thickness and porosity for some methods, the duplicate specimen scheme w11l require an additional independent measurement of at least one of the interfering parameters. If duplicate specimens cannot be obtained, single specimens can be used, but the destructive examination destroys the reference and nothing can be repeated.

Inspection responses from various NDT methods can be correlated to establish the condition of a specimen. The use of established methods together with the method under development strengthens the correlation. 'l'here have not been many opportunities to use this scheme on coatings.

For calibration work, one can use a hybrid scheme, in which the specimen or standard used to create a specific inspection response bears no signiticant resemblance to the workpiece to be inspected. Such a specimen provides a calibration point for the instrument only; it will not provide data to help build a correlation.

\subsection{BIBLIOGRAPHY}

R. C. McMaster, ed., Nondestmuctive Testing Handbook, The Ronald Press, New York 1959, Vo1 I, Sect, 1-5. 


\section{PENETRATING AND BACKSCATTER RADIATION METHODS}

The methods discussed in this chapter have a common feature: The sample is interrogated by lonizing radiation (e.g. beta, gamma, or $x$ rays). Information about the sample is obtained by observing, recording, and analyzing the radiation that is transmitted through the sample, scattered from it, or changed to another form before. emission. Methods examined for potential application to coating inspection include transmission radiography or gaging, backscatter . radiography, beta-ray backscatter gaging, and $x$-ray fluorescence measurement.

\subsection{AṔPLICATIONS TO COATING INSPECTION}

\subsubsection{Transmission Radiography and Gaging}

Transmission methods use $x$ rays or gamma radiation. Radiation passing through the sample is recorded on film directly or is sensed by some other detector and electronically collected, processed, and displayed: Proper placement of the source and detector requires access to two sides of the sample.

The data obtained can indicate flaws or artifacts in the substrate as well as in the coating; however, interpretation may not permit differentiation of coating flaws from substrate flaws. The sensitivity of the technique depends on the energy of the radiation and the types of materials interrogated. Differences, in density or thickness and atomic number can be detected by $\mathrm{x}$ or gamma radiation with energies less than $1 \mathrm{MeV}$. Radiation energies greater than approximately $1 \mathrm{MeV}$ can detect only thickness or density variation.

The use of film as a detector provides a permanent plan view record with $100 \%$ coverage of selected areas. However, the cost could be high if large areas are routinely imaged. Some economy results. from screening by other methods and using radiography selectively.

The radiographic systems that we used were limited in portability; however, portable units having at least equivalent performance are commercially available and could be oblained. Both sourec and detector 
designs would need to be considered to ensure the capability to inspect various sample geometries. Rapid, localized variations in transmission cause corresponding changes in film density, which are easily interpreted by experienced readers. Gradual variations over large linear distances may be detectable only with the aid of a recording densitometer.

\subsubsection{Backscatter Radiography}

Backscatlei methods usc à film emulsion placed in intimate contact with the sample surface. High energy $x$ or gamma rays pass through the film with little interaction and impinge on the sample surface, producing scattered radiation to which the film is more sensitive by a combination of mechanisms, including photoelectron ejection, Compton scattering, and fluorescence. In this application, the coating acts like the intensifier screen commonly used in conventional (transmission) radiography.

The method senses surface flaws, such as cracks, and variations in density or atomic number. Sharp local variations are very easy to see; more gradual variations may require film density measurement. Backscatter radiography is done from the coated side so aripss may be limited by the radiation source size and geometriral factors.

\subsubsection{Beta-Ray Backscatter}

Energetic electrons or positrons scatter from the nuslei in a material, with a cross section proportional to $Z^{2}$, where $Z$ is the atomic number. For a mixture of nuclei, the scattered intensity depends on the root-mean-square (rms) value of $Z$ and the density of the material. Thlckness of one material coated with another is measured by the variation in rms $Z$ produced by different proportions of the materials. Commercially available equipment can perform the measurements from one side (the coated side) of the sample. The measurable range of coating thickness is limited'by the ability of the beta particles to penetrate matter [the equivalent of $0.18 \mathrm{~mm}$ (0.007 in.) Ni]. 


\subsubsection{X-Ray Fluorescence (XRF)}

Impinging $\mathrm{x}$ or gamma radiation ejects photoelectrons from target atoms in the sample, preferentially those in the inner atomic (K) shells. Outer shell electrons drop into the vacancies, and the atom emits characteristic radiation, preferentially the K $\alpha$ ray. Each element emits $x$ rays with different characteristic energies, so an energy-sensitive detector can identify elements present by their characteristic $\mathrm{x}$-ray lines.

$\mathrm{X}$-Ray Fluorescence can potentially measure variations in composition, thickness, and density, although distinguishing the latter two may be difficult. The useful range of measurable thickness will depend in a complicated way on the density and atomic number of the measured material. Commercially available energy-sensitive detectors are cumbersome and have been mainly used in laboratories. However, some manufacturers are developing miniaturized, portable units for mining and well-1ogging applications.

\subsection{EXPERIMENTAL WORK}

\subsubsection{Transmission Radiography}

We have routinely radiographed specimens of various sprayed coatings on $3.18-\mathrm{mm}(0.125-\mathrm{in}$ ) alloy 800 plates. We used a tungsten target tube with a $4-\mathrm{mm}$ focal spot, operated at $127 \mathrm{kVp}$. The film emulsion was placed next to the coating at $1.4 \mathrm{~m}$ (54 in.) film-focus distance, and a 0.25-mm (0.010-in.) lead intensifying screen was placed behind the film base. Radiography proved useful in the evaluation of crack specimens. Some cracks that were not visible on the sample surface were detected on the radiographs. Other specimens have been substantially clear of defect indications.

A similar setup was used to radiograph free-standing layers of coating materials. The $\mathrm{x}$-ray tube voltage was reduced to $50-80 \mathrm{kVp}$, depending on the thickness and $Z$-value of the specimen. Radiographs of $\mathrm{ZrO}_{2}$ coatings showed high-density inclusions, which appear to be grains of free zirconium. Some grains are visible on the surface; these were identified as zirconium by electron microprobe analysis. 


\subsubsection{Backscatter Radiography}

Figure 3.1 shows a typical setup. The metals and plastic filter out the soft (i.e., low-energy) portion of the x-ray spectrum from

ORNL-DWG 78-124
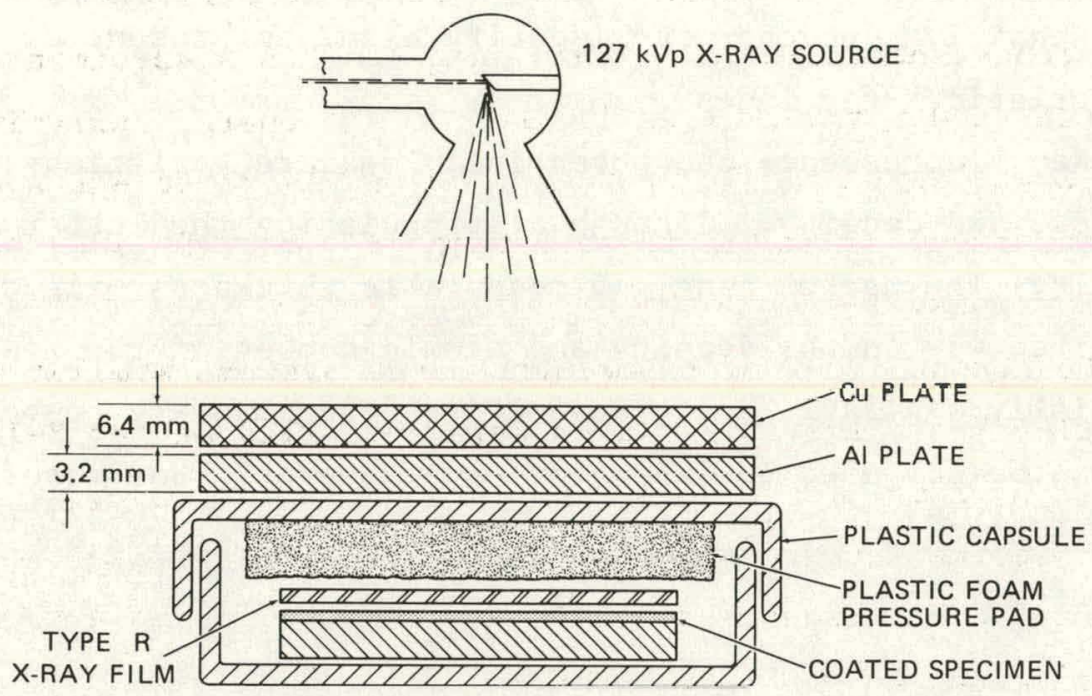

Fig. 3.1. Film Pack, Filter, and X-Ray Tube Arrangement for Backscatter Radiography of Plasma-Spray-Coated Specimens.

the source. We used this method to examine the specimen (ANL-C5) received from Argonne National Laboratory because it contained elements with a wide variation in $Z$, from titanium $(Z=22)$ to tungsten $(Z=74)$. [Specimen $\mathrm{C} 5$ is a 50 by $50 \mathrm{~mm}$ ( 2 by 2 in.) piece of $3.2-\mathrm{mm}(0.12-\mathrm{in}$.) alloy 800 plate coated with approximately $0.25 \mathrm{~mm}(0.010 \mathrm{in.})$ of a material prepared $\perp$ oca $\perp \perp y$ at ANL trom 'I'iC and a commercia $\perp$ cobalt-base powder. Approximate composition of the coating is $\mathrm{Co}-24 \% \mathrm{Cr}-10 \% \mathrm{Ni}-7 \% \mathrm{~W}-$ $4 \% \mathrm{Ti}-1.5 \% \mathrm{C}]$. The radiographs contained a number of point indications, which were apparently low- 7 inclusions, possibly holes. When we used the method on crack specimens, the radiographs showed increased exposure that is, higher film density - from cracks open to the surface.

\subsubsection{Beta-Ray Backscatter}

Preliminary experiments were run on $\mathrm{ZrO}_{2}$ specimens using a borrowed system at the Oak Ridge Y-12 Plant. This system contained a ${ }^{147} \mathrm{Pm}$ 
beta-ray source. We were unable to demonstrate sensitivity to various $\mathrm{ZrO}_{2}$ thicknesses, possibly because the intensity of the source was too 1ow.

\subsubsection{X-Ray Fluorescence}

The earliest experiments used a portable diffraction-type $\mathrm{x}$-ray fluorescence spectrometer. ${ }^{1}$ This unit excites a specimen with $40-\mathrm{kVp}$ tube-generated $x$ rays; it is limited to the energy analysis of elements having $Z$ at least 23. In tests on the metal-coated ANL specimen (C5), we demonstrated ${ }^{2}$ the ability to distinguish materials by alloying-element concentrations.

The second group of experiments used systems similar to that shown schematically in Fig. 3.2, which were installed at the Y-12 Plant. Some of these systems used $\mathrm{Ge}(\mathrm{Li})$ detectors and others used Si(Li) detectors. A ${ }^{153} \mathrm{Gd}$ source excited the fluorescence. Figure 3.3 shows the data obtained and indicates that fluorescence is a feasible technique for the determination of $\mathrm{ZrO}_{2}$ thickness near $0.25 \mathrm{~mm}$ (0.010 in.).

${ }^{1}$ Norelco Portaspec Model 12094, North American Phillips Corporation.

${ }^{2}$ G. W. Scott, "Radiation Techniques," Coal Technology Program Quart. Prog. Rep. March 31, 1976, ORNL-5159, pp. 94-96.

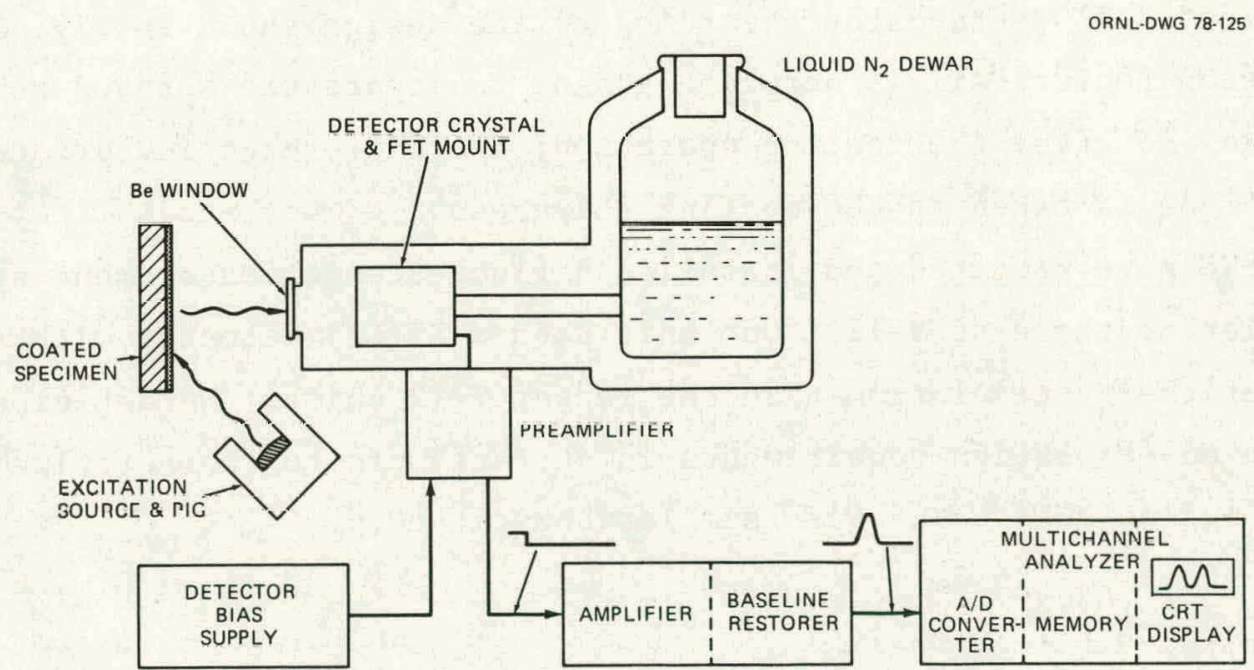

Fig. 3.2. X-Ray Fluorescence Measurement System. 


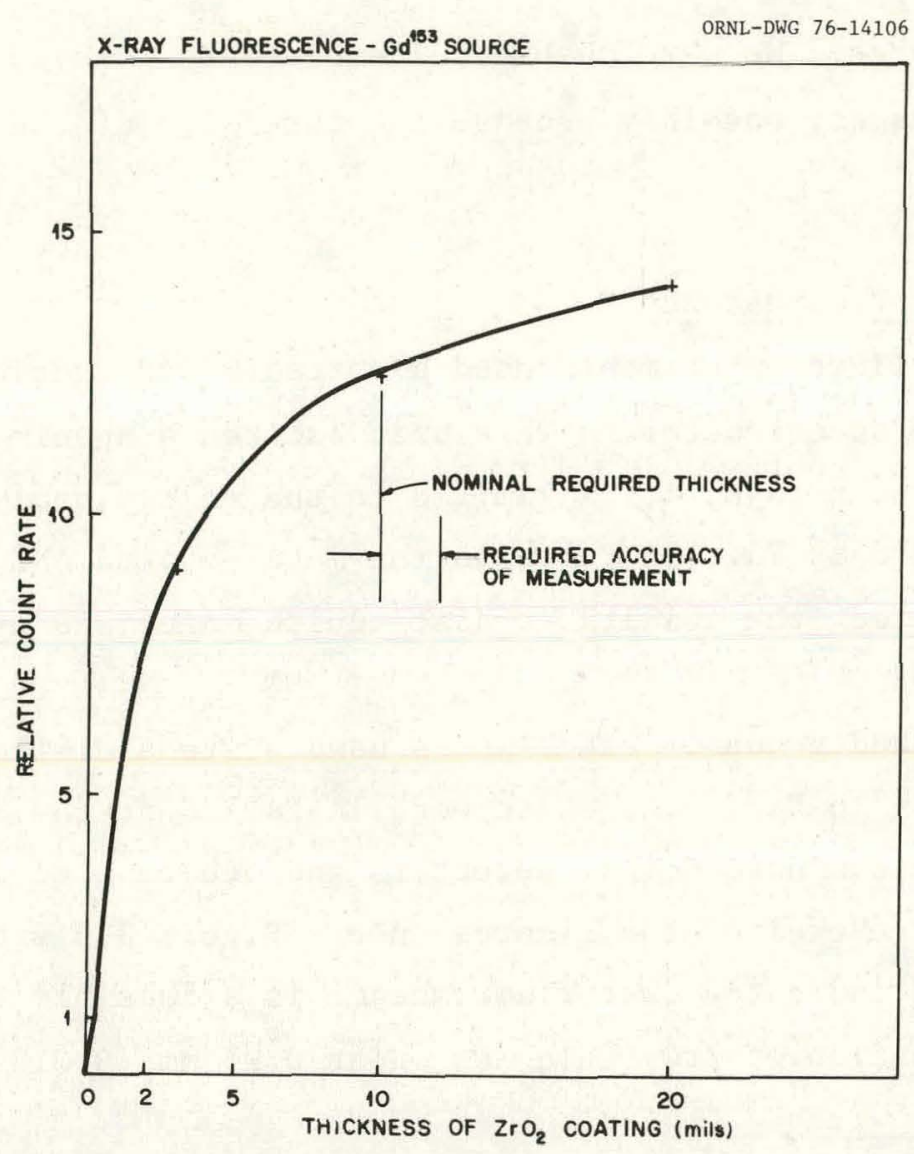

Fig. 3.3. Count Rate in $\mathrm{Zr} \mathrm{K} \alpha \mathrm{X}$-Ray Peak vs $\mathrm{ZrO}_{2}$ loating Thickness. To convert, $1 \mathrm{mil}=0.25 \mu \mathrm{m}$.

To accurately determine the sensitivity of the technique we have fabricated $\mathrm{ZrO}_{2}$ standards according to the design shown in Fig. 3.4. The step feature allows accurate gaging to locate the sprayed surface before and after the coating operation; the difference in surface locations is taken as the coating thickness.

We have procured and installed a fluorescence measurement system similar to thnse at $\mathrm{Y}-12$ Our unit uses a Si(Li) detcctor with sliglıLIy better energy resolution than the larger Y-12 unils. We anticipate improved resolution requirements in our attempts to characterize alloy coatings on substrates with similar constituents. 


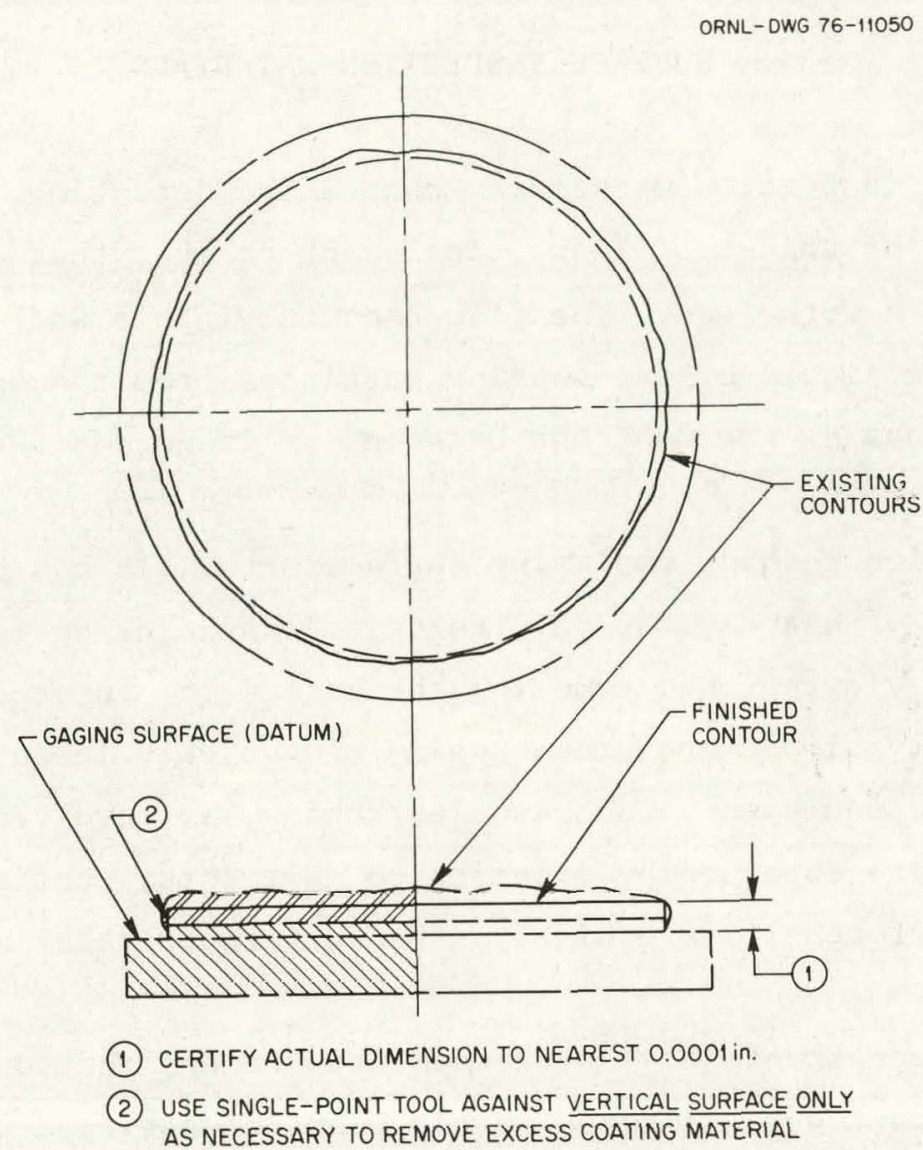

Fig. 3.4. Features and Construction Steps for Plasma-Sprayed Coating Thickness Standards. To convert, 1 in. $=25.4 \mathrm{~mm}$.

\subsection{BIBLIOGRAPHY}

Transmission Radiography

C. G. Gardner, "Kadiography," Nondestmuctive Testing, A Survey, NASA-SP-5113 (1973), Chap. 4.

\section{Beta-Ray Backscatter}

J. D. Fox and G. M. Taylor, "A Statistical Theory of Design for Plating Thickness Measurements by Radiation Backscatter Methods," Mater. Eval. 28(1): 17-24 (1970).

O. H. Kriege and D. H. Boone, "Nondestructive Characterization of Diffusion Aluminide Coatings," Mater. Eval. 32: 38-44 (1974).

\section{X-Ray Fluorescence}

R. Woldseth, X-Ray Energy Spectrometry, Kevex Corporation, Burlingame, Calif., 1973. 


\section{SURFACE INSPECTION MATERIALS}

Surface inspection materials enhance the detection, by visua1 observation, of void-type flaws, including cracks, that are open to a surface of a workpiece. The flaw becomes visible when it traps a dye-bearing liquid or dye-bearing particles from a suspension, thereby increasing the contrast between its image and the surrounding surface.

Inspection methods employiny surface materfals can be applied to a variety of shapes, the only restrictions being access for application, viewing, and removing the material. Inspection procedures are relatively simple and hence easily and quirk1y learned. No sophisticated equipment, such as electronics, is involved. Positive indications are obtained by experienced operators; consistency and reliability of results are highly dependent on operator skill and vigilance.

Liquid penetrants have been examined for application to all types of sprayed coatings. Filtered particle and electrified particle techniques were examined for use on ceramic coatings.

\subsection{APPLICATIONS TO COATING INSPECTION}

\subsubsection{Liquid Penetrants}

Liquid penetrants are dye-bearing liquids. They are trapped in surface-opening flaws and are either observed in the flaw or withdrawn by developer action for easier observation. The basic steps in a penetrant cycle are:

1. cleaning the workpiece,

2. applying the penetrant,

3. removing excess penetrant (from defect-free areas of the surface),

4. application of an absorbent coating material (developer) to draw trapped penetrant from defects from easier viewing,

5. visual inspection, and

6. cleaning penetrant and developer materials off the workpiece after inspection. 
Penetrants are classified by:

1. the type of dye used, visible or fluorescent;

2. the rinse medium used to remove excess penetrant, water or a solvent;

3. the liquid carrying the dye, water or oil based;

4. type of developer, wet or dry;

5. intended application; and

6. resolution (i.e., sensitivity to small flaws). Although a variety of special-purpose materials are available, the porous surfaces of sprayed coatings require special procedures as well. Excess penetrant must be removed from normal porosity to reduce the background indications so real defects can be seen. The industrial environment must be controlled somewhat for penetrant use; temperature should be kept within 4 to $50^{\circ} \mathrm{C}$ $\left(40-120^{\circ} \mathrm{F}\right)$, and contamination of the penetrant materials must be avoided.

\subsubsection{Filtered Particles}

The inspection material is a liquid suspension of size-graded fluorescent dye particles. Open defects, especially cracks, preferentially absorb the liquid, depositing dye particles at the entrance of the defect; this collection of particles produces the indication of the defect. The process steps are application, observation, and, if necessary, removal.

Filtered-particle test materials are commercially available $e^{1}$ in five particle size ranges, suitable for inspecting pressed aggregates of powders ranging from 100 mesh to those fine enough to be handled with liquid-penetrant processes. The test particle ranges give varying degrees of resolution. The materials and method were originally developed for application to green sanitary ceramic ware and power line insulators.

The particle suspension must be poured or sprayed on the workpiece surface in a manner that allows the particles to move freely; brushing destroys indications during formation by moving the particles away from locations when they settle out. Repeated applications with drying allowed between them can produce "drain marks" and other spurious indications. Ultraviolet illumination and solvent exposure are the only associated hazards, and both are easily controlled.

\footnotetext{
${ }^{1}$ Partek, from Magnaflux Corporation, Chicago.
} 


\subsubsection{Electrified Particles}

The inspection material is a calcium carbonate powder, which is air-sprayed through a hard-rubber nozzle. The calcium carbonate is a triboelectric material - that is, one that can easily strip off outer electrons by friction against appropriate "acceptor" surfaces, in this case the nozzle. When the charged powder particles approach a dielectric layer (coating) backed by a conducting metal plate, conduction electrons in the metal are drawn toward discontinuities (flaws) in the coating. This preferential attraction occurs hecause the air column in a flaw transmits the electrostatic field more readily than the dielectric does. On the surface, the powder particles cullect around open flaws.

The powder and spray equipment are available commercially, ${ }^{2}$ although they could be homemade. The powder is safe against dust explosion, and there are no other hazards.

\subsection{EXPERIMENTAL WORK}

A number of screening experiments have been performed ${ }^{3-6}$ on various coatings with the materials discussed above. The following sections summarize the results.

\subsubsection{Specimen Fabrication}

The first specimen available for surface material testing (ANL-C5) came from Argonne National Laboratory in unknown condition, with no test data of any kind for comparison with our work. To avoid damaging it, no attempt was made to create a surface defect.

${ }^{2}$ Statiflux, from Magnaflux Corporation, Chicago.

${ }^{3}$ S. D. Snyder, "Liquid Penelranl Techniques," Coal Technology L'rogram Quart. Prog. Rep. Mar. 31, 1976, ORNL-5159, p. 97.

${ }^{4}$ S. D. Snyder, "Liquid Penetrant Techniques," Coal Technology Program Annu. Interim Rep. June 30, 1976, ORNL-5208, pp. 138-42.

${ }^{5}$ S. D. Snyder, "Liquid Penetrant Techniques," Coal Technology Program Quart. Prog. Rep. Sept. 30, 1976, ORNL-5224, pp. 64-68.

${ }^{6}$ S. D. Snyder, "Surface Inspection Materials," Coal Technology Program Quart. Prog. Rep. Dec. 31, 1976, ORNL-5252, pp. 90-91. 
For later work with ceramics and cermets, we designed the specimen shown in Fig. 4.1(a). The design in Fig. 4.1(b) was developed later, to alleviate some of the undesirable effects, such as spalling, of the rapidly varying stress distribution across the throat of the earlier design. The fabrication technique works for coatings that are more brittle than the substrates. We considered thermal, bending, and tensile stresses as ways to break the coating. Thermal methods are generally unpredictable and difficult to control; they are omnidirectional and as likely to produce spalling as cracking. Tensile or tensile plus bending produces the best results. Transmission radiography provides a reliable indication of soundness before stress testing.

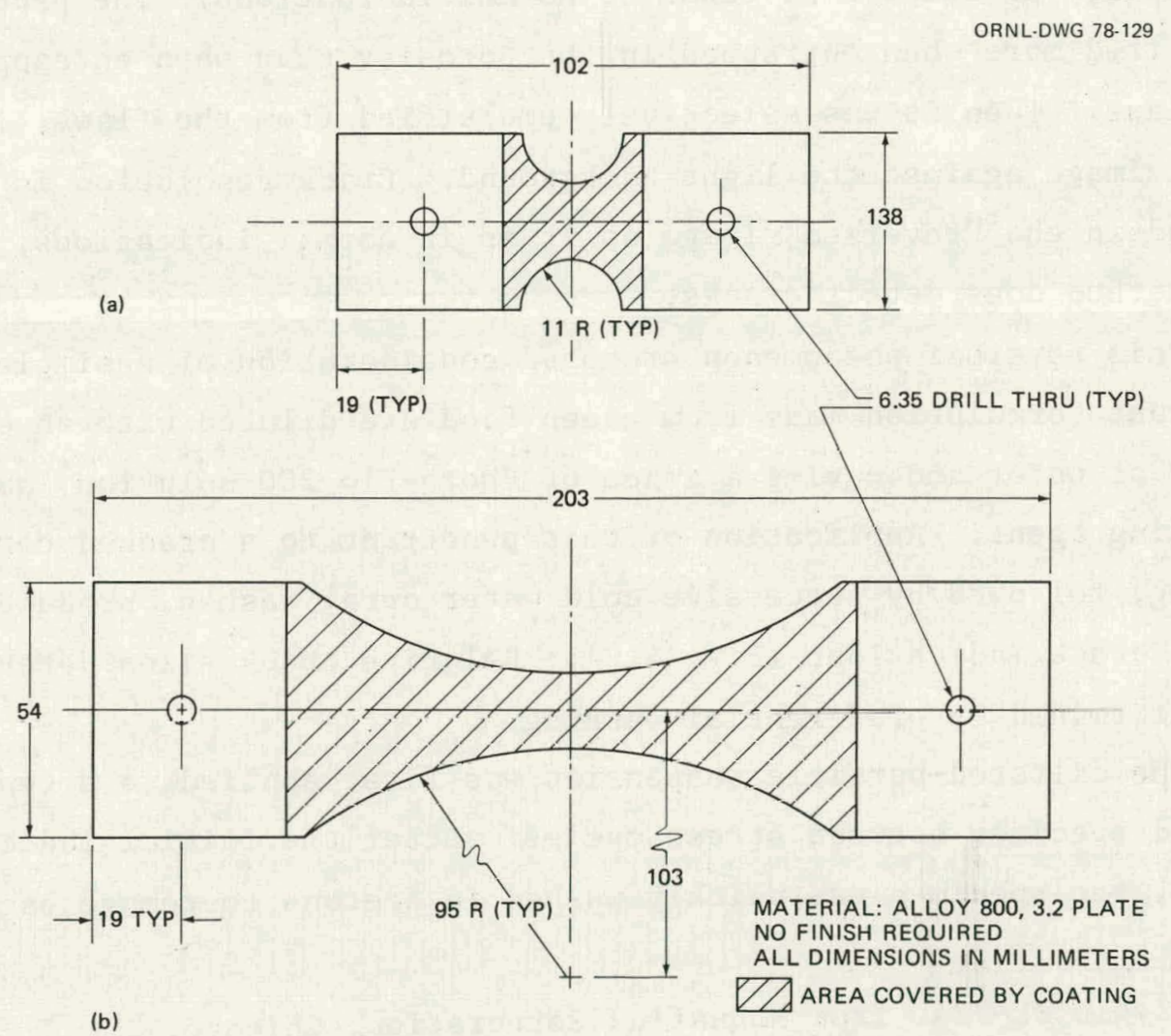

Fig. 4.1. Test Specimens for Surface Inspection Materials. The coating is cracked in the throat area by applying tension to stretch the substrate. 


\subsubsection{Ceramic Coatings}

We used a commercially available ${ }^{7}$ liquid penetrant for most penetrant testing. It is a high-resolution, postemulsified, waterwashable, fluorescent penetrant.

Ceramic coatings retain penetrant entrapped in surface porosity, producing high background indications and a difficult removal problem. Alcohol, acetone, and naptha were used as stripping agents; however, because they are aggressive solvents, immersion timing is difficult to control adequately.

The standard application procedure (recommended by the manufacturer) produced background indications that mask any defects. A modified procedure, based on the Interim Drying Equilibrium Augmentation (IDEA) principle, ${ }^{8}$ produced a reversal of normal indications. The penetrant stabilized more when entrapped in the porosity than when entrapped in the flaws. Then it was selectively emulsified from the flaws, leaving a dark image against the light background. Crack resolution is not as good in the "reversed" image as it is in normal indications, but this method does detect cracks.

This reversal phenomenon prompted consideration of a simple penetrant formulation made from green food dye diluted with an equal volume of water and having a trace of Photo-F1o 200 solution $^{9}$ added as a wetting agent. Application of this penetrant to a cracked ceramic coating, followed by successive cold water spray washes, produced useful crack indications (Fig. 4.2). Relative crack sizes detected are determined by preferential washing.

'l'he filtered-particle suspension was first applied to a tensilecracked specimen between stress cycles. After the initial indication formed, the specimen was quickly washed in acetone to remove background,

${ }^{7}$ Zyglo ZL-22A, from Magnaflux Corporation, Chicago.

${ }^{8} \mathrm{~J}$. R. Alberger, "Nondestructive Evaluation of Surface Microstructure Using High-Performance Fluorescent Penetrants," Section P-020.22, Bul1. 751010, Shannon-Gluw, Inc., Los Angeles, Calif.; presented to Spring Conference of the American Society for Nondestructive Testing, March 1975.

${ }^{9}$ Eastman Kodak Company, Rochester, N. Y. 

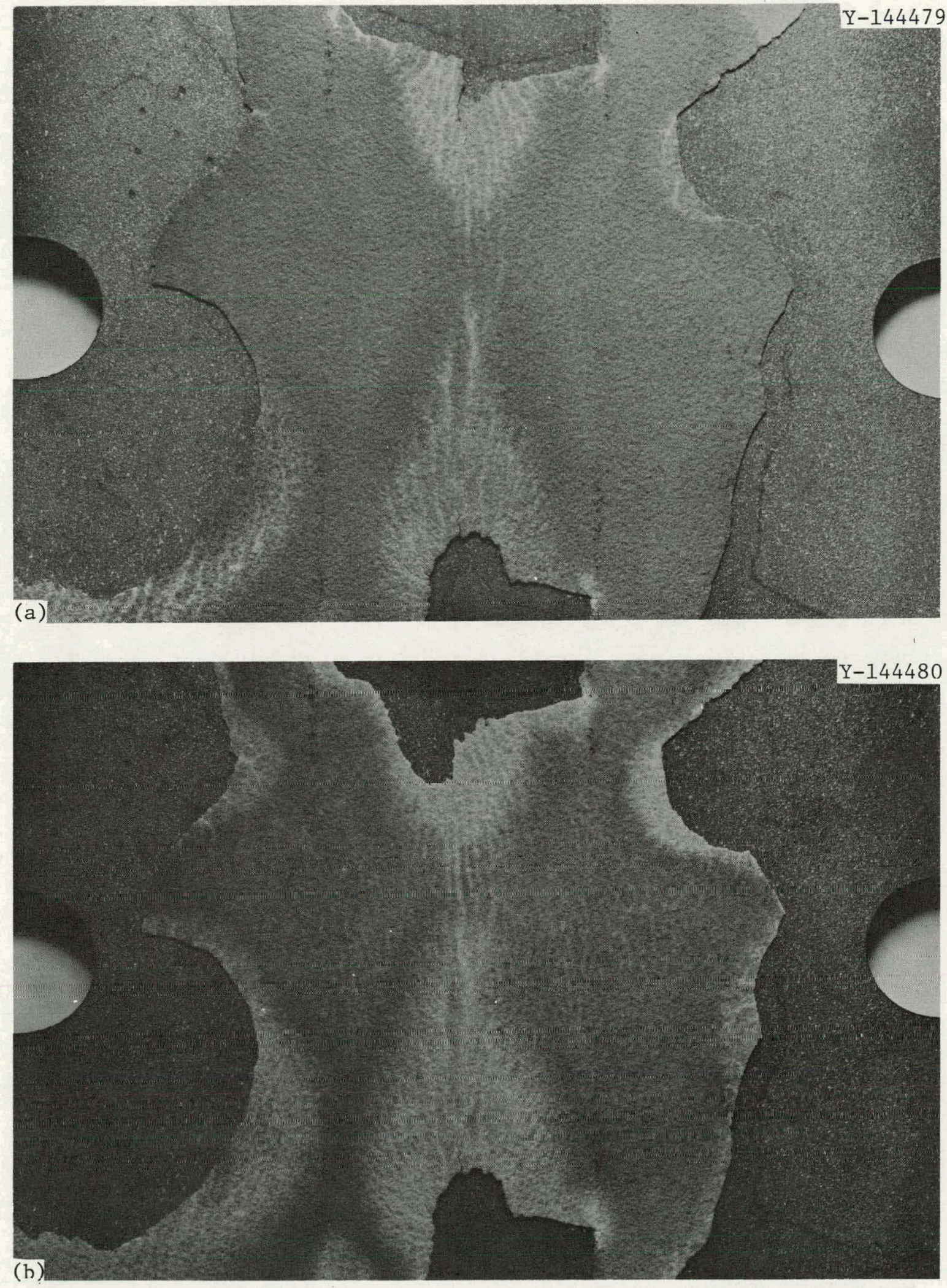

Fig. 4.2. Specimen OR-JC-76 (Ceramic Coated) After Application of Green Food Dye and 15-s Spray Washes with Cold Water. 3.5x. (a) One wash. (b) Two washes. 
producing the indications shown in Fig. 4.3. For reasons unknown, subsequent tests have never produced images of the quality shown in the figure.

The electrified particle technique was tested on a tensile-cracked specimen. The powder adhered and built up a pattern on the surface; however, the pattern was based on the surface porosity of the material, and the clutter was so great that indications of actual flaws could not be distinguished.

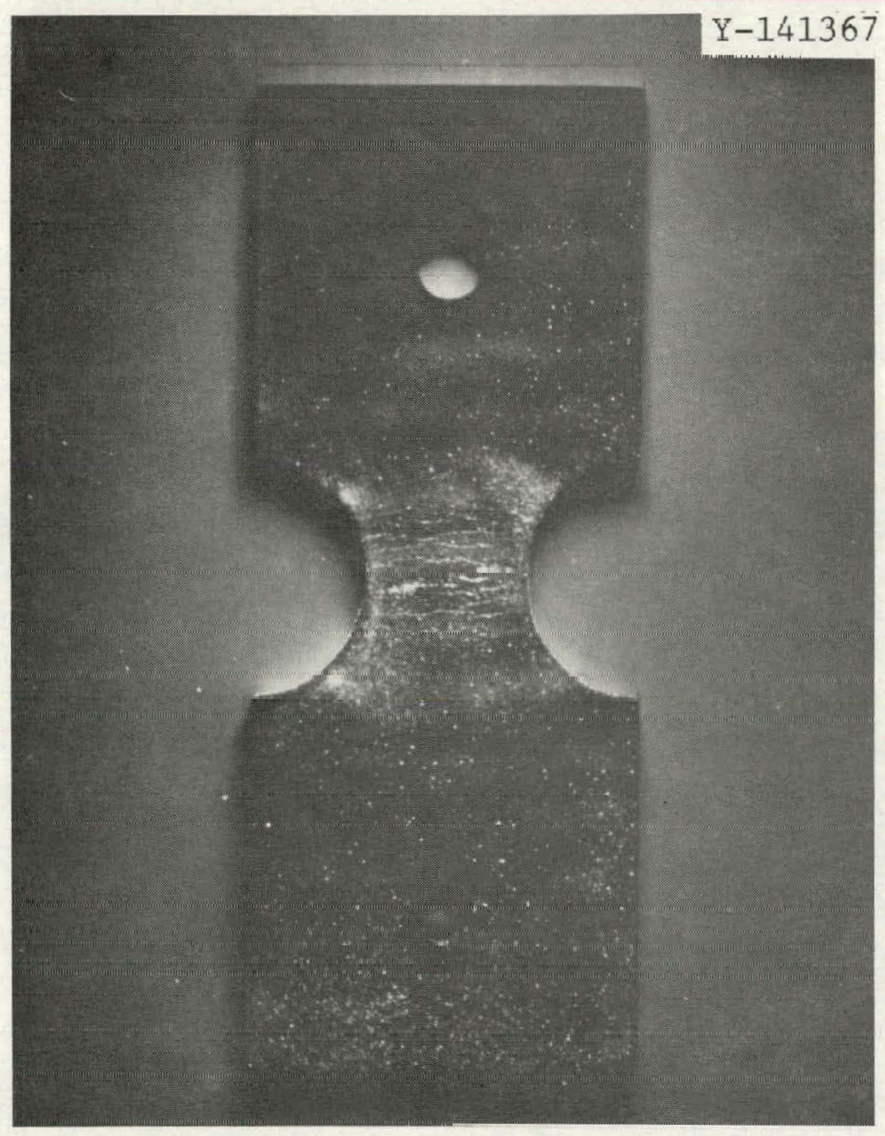

Fig. 4.3. Filtered farticle Indications on a Ceramic Tensile Cracked Specimen. Initial application was followed with an acetone wash.

\subsubsection{Cermet Coatings}

Cermet coatings consisting of $50 \% \mathrm{ZrO}_{2}-50 \% \mathrm{NiCrAl}$ were sprayed on alloy 800 substrate tensile-crack specimens. Several of these specimens were cracked by tensile plus bending in the same manner as the ceramiccoated specimens. 
The ZL-22A liquid penetrant was used, following the IDEA-based procedure, ${ }^{8}$ and cracks were detected by the reversal process as with the ceramic coating. An example of the appearance of the crack indications is shown in Fig. 4.4.

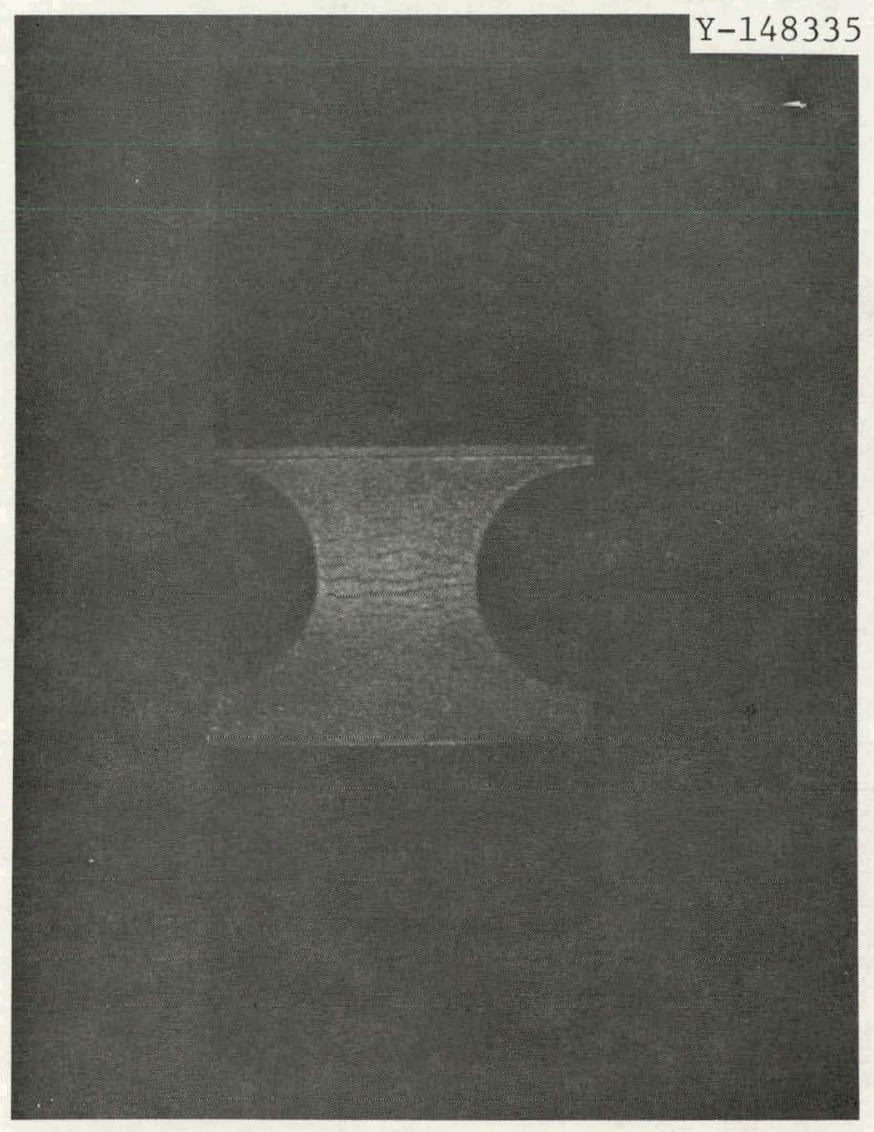

Fig. 4.4. Cracks in Cermet-Coated Specimen CP72T-C01 as Detected by the ZL-22A Penetrant Reversal Method.

\subsection{BIBLIOGRAPHY}

\section{Liquid Penetrant Testing}

R. L. Pasley, "Liquid Penelranls," Nondestructive Testing, A Survey, NASA SP-5113 (1973), Chap. 2.

R. C. McMaster, ed., Nondestructive Testing Handbook, Ronald Press, New York, 1959, Vol. I, Sects. 6, 7, and 8 . 
Filtered-Particle Testing

R. C. McMaster, ed., Nondestructive Testing Handbook, Ronald Press, New York, 1959, Vo1. I, Sect. 9.

Electrified Particle Testing

R. C. McMaster, ed., Nondestmuctive Testing Handbook, Ronald Press, New York, 1959, Vol. II, Sects. 28 and 29. 


\section{DIELECTRIC INSPECTION METHODS}

Methods described in this chapter rely on the effect that a layer of dielectric material has on electric fields that exist in the same region of space. Ceramic coatings are dielectric layers; those methods are not effective for cermets or metals. Dielectrics are characterized by high electrical resistivity and capacitance, that is, ability to store energy in an electric field; ceramics also have high dielectric strength - that is, resistance to arc breakdown.

Testing or measuring methods applicable to ceramic coatings include capacitance gaging, microwave measurements, and arc discharge testing.

\subsection{APPLICATIONS TO COATING INSPECTION}

\subsubsection{Capacitance Gaging}

In its simplest form, a dimensional capacitance gage is a metal rod in close proximity to a metal workpiece, with both members connected to a capacitance measuring device, such as an ac bridge. The measured capacitance changes with the spacing between the probe and the workpiece; it is measured as a capacitive reactance.

Fig. 5.1 shows a modern instrument, in which the second electrode is a concentric cylinder insulated from the metal rod to form a fixed capacitance. When this probe approaches a metal surface, part of its fixed capacitance is shorted out. The ac bridge operates in an unbalanced condition, providing a continuous output, which is "linearized" to produce a readout that is linearly proportional to the spacing (gap) between the probe and workpiece. Alternatively, the probe capacitance can be made part of an oscillator circuit, which produces a variablefrequency output for linearization.

If a dielectric object approaches the probe, the capacitance of the probe increases over the value it had when surrounded by air. If a metal object coated with a dielectric is brought near the probe (Fig. 5.1), the probe capacitance will be higher than if the object were bare metal at the same position. An instrument with adequate range can be calibrated to measure the probe-to object gap in cither of these situations. 


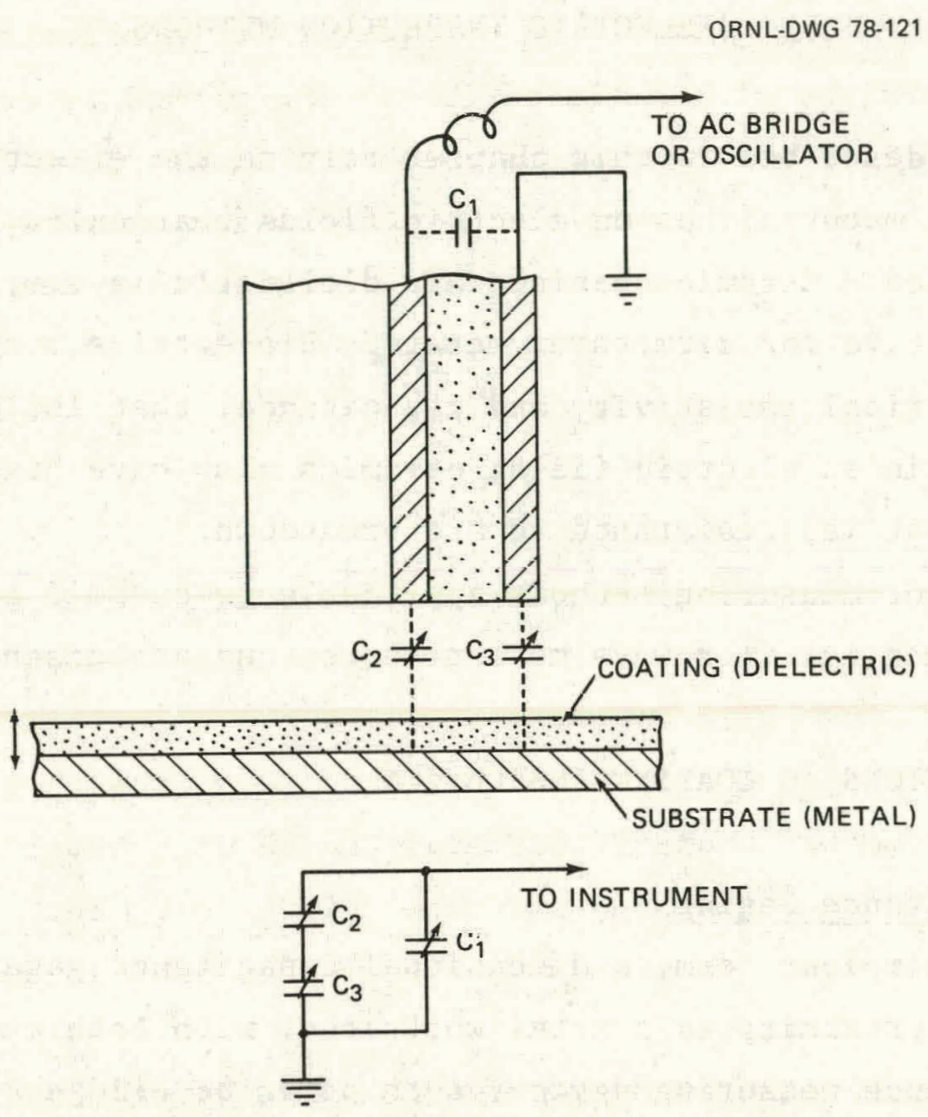

Fig. 5.1. Schematic of a Dimensional Capacitance Probe Applied to a Coated Metal Object and its Electrical Equivalent.

The practical measurement of Lesling of ceramle coatings is complicated by possible inhomogeneity in the coating. For a fixed gap between the probe and the metal substrate, the output of the instrument depends on the amount of (dielectric) coating material present; a thin 1ayer of dense ceramic may have the same dielectric effect as a thick layer of porous ceramic, and the instrument cannot distinguish these two cases.

While it is desirable to maintain a tixed, or at least known, gap between the probe and the substrate, it is easier to design an inspection device that will maintain a fixed standoff between the probe and the coating surface. When operated in this manner, the instrument can indicate variability in the coating response, with the same restrictions noted above, but additional tests will be required to ascertain the cause of the variation. 
Capacitance gaging should be considered for application to ceramic coatings, regardless of its limitations. The method is capable of very high accuracy, which would be used most advantageously in combination with other methods. For example, the combination of a capacitance probe with an eddy-current lift-off sensor in a device that mechanically contacts the coating surface could provide complete information on ceramic coating thickness and porosity.

\subsubsection{Microwave Measurements}

Microwave radiation encountering a dielectric layer penetrates it or reflects from it; in all but a few special cases, some energy penetrates and some reflects. The dielectric transmits microwaves at a velocity lower than the free-space velocity, so the phase relations between reflected and transmitted waves change with depth in the dielectric. Dielectrics may also attenuate the wave. Therefore, both phase and amplitude measurements in microwave systems can provide information about a dielectric material.

To perform a microwave measurement, a dielectric coating on a metal can be made a reflecting element, such as in an interferometer system, or a transmitting element, such as in a stripline resonator. The porosity effect described in Sect. 5.1.1 produces the same uncertainty in microwave measurements. Here again, two measurements must be made to distinguish between thickness and porosity variations; however, both measurements can be made on the microwaves alone, if both phase and amplitude are measured. A single-parameter measurement such as reflected power can be used as a screening test to locate areas of coating variability for examination by other methods.

Reflected power and interferometric measurements can be made with noncontacting devices, but compensation must be provided for any substrate motion along the direction of wave propagation; therefore, scanning system design is somewhat difficult. Transmission resonating devices, on the other hand, require intimate contact with the coating surface, so scanning is probably not practical at all. 


\subsubsection{Arc Discharge Tests}

Most dielectric materials have a higher dielectric strength (i.e., a greater resistance to electric arc breakdown) than ambient air does. The ceramics used for spray coatings have very high strengths and are similar to materials used for high-voltage insulation. A gap between two electrodes requires a much higher voltage to strike an arc if the gap is filled with a ceramic than if it is filled with air. To inspect for cracks or through-penetrating defects, a probe at sufficient potential to strike an arc in air or in a reduced thickness of ceramic is passed over the coating. H'laws can then be located at points where arring nrrurs. Simple instruments incorporating high-voltage sources and current flow indicators have heen 1 sed for many years to test coatingo in tanks, paint on ship hulls, and similar applications.

A number of refinements can improve the sensitivity of the method. To sense reductions in coating thickness or flaws that do not penetrate the coating, the applied voltage would have to be compensated for changes in the clearance between the scanning probe electrode and the substrate and for changes in the humidity and temperature of the ambient air. To improve the resolution of cracks, the probe must contain an electrode shaped to confine the highest field intensity to a very small region. Sustaining an arc once it is struck requires much lower voltage than the initial strike, so an arc tends to persist as Lle prube is carried away from the defect site. This effect destroys resolution and produces oversize defect indications on recording equipment. Pulsing the supply voltage or the use of an arc-quenching circuit might alleviate this persistence. Finally, for high-resolution inspection or spot repair capability, a plan view record of arc indications is desirable.

$\Lambda$ number of simple high-voltage testers, using brush electrodes, are available commercially. We found no units on the market with voltage compensation, mechanical scanning, or plan-view recording capability. 


\subsection{EXPERIMENTAL WORK}

\subsubsection{Response of a Dimensional Capacitance Gage}

We borrowed a commercial dimensional capacitance gage ${ }^{1}$ from $\mathrm{Y}-12$. We experimentally tested the linearity of its response to changes in the proximity of metal surfaces and ceramic coated $\left(\mathrm{ZrO}_{2}\right)$ metal substrates and examined variations in the response to different thicknesses of ceramic. $^{2}$ Figure 5.2 shows the results obtained.

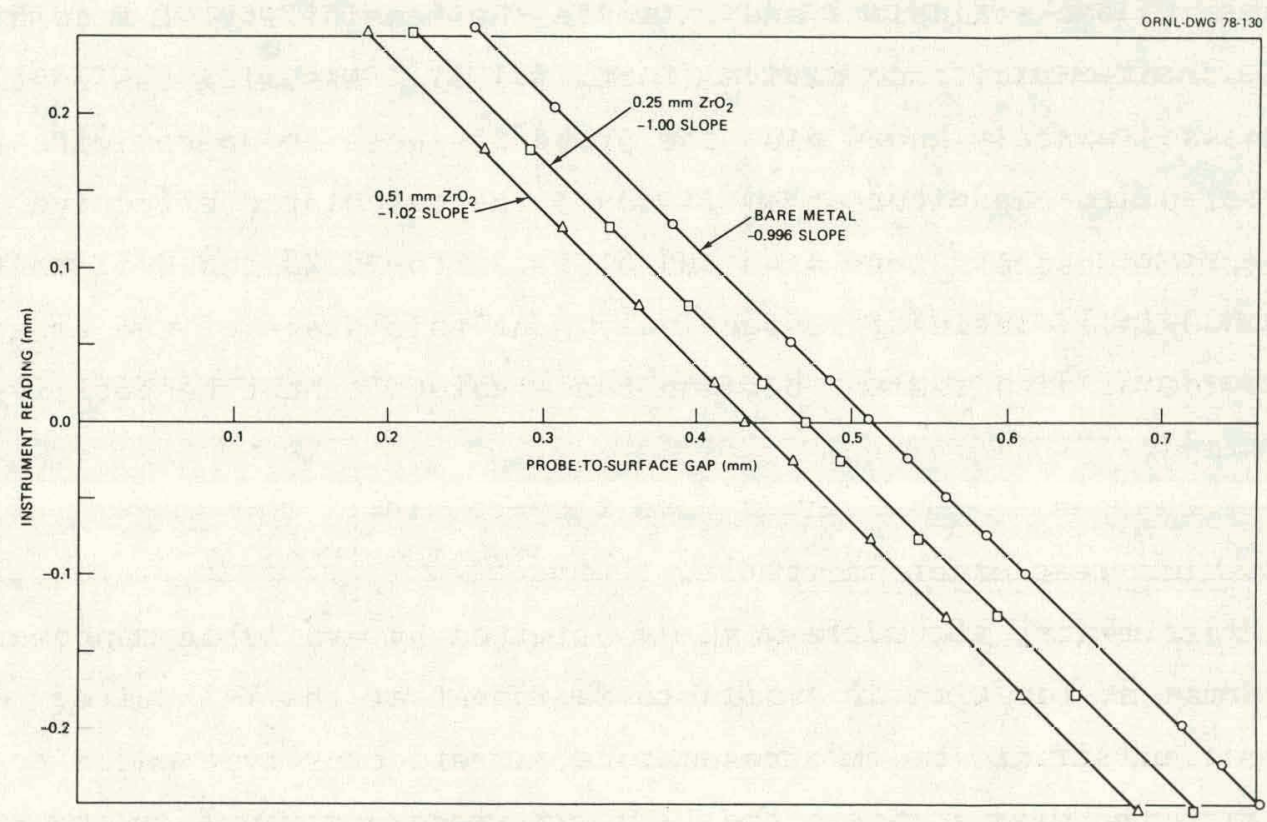

Fig. 5.2. Response (Readout) of a Dimensional Capacitance Gage as a Function of its Position Relative to the Surfaces of One Bare Metal Specimen and Two Ceramic-Coated Specimens.

The instrument demonstrated highly accurate linear responses to changes in the proximity of both metal and ceramic surfaces. Equal incremental changes in the gap produced equal incremental changes in the instrument response for both surfaces. However, the absolute dimensions of the probe-to-specimen gaps were different for the metal

${ }^{1}$ Microsense mode1 3046A, by ADE Corporation, Watertown, Mass.

${ }^{2}$ G. W. Scott, "Dielectric (Capacitance) Testing," Coal Technology Program Annu. Interim Rep. June 30, 1976, ORNL-5208, pp. 142-143. 
surface and each of the two thicknesses of ceramic coating tested. A specific value of the instrument readout could be obtained for one gap dimension between the probe and a metal surface; the same value could also be obtained for each of the two combinations of coating thickness and probe-to-coating-surface gap. As the coating thickness increased, the gap producing a specific instrument reading became smaller. These results are consistent with the operating principles of the instrument described above.

From the data obtained at "0.00" instrument readings, it is possihle to hark-sa1ru1ate and estimate the feasibility of a combination eddy-current-capacitance device (Sect. 5.1.1). Assuming the coating thicknesses exactly known plus the probe response to approximate a parallel-plate capacitor at small gaps, the calculated effective dielectric constants were 6.45 and 6.39 for the 0.25 and $0.51-\mathrm{mm}(0.010$ and 0.020-in.) coatings, respectively. At this stage of the experiments, the source of disagreement between these values cannot be positively determined.

\subsubsection{Microwave Development}

Experimental microwave work was limited by available manpower and the permanent location of available equipment at the Y-12 site. We decigned and fabricated two rcsonators, a reflector type and a trausmission type, to operate in the 1-10 GHz frequency range. Both resonators were fabricated as microstrip configurations; when they are placed against a ceramic coating on a grounded metal substrate, the resulting configuration will be a complete stripline segment. (A stripline consists of a central conducting strip separated by dielectric layers from two wider, grounded conducting strips; it has properties similar to a coaxial cable).

\subsubsection{Arc Discharge Testing}

objectives of the initial experiments were to: (1) demonstrate the reliability of the arc discharge technique by repeatedly detecting crack- or hole-type flaws in ceramic coatings; (2) develop a useful output, recording or display, of the flaw formation. Subsidiary tasks included (1) studying the parameters controlling flaw resolution and (2) modifying the system to optimize detection ability and resolution. 
Our initial locally assembled setup included a high-voltage source, an insulated specimen holder, a crude probe, and a voltage recorder. Figure 5.3 shows an overall view of the system, including the scanner that evolved. Various types of specimens were tried; the best results were obtained with tensile-cracked specimens (see Sect. 4.2.1) developed for surface material testing.

Arc current data were gathered from one-dimensional (straight-line) scans of the probe across cracked specimens. The best resolution was obtained with a probe electrode made by grinding a 2.3-mm (0.092-in.) tungsten rod to a $30^{\circ}$ (included angle) tip with a radius of $50-80 \mu \mathrm{m}$ $(0.0020 .003 \mathrm{in.})$ and scanning this tip as close to the coating surface as possible without scraping [within approximately $0.12 \mathrm{~mm}$ (0.005 in.)] Earlier trial electrodes included round-ended rods and an 80- $\mu \mathrm{m}$ (0.003-in.) tungsten wire. These arc current data were used to construct Figs. 5.4 and 5.5. Figure 5.4 shows the locations of maximum (i.e., local peak) arc currents measured on successive line scans across the specimen. Figure 5.5 shows the arc current variation along what appeared to be the major crack system in the specimen. The crack appears to be wider or deeper at the edges of the specimen, thus passing more current. Figure 5.6, an enlargement of a section of Fig. 4.3, can be compared with Fig. 5.4 to show the similarity of crack shapes obtained by the two methods. To speed up the process of constructing maps like Fig. 5.4, we developed a plan-view recording system. ${ }^{3}$ This system contains circuitry that detects a threshold value of arc current and changes the writing status of a raster-scanning recorder pen if the current exceeds the present threshold. The result is a plan view of the area scanned by the voltage probe with inked lines (or, alternatively, noninked lines) indicating cracks that "pass" more than the threshold value of arc current.

Figure 5.7 shows two scans obtained with the system. These scans are idenlical except for the writing mode. In the "positive" mode inking occurs where the arc current exceeds the threshold; in the "negative" mode, inking occurs everywhere except where the arc current exceeds the threshold.

${ }^{3}$ G. W. Scott and E. V. Davis, An Arc-Discharge System for Nondestructive Detection of Flaws in Thin Ceramic Coatings, ORNL/TM-6176 (in press). 


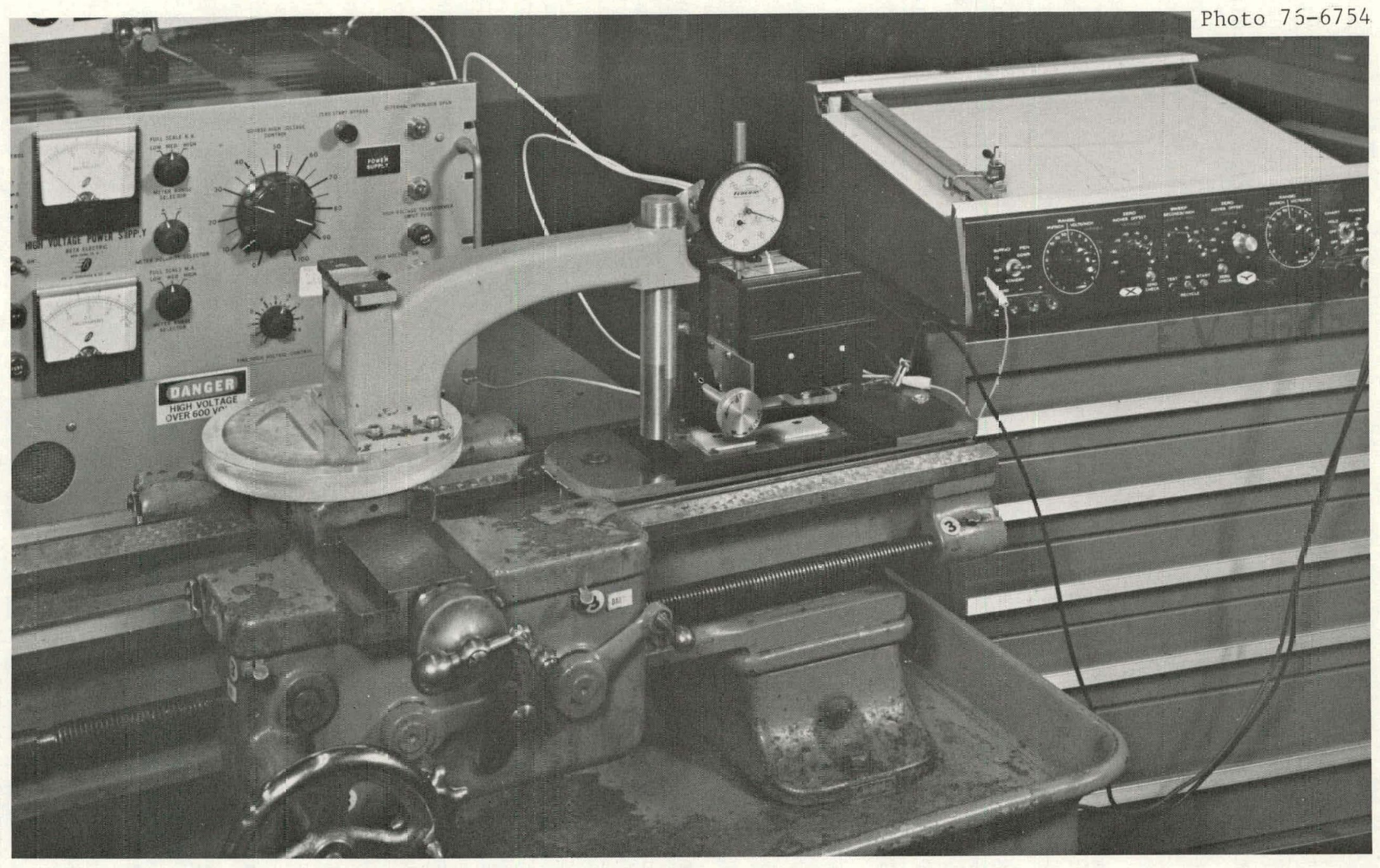

Fig. 5.3. Arc Discharge Testing System. 


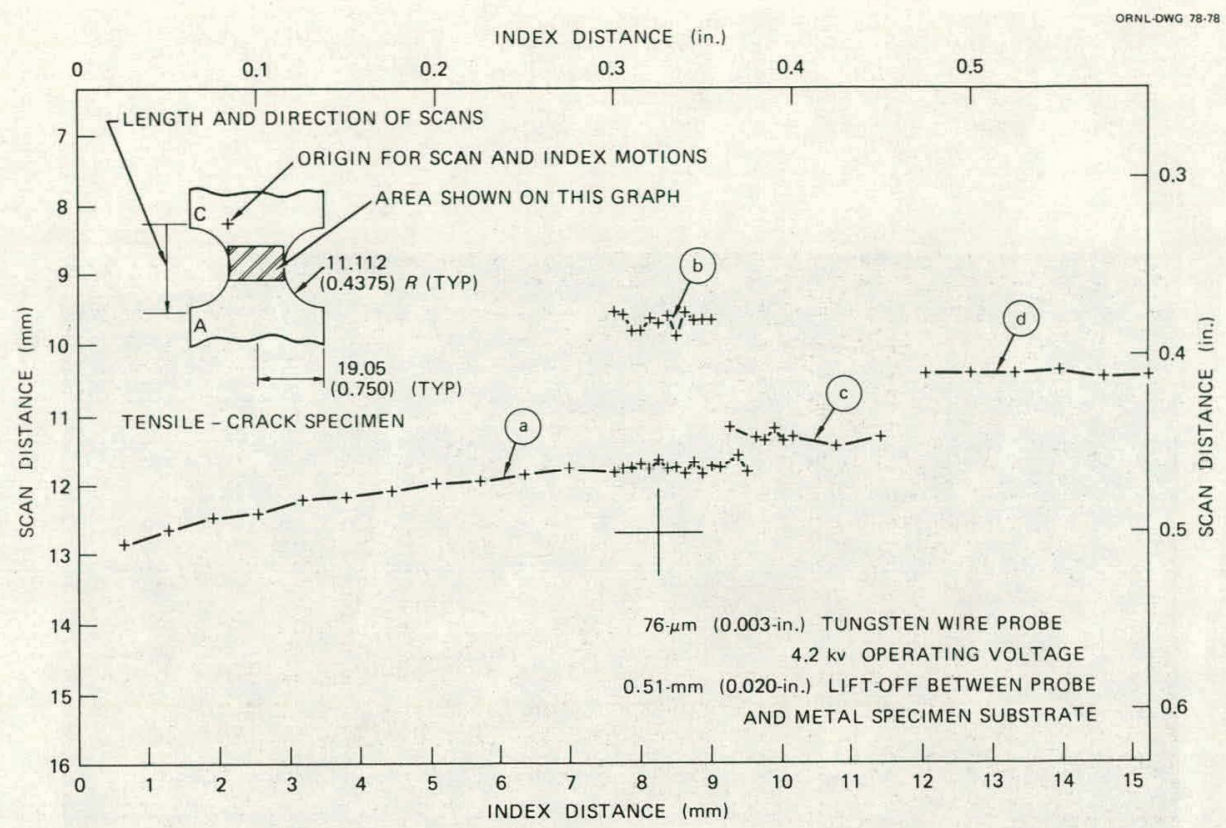

Fig. 5.4. Map of Cracks in a Tensile-Cracked Ceramic Coating Specimen Produced from Arc-Current Measurements in an Arc Discharge Test.

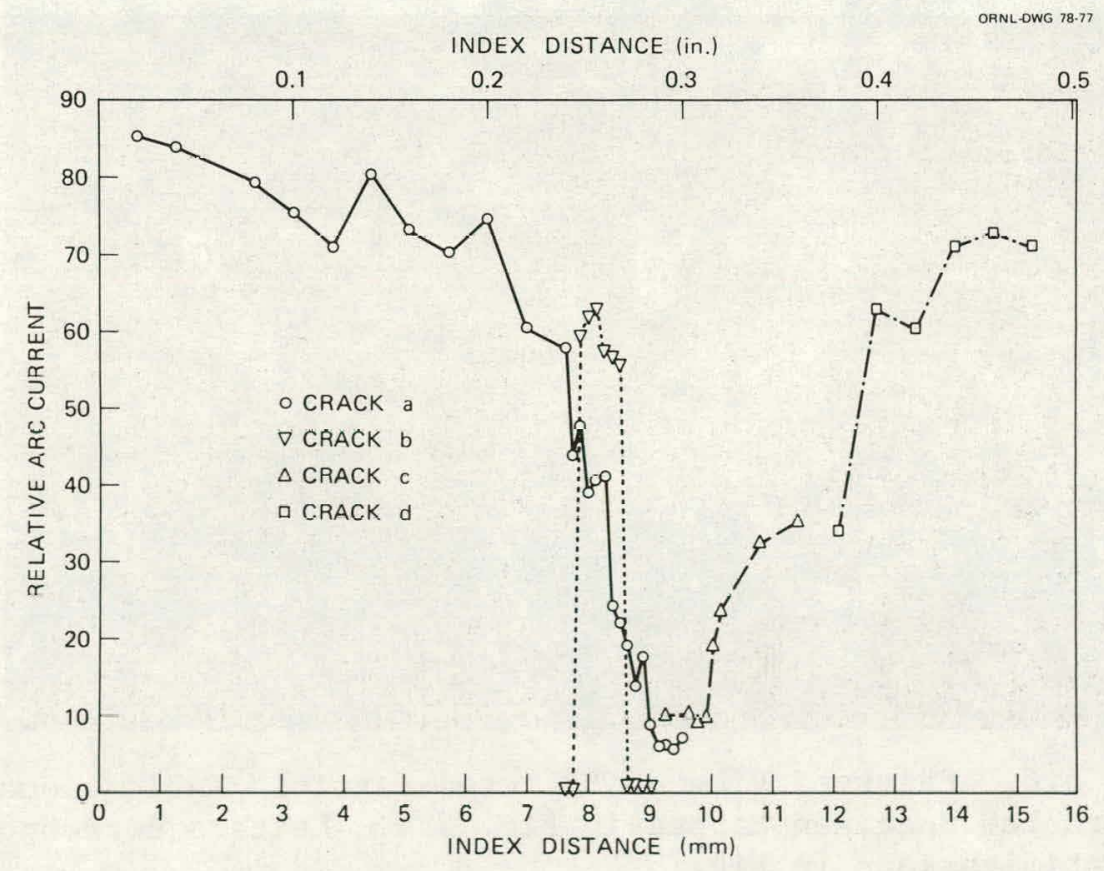

Fig. 5.5. Arc-Current Measurements Along Segments of a Crack System in a Tensile-Cracked Ceramic Coating Specimen. 


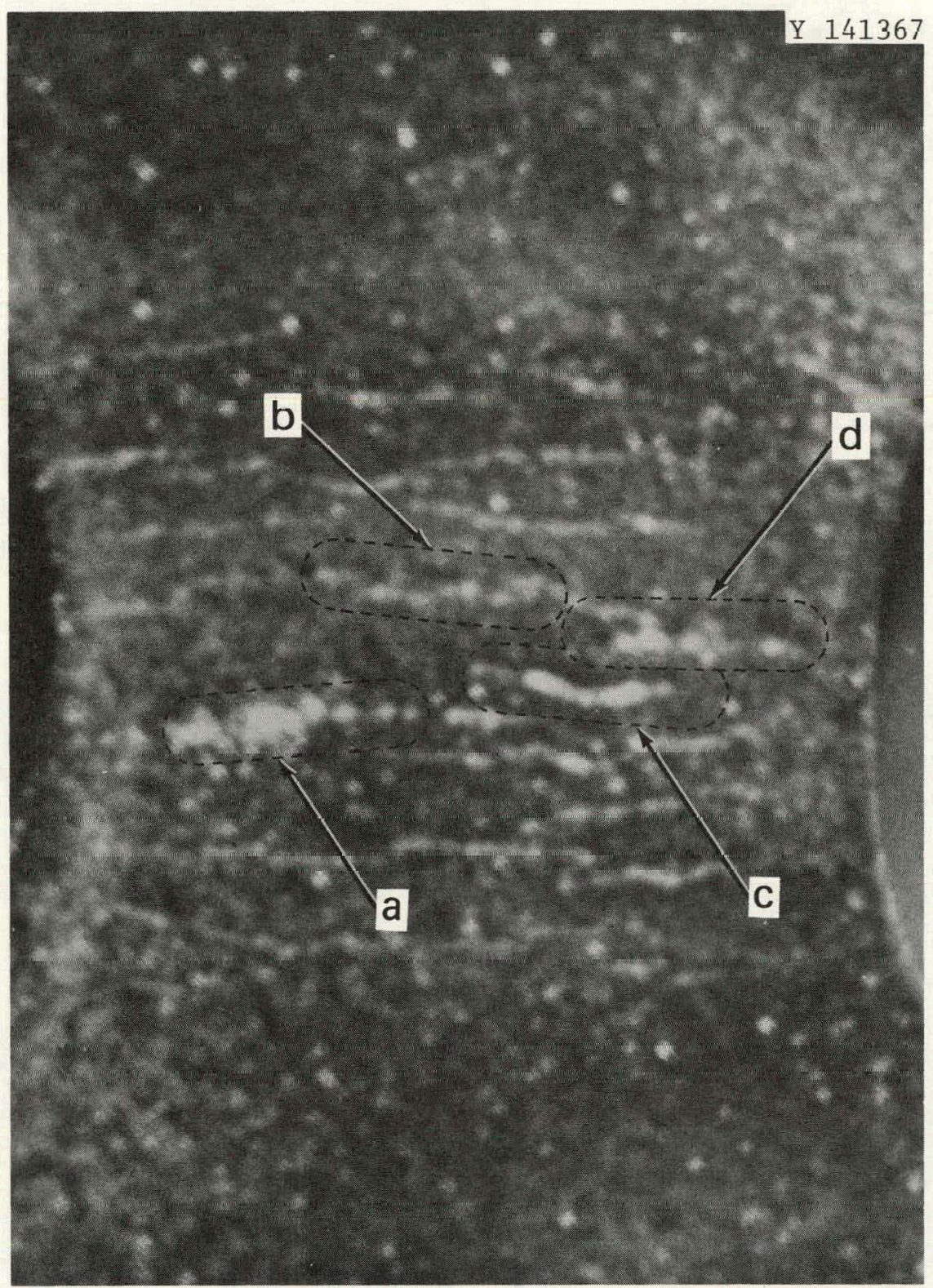

Fig. 5.6. Enlarged View of Filtered-Particle Indications from Tensile-Cracked Specimen Mapped in Fig. 5.4. Letters correspond to crack identifications in Fig. 5.4 . 
$Y-150345$

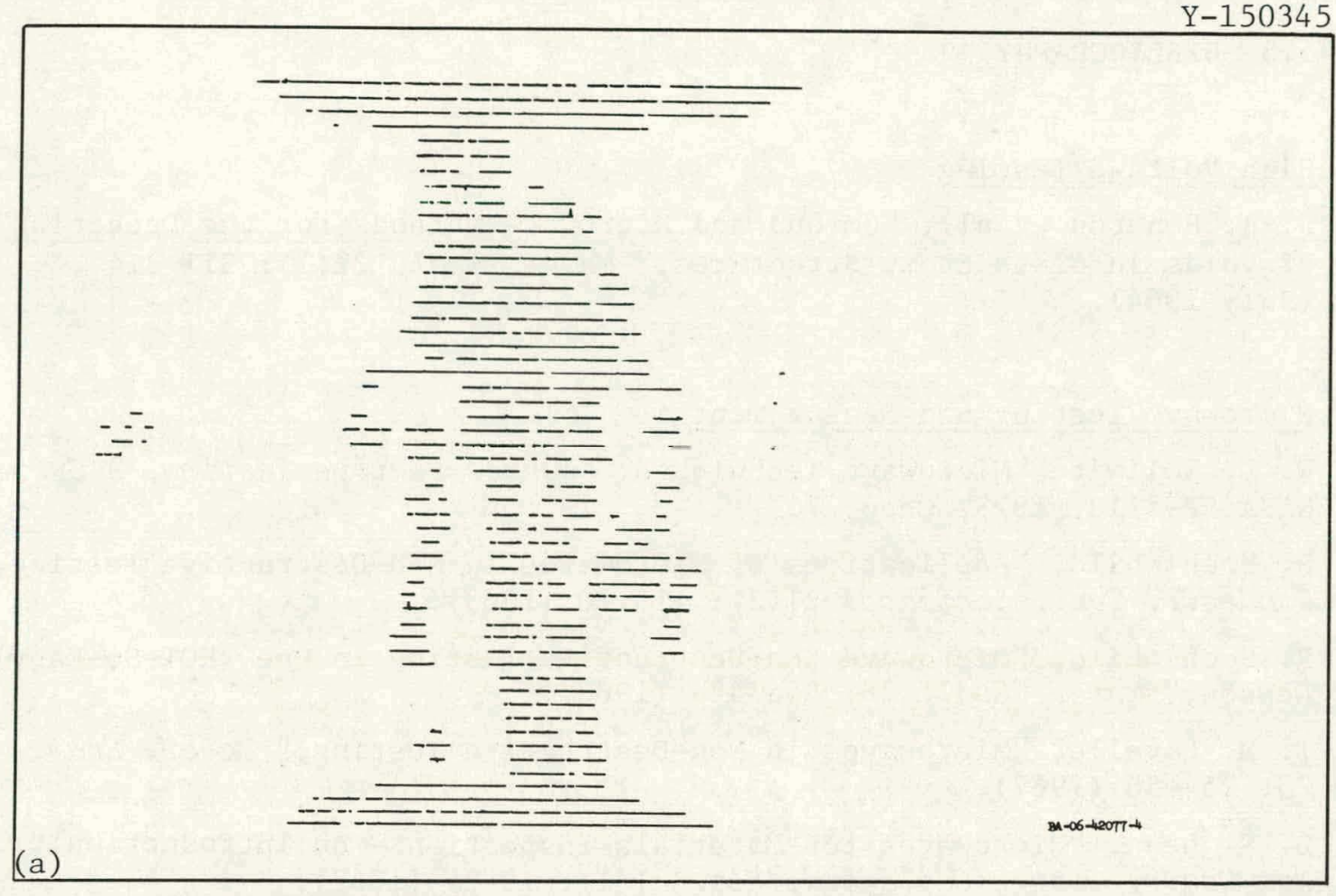

$\mathrm{Y}-150346$

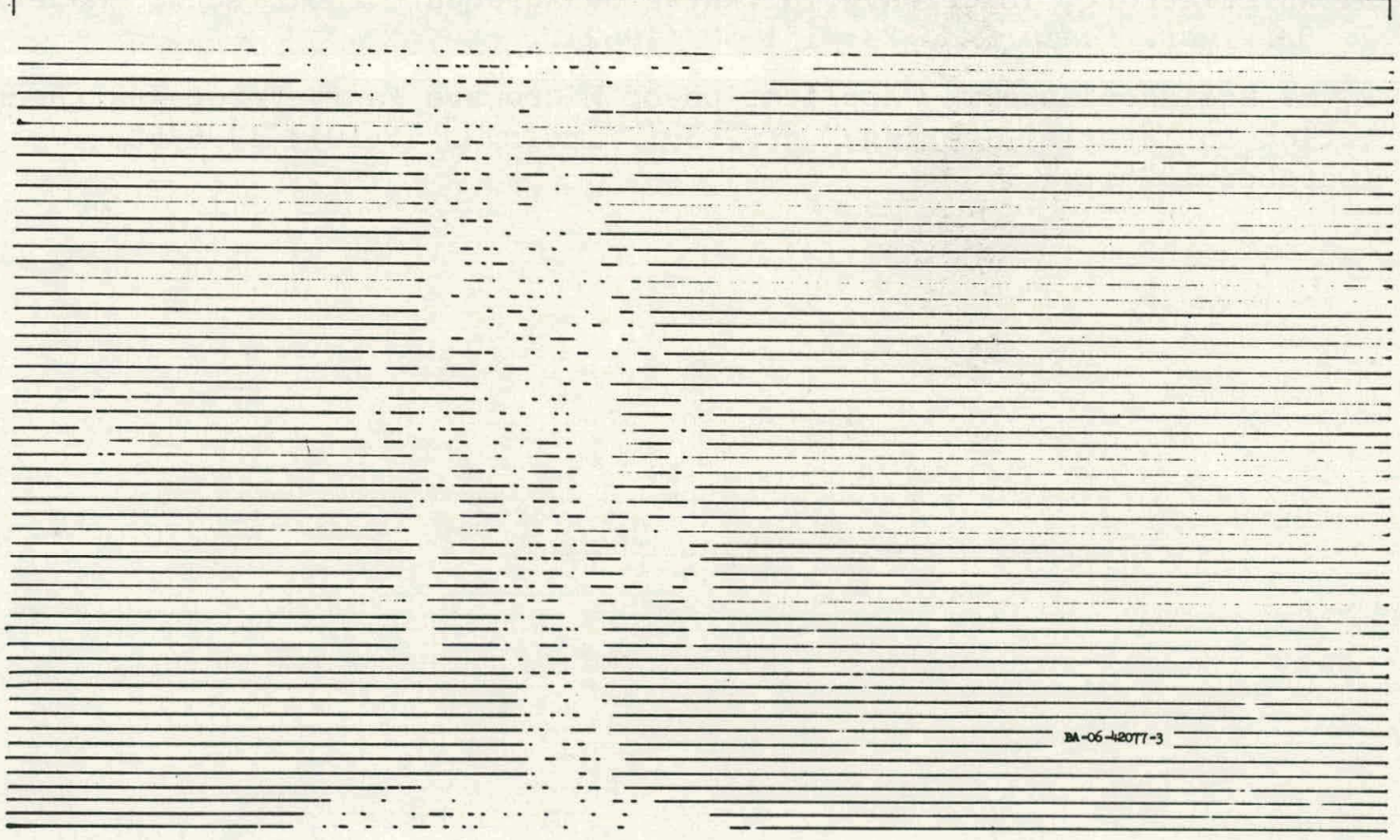

(b)

Fig. 5.7. Plan View Scans by Arc-Discharge Testing System of a Cracked Coating Specimen. Arc current threshold $280 \mu \mathrm{A}$. (a) Positive mode. (b) Negative mode. 


\subsection{BIBLIOGRAPHY}

\section{High Voltage Testing}

J. A. Hendron et al., "Corona and Microwave Methods for the Detection of Voids in Glass-Epoxy Structures," Mater. Eval. 22(7): 311-314 (July 1964).

\section{Microwave Testing and Measurement}

W. L. Rollwitz "Microwave Techniques," Nondestructive Testing, A Survey, NASA-SP-5113, 1973, Chap. 7.

R. Hochschild, "Applications of Microwaves in Non-Destructive Testing," Nondestr. Test. (Chicago) 21(2): 115-20 (1963).

R. Hochschild, "Microwave Non-Destructive Testing in One (NOT-So-Easy) Lesson," Mater. Eval. 26: 33a-42a (1968).

T. M. Lavelle, "Microwaves in Non-Destructive Testing," Mater. Eval. 25: 254-58 (1967).

D. S. Dean, "Microwaves for Materials Inspection - An Introduction," Non-Destr. Test. (Guildford, Fla.) 1(1): 19-24 (1967).

D. Whistlecroft, "Microwave Thickness Measurement of Dielectric Materials," J. Br. Inst. Radio Eng. 23: 151-55 (1962).

P. S. Ncelakantaswamy, "Application of Microwave Fabry-Perot Instrumentation to Material Testing," Rev. Sci. Instrum. 46(10): 1396-98

(October 1975). 


\section{ELECTROCHEMICAL METHODS}

Electrochemical methods investigated have two common features: they use phenomena associated with reactions between ionic species in electrolytic solutions and solid electrodes immersed in these solutions, and they employ an electrical measurement to determine the status of the electrochemical system, from which other information can be deduced.

Simple conductivity devices using wet-sponge-covered electrical probes have been used for inspecting painted tanks and similarly protected containers for many years. Instruments in current industrial use monitor for leaks in tanks lined with inorganic materials by sensing current flow induced by galvanic potentials. The phenomenon of differential electrode capacitance has been known for many years, but as far as we can determine, the results described below constitute the first attempt to apply it as a nondestructive testing method.

Electrochemical methods may monitor a complete unit, such as a tank, by filling with an electrolyte and measuring a property such as galvanic current. Such a method forgoes the capability for precise flaw location. Specific flaw location in many cases requires the use of a probe device, which may or may not be totally immersed in the electrolyte.

Electrochemical methods examined for application to coating inspection have included (1) measurement of galvanic potential, with no current flow, (2) measurement of galvanic current, with no restrictions on porential, and (3) differential capacitance.

\subsection{APPLICATIONS TO COATING INSPECTION}

\subsubsection{Galvanic Methods}

When a metal is immersed in an electrolyte (e.g., an ionic salt in water), a galvanic potential is set up across the metal-electrolyte interface. When two dissimilar metal electrodes are immersed in a common electrolyte, a potential difference is observed between them. This potential can be measured with a simple voltmeter and will vary 
with the amount of current allowed to flow or impressed through the cell. The potential can also be affected by the presence of other metals in the cell.

Alternatively, one can measure the galvanic current and ignore any voltage variation. The effect of metallic objects outside the current path (i.e., not electrically connected to the circuit) is minimized by this approach. Geometrical factors can also be ignored because the presence or absence of current is the parameter of interest in applications.

In general, galvanic methods would apply to impermeable coatings of insulating materials (dielectrics). Breaks in the coating would expose metal and produce galvanic potential indications or allow current flow. Galvanic current appears more likely to produce reliable flaw indications, free of outside interfering effects. Current flow measurement may provide some indication of flaw size.

\subsubsection{Differential Electrode Capacitance (DEC) Methods}

At a single metal-electrolyte interface, charged ions in solution are attracted by charges in the metal to form an electrical double layer at the interface. The signs of the charges are controlled by the potentials of the half-cell and any that are imposed on the system. This double layer has an associated capacitance, which can be measured.

Electrical measurement of the DEC requires a full cell, including the workpiece (test electrode) and a reference electrode. External circuitry measures a composite circuit including the reference electrode capacitance in series with the workpiece capacitance and various series and parallel conductances (assoclated with the electrolyte). Making the reference electrode capacitance large makes the measurement more sensitive to changes in the smaller workpiece capacitance.

Coating a metal workpiece with dielectric reduces the DEC by reducing the electric field intensity between charges in the double layer. The density of charge in the double layer is thereby reduced, so its capacitance decreases. The difference in DEC between a bare 
metal surface and one coated with impermeable dielectric is quite large. There are also minor differences between various metal surface conditions. Therefore, the intermediate case, plasma-sprayed cermets, is a potential application. In all coating applications, the exposure of substrate material would be expected to change the DEC value; breaks in ceramic or cermet coatings should increase it; breaks in metal coatings might decrease it. For metal coatings, the method may be more useful as an indicator of uniform porosity than as a flaw detector.

There are no commercial instruments specifically designed to use DEC for the indication of any surface characteristic. Industrial application would require development of prototype instrumentation.

\subsection{EXPERIMENTAL WORK}

\subsubsection{Galvanic Potential}

We performed brief feasibility experiments on specimens of $\mathrm{ZrO}_{2}$ coated on alloy 800 substrates early in the program. ${ }^{1,2}$ Potential measurement with a high-impedance voltmeter indicated an anomalous potential from the coating, which apparently resulted from free zirconium flakes in the coating (Sect. 3.2.1). A conductivity measurement showed much higher conductivity than one would expect for an impermeable coating, indicating the possibility of through-porosity; that is, porosity extending completely through the coating to the substrate.

\subsubsection{Differential Electrode Capacitance}

We measured capacitance and conductance as a function of immersed area $^{3}$ for three specimen types: a bare alloy 800 strip, an alloy 800

${ }^{1}$ R. W. McClung and G. W. Scott, "Electrolytic Probe," Coal Technology Program Prog. Rep. June 1976, ORNL/TM-5595, p. 22.

${ }^{2}$ G. W. Scott, "Electrochemical Testing," Coal Technology Program Quart. Prog. Rep. Sept. 30, 1976, ORNL-5224, pp. 68-69.

${ }^{3}$ G. W. Scott, "Electrochemical Testing," Coal Technology Program Quart. Prog. Rep. Dec. 31, 1976, ORNL-5282, pp. 95-97. 
strip coated with $0.25-\mathrm{mm}$ (0.010-in.) $\mathrm{ZrO}_{2}$, and an alloy 800 strip covered with a continuous film of Mylar tape. Figure 6.1 shows the laboratory equipment and setup used for the measurements; Fig. 6.2 shows the electrical circuit. Measurements made with two different electrode-electrolyte configurations show the effects of geometry variation on bare and spray-coated specimens. Figures 6.3 and 6.4 show the capacitance and conductivity data. To compare the behavior of an impermeable coating, we made the measurements shown in Figs. 6.5 and 6.6. Note the order of magnitude changes in both capacitance and condurtanse from the other experiments. The capacitance of the Mylarcovered electrode can be calculated as though 1 t were d dıy parallel platc capacitor with the electrolyte acliny as one plate.

From the difference in capacitances per unit area, one can conclude that the DEC method has adequate sensitivity to detect flaws in sprayed coatings when the flaws expose the substrate and occupy a significant fraction of the area of a fixed-area probe. For example, if the coated and bare-metal specimens differ in capacitance per unit area by $20 \%$, a flaw exposing $25 \%$ of the probe area would produce a $5 \%$ change in the capacitance, which should be detectable. One can also conclude that the method would be highly sensitive to flaws in impermeable coatings, such as paint or fully dense ceramics. It appears likely that a combination of probe design and electronic correction circuits could linearize the response for flaw size measurement.

\subsection{BIBLIOGRAPHY}

\section{Galvanic Methods}

J. H. Bender, Jr., el d1., "Electrode Potential Testing," Nondester. Tesl. (Chination) 18(2): 99-102 (Mar,-Apr. 1960).

Applications of Aerospace Technology in Industry - Nondestmuctive Testing, NASA Technology Utilization office, April 1972: 87-88 (also NASA Tech. Brief 68-10378).

\section{Differential Electrode Capacitance}

D. C. Grahame, "The Electrical Double Layer and the Theory of Electrocapillarity," Chem. Rev. 41: 441-501 (1947). 


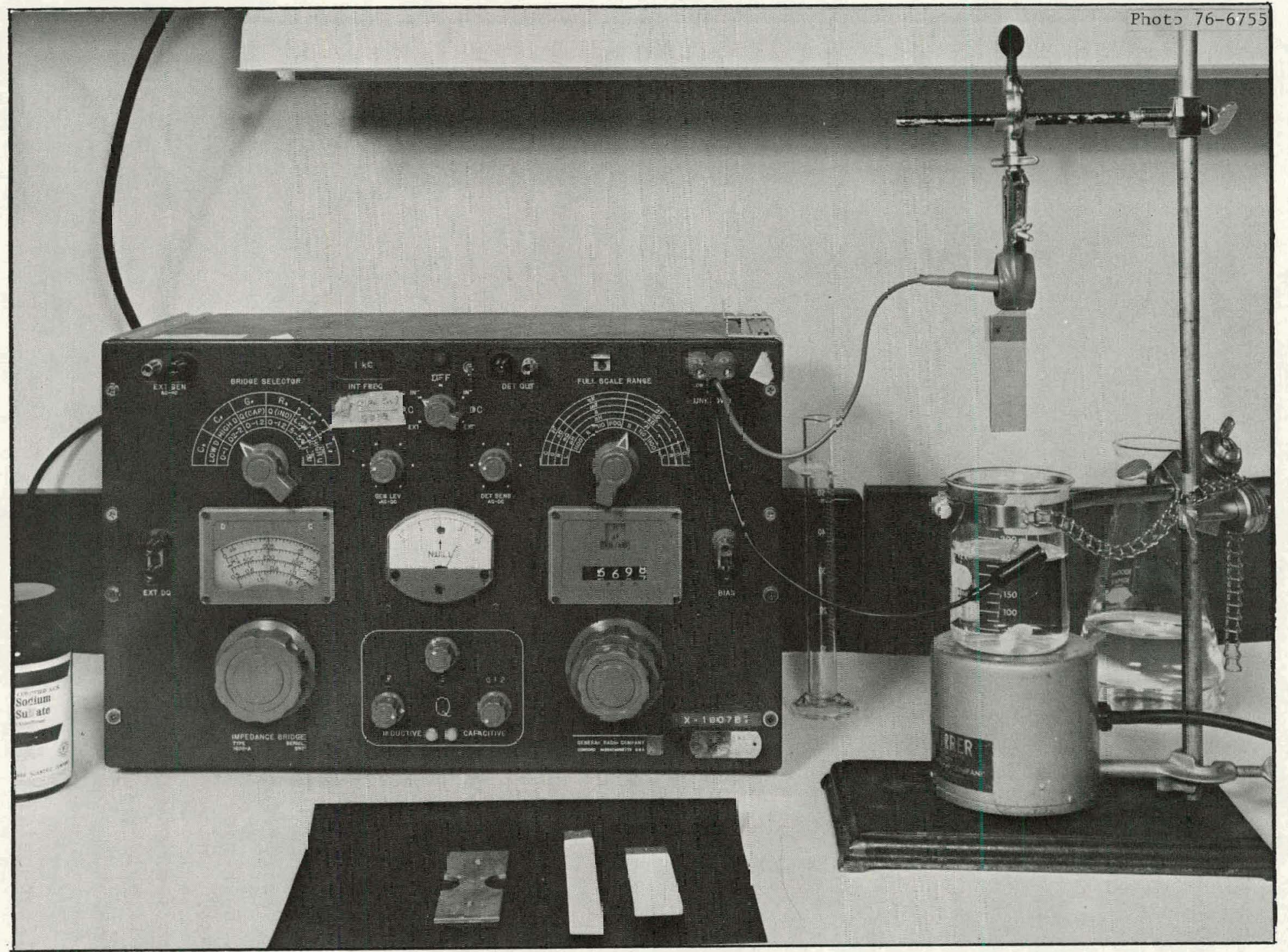

Fig. 6.1. Apparatus and Specimens Usec to Measure the Differenti $\exists 1$ Japєcitance of $\mathrm{Bare}$ and $\mathrm{ZrO}_{2}-$ Coated Alloy 800 in Electrachemical Cells. 
ORNL-DWG 78-126

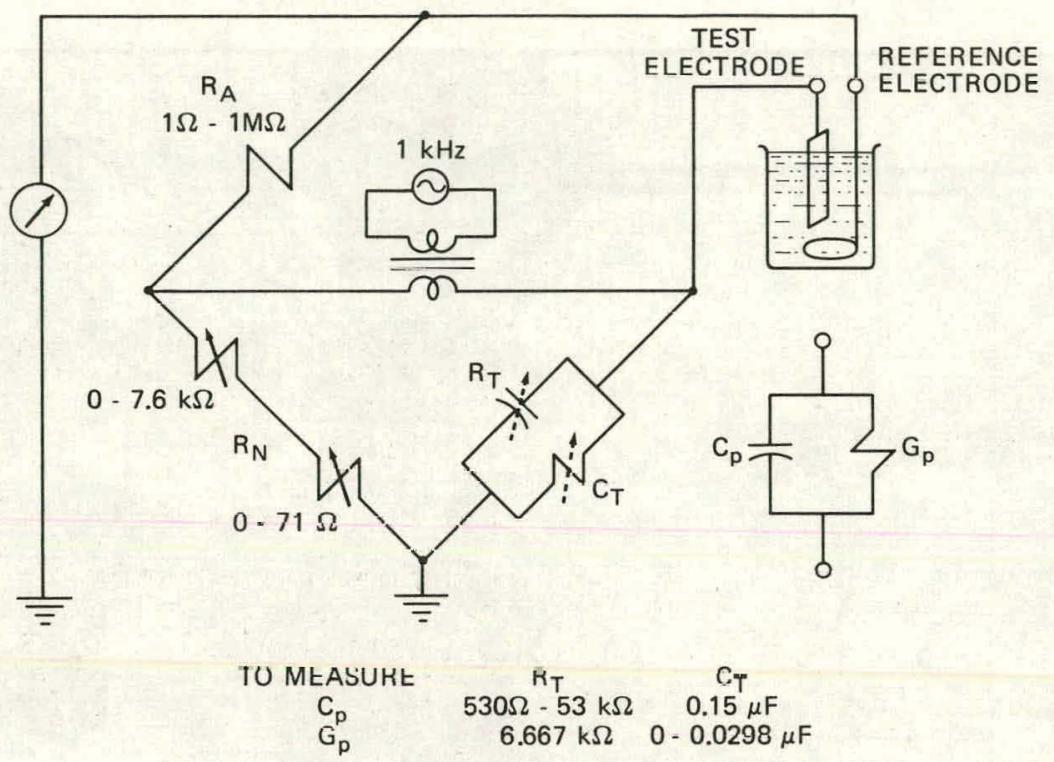

Fig. 6.2. Alternating Current Bridge Circuit and Equivalent Cel1 Circuit for Differential Electrode Capacitance Measurements.

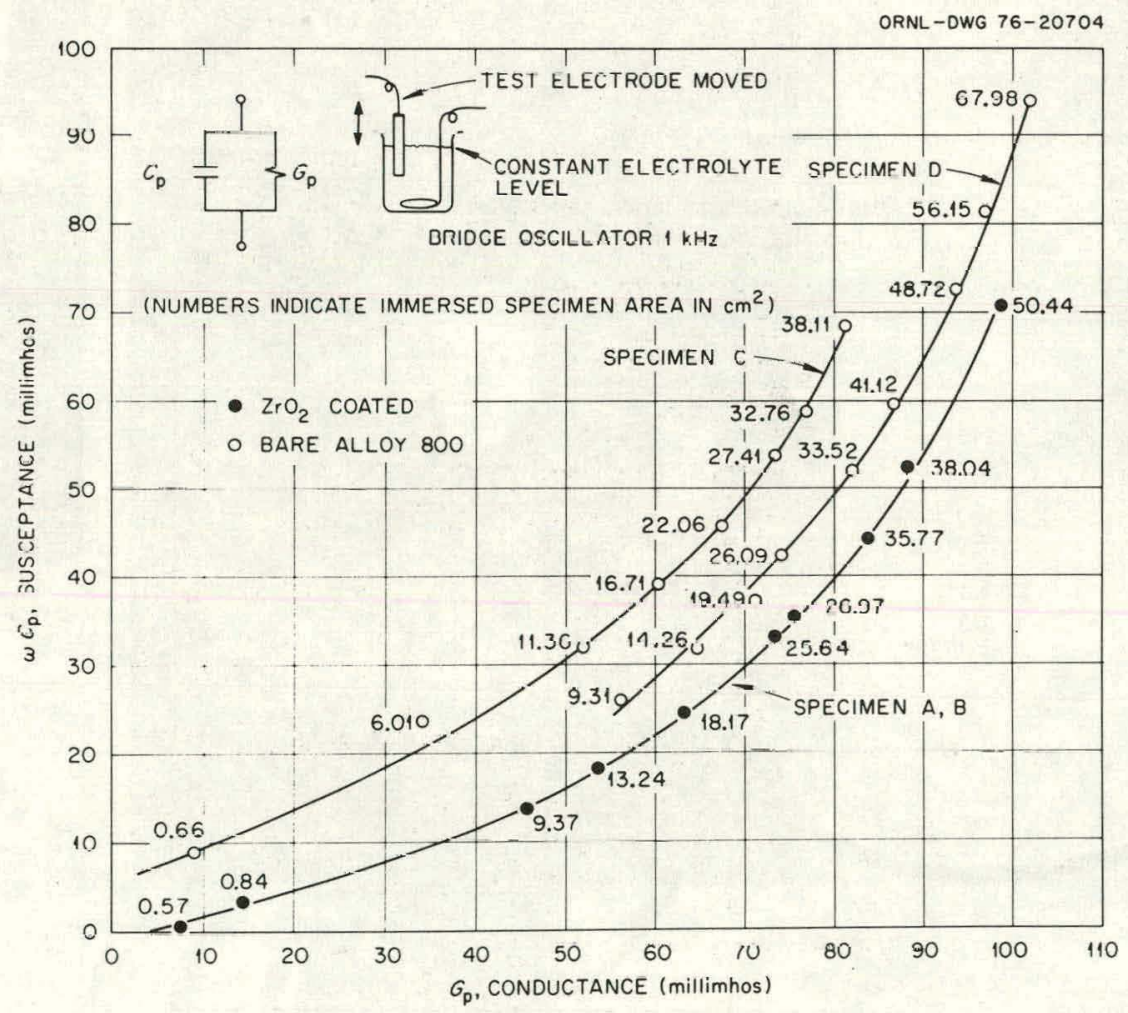

Fig. 6.3. Admittance Plane Plot of Alloy $800-\mathrm{ZrO}_{2}$ Electrochemical Measurements with Moving Test Electrode. Units on the axes are millisiemens. 


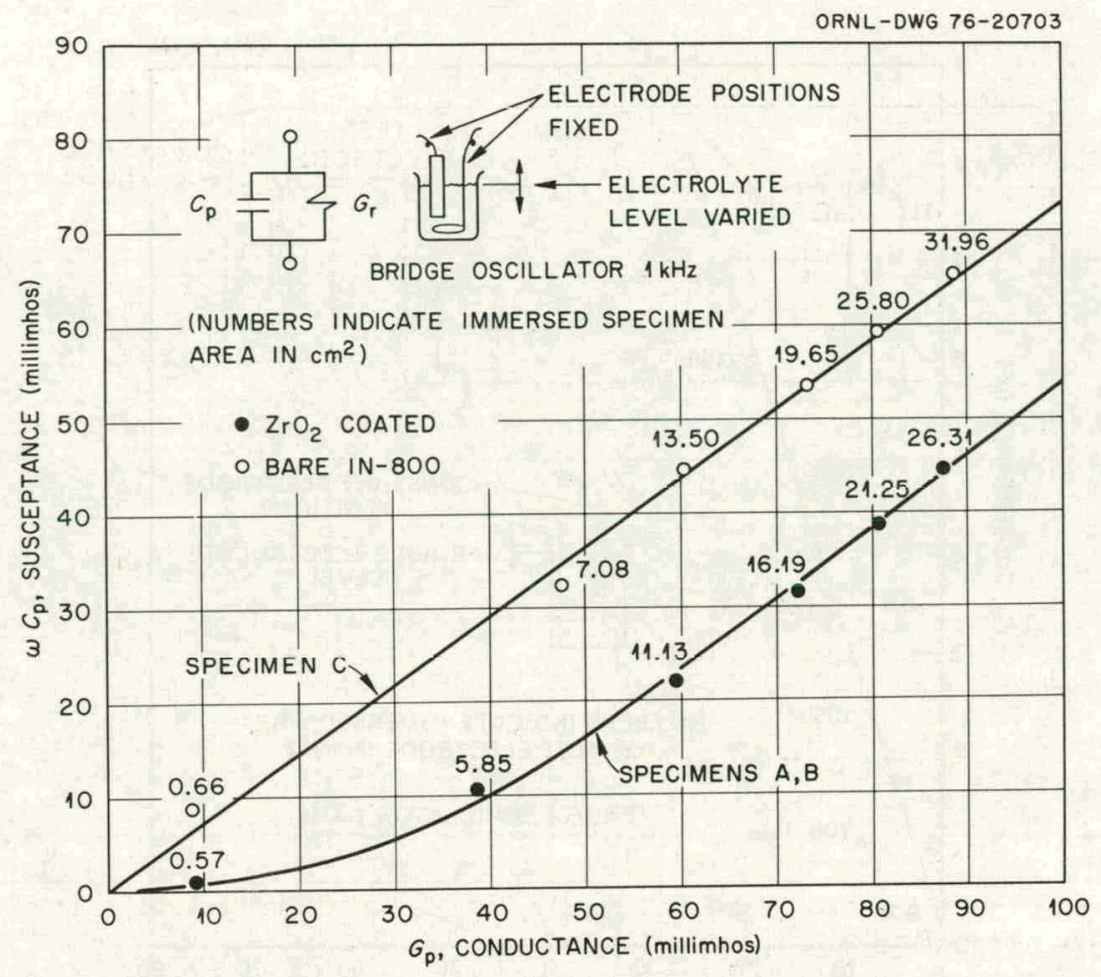

Fig. 6.4. Admittance Plane Plot of Alloy 800- $\mathrm{ZrO}_{2}$ Electrochemical Measurements with Fixed Electrodes and Variable Electrolyte Level. Units on the axes are millisiemens.

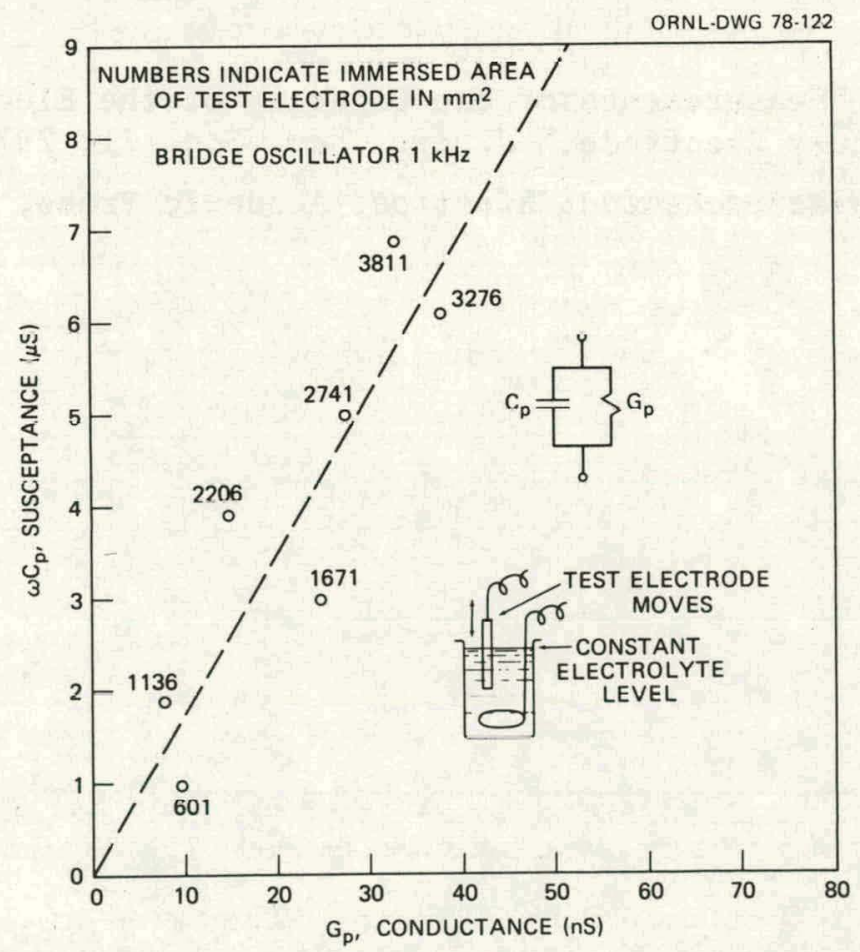

Fig. 6.5. Admittance Plane Plot of Mylar-Covered Alloy 800 Electrochemical Measurement with Moving Test Electrode. 


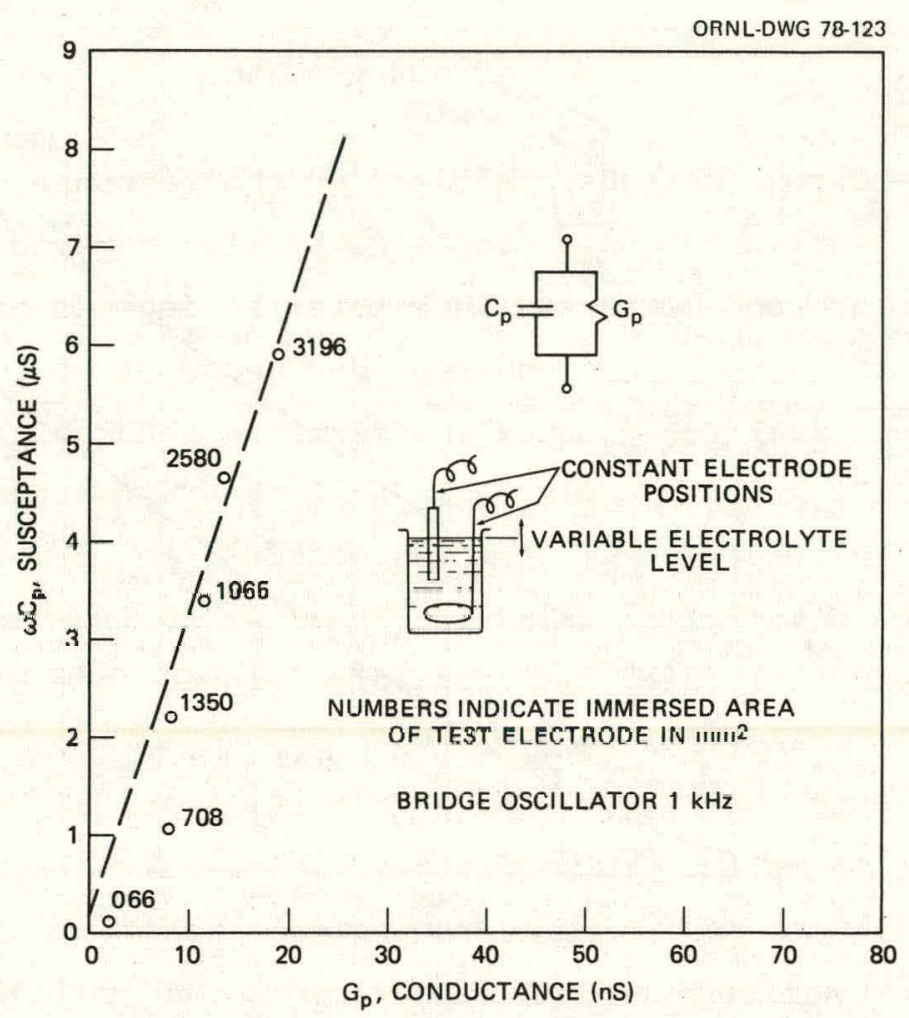

Fig. 6.6. Admittance Plane Plot of Mylar-Covered Alloy 800 Electrochemical Measurements with Fixed Electrodes and Variable Electrolyte Leve1.

D. C. Grahame, "Measurements of the Clapacity of the E'Lectrica $\perp$ Double Layer at a Mercury Electrode," J.Am. Chem. Soc. 11: 2y/b-18 (1949).

K. J. Vetter, Electrochemical Kinetics, Academic Press, New York, 1967. 


\section{EDDY-CURRENT METHODS}

A11 eddy-current methods are based on the response of workpiece materials to electric currents generated by electromagnetic induction. The generation of those currents in a material depends on several factors: (1) the strength, frequency, and geometry of the inducing field; (2) electrical resistivity and magnetic permeability of the material; and (3) any gaps, flaws, layers, or other artifacts producing rapid changes in electrical properties within a small volume. The response of the material is measured either as an impedance change in the inducing (driver) coil or as currents induced from the material into a second (pickup) coil.

Eddy currents were first used nearly 100 years ago for sorting metals. Since then, they have been used to measure electrical properties, to measure thicknesses of single and multiple layers of conductors, and to detect defects. Eddy-current measurements can indicate other conditions that correlate well with electrical properties, such as heat treatment in steels.

Early eddy-current inspection procedures were developed by trial and error and other empirical methods; many are still done this way. Modern methods of inspection development and equipment design use solutions to the electromagnetic field equations generated by digital computers from analytical approximations. These methods apply to new instrument designs and can also be used to optimize the application of existing commercial instruments. The inspection problem can be optimized by designing special equipment, such as coils, or by selecting the best operating conditions for existing instruments.

For our coating applications thus far, we have used hybrids of homemade and commercial instruments and made measurements in transmission and reflection modes. 


\subsection{APPLICATIONS TO COATING INSPECTION}

\subsubsection{Through-Transmission Methods}

Modern computational optimization methods require at least baseline estimates of electrical resistivity and magnetic permeability. Published data on sprayed coatings do not contain adequate measurements of these properties.

Resistivity and permeability can be measured indirectly by an instrument having well-characterized geometric and circuit parameters. Because resistivity and permeability changes affect eddy-current response much less than changes in lift-off, the elimination or control of lift-off effects is highly desirable in electrical property measurements. The fixed coil spacing in the through-transmission configuration (Fig. 7.1) assures that the sum of lift-off and specimen thickness remains constant; accurate measurement of the specimen thickness yields comparable accuracy in the value of lift-off. The axial position of the specimen between the coils does not affect the response, and the remaining parameters of the instrumentation can be measured with sufficient accuracy that their error contributions can be ignorcd.

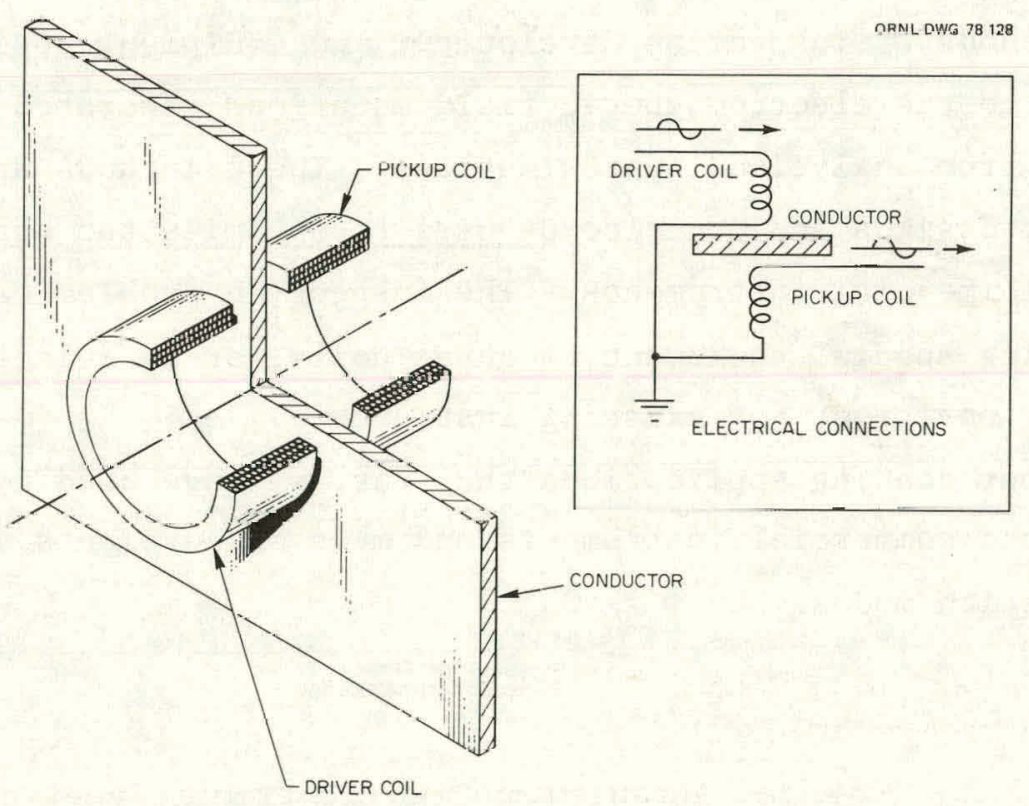

PHYSICAL ARRANGEMENT

Fig. 7.1. Physical Arrangement and Electrical Schematic of a Through-Transmission Eddy-Current Coil System. 
The measurement of amplitude and phase of the voltage across the receiving (pickup) coil provides two numbers and allows the calculation of the two unknown material properties. Corroborative data can be obtained by repeating the measurement at various frequencies. We are developing a technique to use measurements taken at two frequencies to compute permeability and resistivity; this method will not require measurements of either the coil spacing or the specimen thickness.

\subsubsection{Reflection Methods}

Many inspection situations require the excitation and sensing of eddy currents from the same side. Ceometrical considerations favor the coil-in-coil arrangement shown in Fig. 7.2: both coils need minimum spacing from the conductor for sensitivity; the coils cannot occupy the

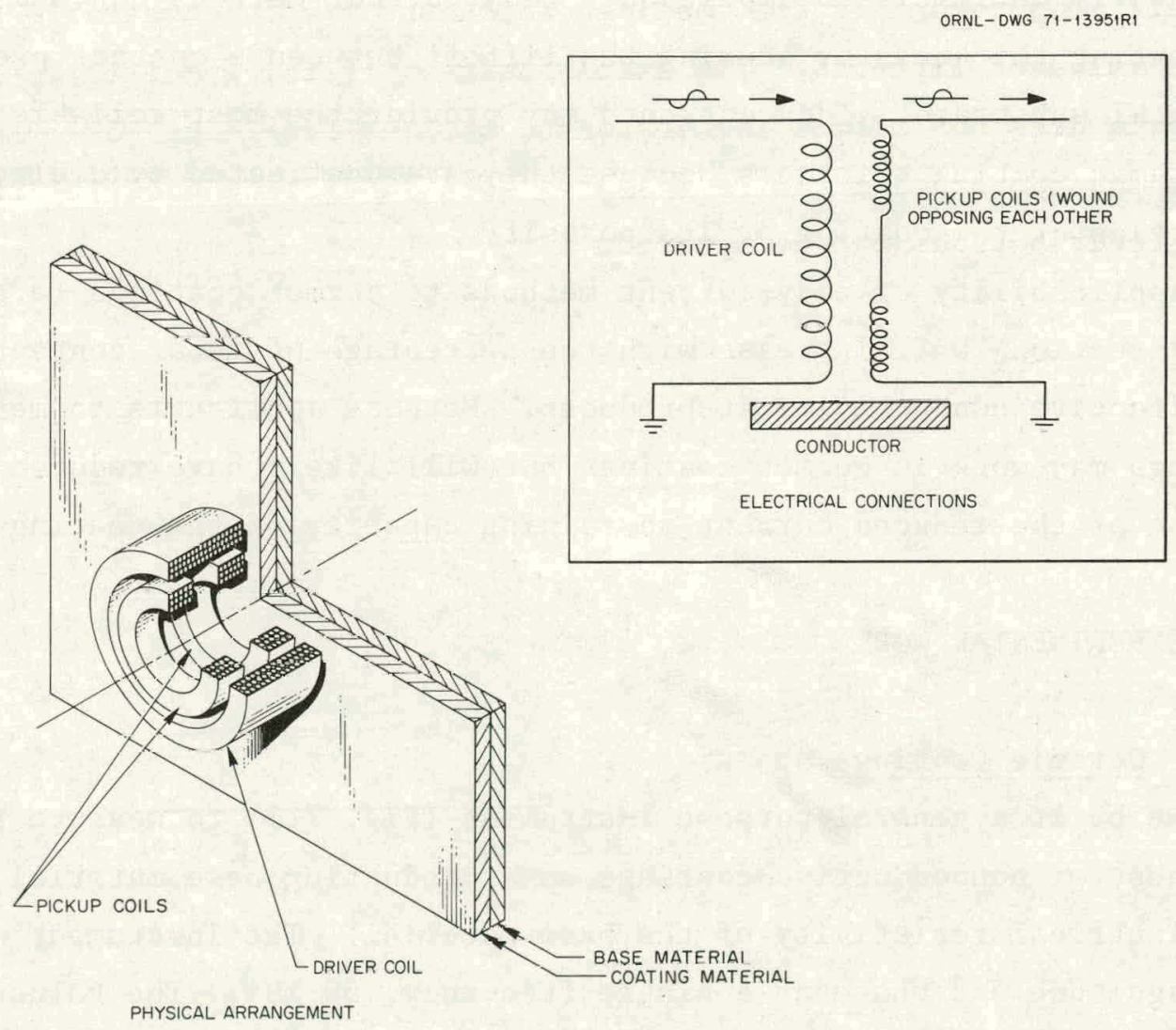

Fig. 7.2. Physical Arrangement and Electrical Schematic of a Reflection-Type Eddy-Current Coil System. 
same region of space, but should be coaxial to simplify calculations; and the driver needs more current-carrying capacity, so it can be made larger. The outer pickup coil (the one farther from the conductor) is added to balance and cancel any current induced in the inner pickup when the assembly is in air, away from any conductor.

The reflection coil shown and the circuitry for use with it are ORNL designs, but have been available commercially. ${ }^{1}$ The probe circuit is a modified bridge with transformer coupling of the ac voltage to the test and reference coils (bottom and top pickup coils). Most commercial bridge instruments use other designs.

The low conductivity of ceramir snatings 1imits the application of eddy currents. Such dielectric substances have very few free (conduction) electrons for induction fields to set in motion. Hence, no measurable eddy currents are induced in the material, and the fields are transmitted with nearly undiminished amplitude. Eddy-current methods can measure the coating thickness by sensing the liftoff between a contact probe and the metal substrate. Eddy currents may provide the most reliable indication of ceramic coating thickness because they are unaffected by dielectric properties of the coating or its porosity.

Applicability of eddy-current methods to cermet coatings (e.g., for flaw detection) will increase with the percentage of metal content and the effective conductivity it produces. Methods applfcable Lu metallic coatings may work in cermet coatings but will likely have reduced sensitivity because of the reduced current-sustaining capacity of the coating material.

\subsection{EXPERIMENTAL WORK}

\subsubsection{Ceramic Coatings}

We buill a genera1-purpose instrument (Fig. 7.3) to measure the thickness of nonconductive coatings on a conducting base material and the electrical resistivity of the base material. The instrument measures the magnitude and phase at a single frequency, $50 \mathrm{kHz}$. The values of

\footnotetext{
${ }^{1}$ Probes are manufactured by Godsey Precision Industries, Kingston, Tenn. The electronic unit is manufactured by Tennelec, Inc., Oak Ridge, Tenn.
} 


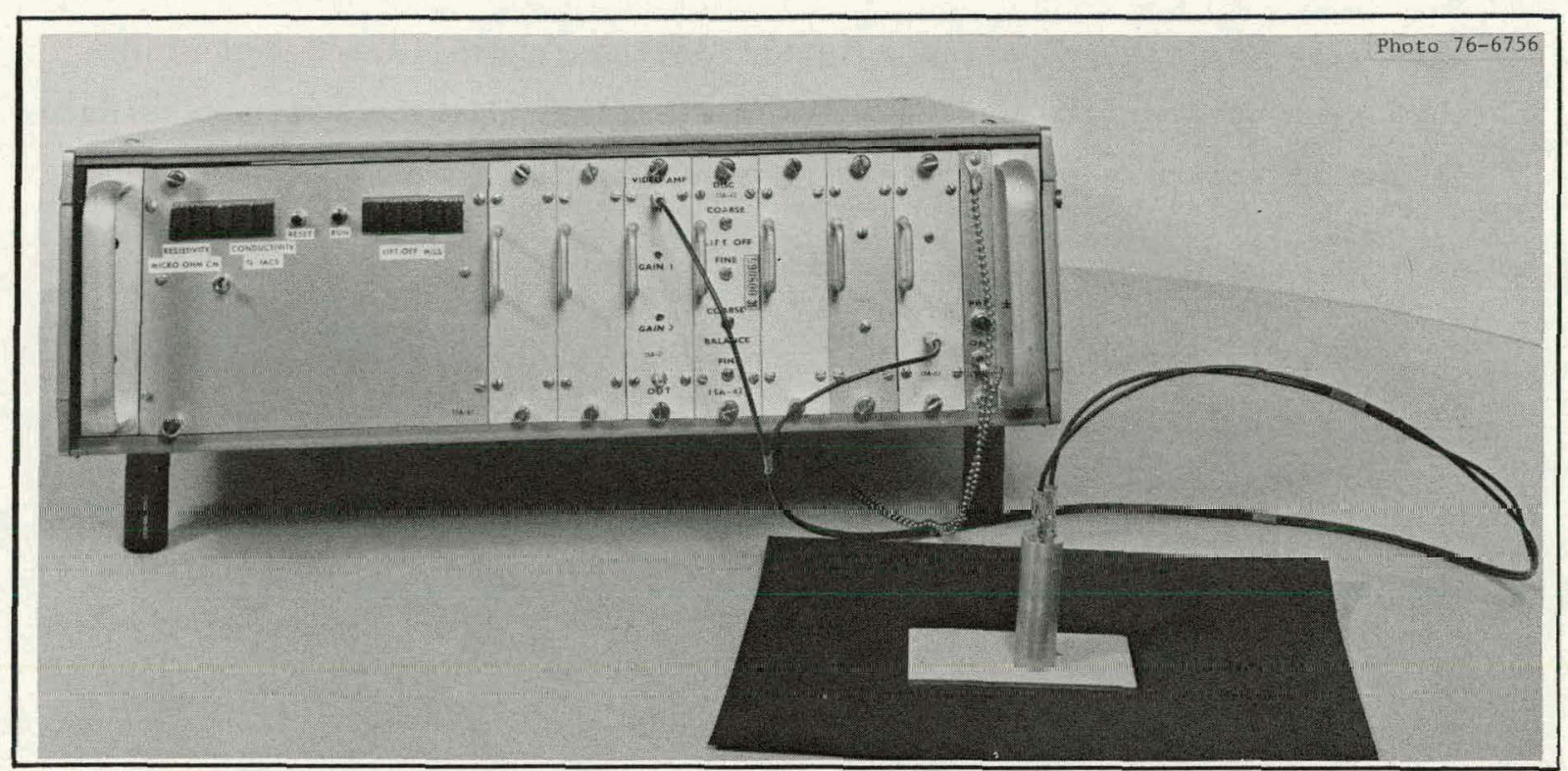

Fig. 7.3. Genera1-Purpose Eddy-Current Instrument to Measure Thickness of Nonconductive Coatings and Base Metal Conductivity.

lift-off and resistivity are automatically computed from these instrument readings by use of a combination of look-up tables, polynominal approximations, and iterations by a microcomputer ${ }^{2}$ contained in the instrument. By measuring two parameters with the instrument and performing the calculations, we obtain lift-off values free from the errors that would be introduced into the readings of a single-parameter instrument by variations in the substrate resistivity. The thickness of the coating can range from 0 to $0.38 \mathrm{~mm}$ (15 mils), and the resistivity of the base material can range from 0.017 to $1.9 \mu \Omega \mathrm{m}$. The accuracy of the nonconductive coating thickness measurements is $\pm 0.5 \mu \mathrm{m}(0.02 \mathrm{mil})$ from 0 to $0.21 \mathrm{~mm}(8.5 \mathrm{mils})$ and degrades to $2.5 \mu \mathrm{m}$ ( $0.1 \mathrm{mil})$ as the thickness approaches $0.38 \mathrm{~mm}$ (15 mils). The accuracy of the resistivity reading is $\pm 0.05 \%$ over the entire resistivity range. We are now working on the computer program and hardware adjustments to install a self-calibration feature.

We have experimentally evaluated one commercial bridge instrument with only magnitude measuring capability to determine its ability to measure

${ }^{2}$ C. V. Dodd and G. D. Conne11, The NDT-COMP8 Microcomputer, ORNL/TM-5773 (March 1977). 
lift-off. We are preparing a report of these results and comparing them with appropriate criteria for maximizing the response of a singleparameter instrument to lift-off variation.

\subsubsection{Cermet Coatings}

Through-transmission experiments have been performed on free-standing layer specimens of $50 \% \mathrm{ZrO}_{2}+50 \% \mathrm{NiCrAl}$ (75-24-1). The conductivity of the material is sufficient to show sensitivity to changes in layer thickness of $25 \mu \mathrm{m}$ (0.001 in.). 


\section{THERMAL INSPECTION METHODS}

Thermal inspection methods are based on local variations in the rate of heat transfer through a workpiece. These variations are detected by measuring temperatures on the workpiece surface. A passive workpiece is interrogated by the injection or removal of heat across some portion of its surface. Thermometric methods measure instantaneous temperatures at points, simultaneously or in a sequential, or scanning, mode. Thermographic methods generate an instantaneous image of a finite area on the workpiece surface and depict temperature as some property of the image, such as brightness, color, or isothermal contours. Scanning thermometric methods with continuous recording can also generate images that represent the entire part. Either method may use contacting or noncontacting detectors.

Thermal methods have enjoyed their greatest application to inspection of layered, bonded, or coated structures. They are most sensitive to lamellar defects, which interrupt heat transmission over a finite area. Structures containing nonmetallic layers are sometimes easier to inspect because heat transmission is less rapid and thermal "images" of defects persist longer.

Early inspection equipment and procedures were developed experimentally. Experiments are still required, but they can be assisted by computational techniques. Rapid computation of solutions to heat flow problems can simulate some experiments and screen out unnecessary ones.

\subsection{APPLICATIONS TO COATING INSPECTION}

\subsubsection{Material Characterization}

Computational methods yield results whose accuracy depends on the accuracy of material property data input to the computations. Accurate thermal data on sprayed coating materials are not available in the literature. Bulk properties can be used as a starting point for feasibility-level computations and test designs. Measurement of thermal properties may be required to provide input for optimization of test designs. 


\subsubsection{Mathematical Modeling}

Transient solutions to one- or two-dimensional heat flow equations can be combined to construct the response of a coating-substrate system to a rapid-scanning or pulsed heat source. Any form of thermal excitation can be decomposed into thermal wave components by Fourier transformation. Each wave component obeys a dispersion law of the form

$$
i \omega=k k^{2}
$$

where

$$
\begin{aligned}
& \omega=\text { the temperature oscillation frequency, } k=\text { thermal diffusivity, } \\
& \text { and } \\
& k=\text { the complex wave number }
\end{aligned}
$$

Equation (8.1) leads to a phase velocity,

$$
v_{p}=(2 \kappa \omega)^{1 / 2},
$$

which depends on the frequency and its corresponding wavelength,

$$
2 \pi(2 \kappa / \omega)^{1 / 2}
$$

The form of equations (8.1) and (8.2) assures that any pulsed heat input will change its pulse shape rapidly and may not be detectable as a pulse with equipment based on current technology.

To detect a defect by scattered heat, the incident wavelength [Eq. (8.3)] should be of the order of the defect size or smaller. The maximum thermal contrast at the surface of a coating layer from a defect at the coating-substrate interface will follow the heat pulse by about the time required for a wave of the corresponding frequency to make a round trip through the coating layer.

Alternatively, one can separate a scanning heat source and delectur to establish quasi-steady-state heat flow conditions. When a source of appropriate size is passed over a coating layer structure at the appropriate 
speed, the transients will pass before the temperature sensor arrives and the temperature profiles will approach their steady-state configuration. Defects will be detected by the difference between the steady-state conditions measured over a defect and over a sound structure.

\subsubsection{Scanning Thermometric Inspection}

Scanning inspection devices use a heat source followed by one or more thermometric detectors. By using two sequential temperature measurements following heating, one can correct for emissivity variations of the workpiece surface. ${ }^{1}$ Typical heat sources are plasma torches, hot gas jets, and eddy-current induction heaters. Radiometers and low-mass (i.e., low thermal inertia) thermistors are used for detection. Continuous processing and recording, synchronized with the scanner motion, can produce a plan-view record of the quasi-steady-state condition at all points in the scan pattern.

\subsection{EXPERIMENTAL WORK}

\subsubsection{Thermal Modeling}

The parameters for a scanning thermometric method were estimated ${ }^{2}$ by use of the HEATING3 program. ${ }^{3}$ The results are used to determine the lifetime of the transient phenomena and the maximum thermal contrast between flawed and nonflawed structures. From these quantities we can determine appropriate scanning speeds, required heating rate for the scanning source, required response time of the temperature detectors, and the proper spacing between the heat source and detectors on the scanning fixture. Figure 8.1 shows the calculated temperature difference

\footnotetext{
${ }^{1}$ D. R. Green, "Principles and Applications of Emittance-Independent Infrared Nondestructive Testing," Appl. Opt. 7(9): 1779-89 (September 1968).

${ }^{2}$ W. A. Simpson, Jr., "Thermal Testing," Coal Technology Program Quart. Frog. Rep. Sept. 30, 1976, ORNL-5224, pp. 61-63.

${ }^{3}$ W. D. Turner and M. Siman-Tov, HEATING3 - An IBM 360 Heat Conduction Program, ORNL/TM-3208 (February 1971).
} 


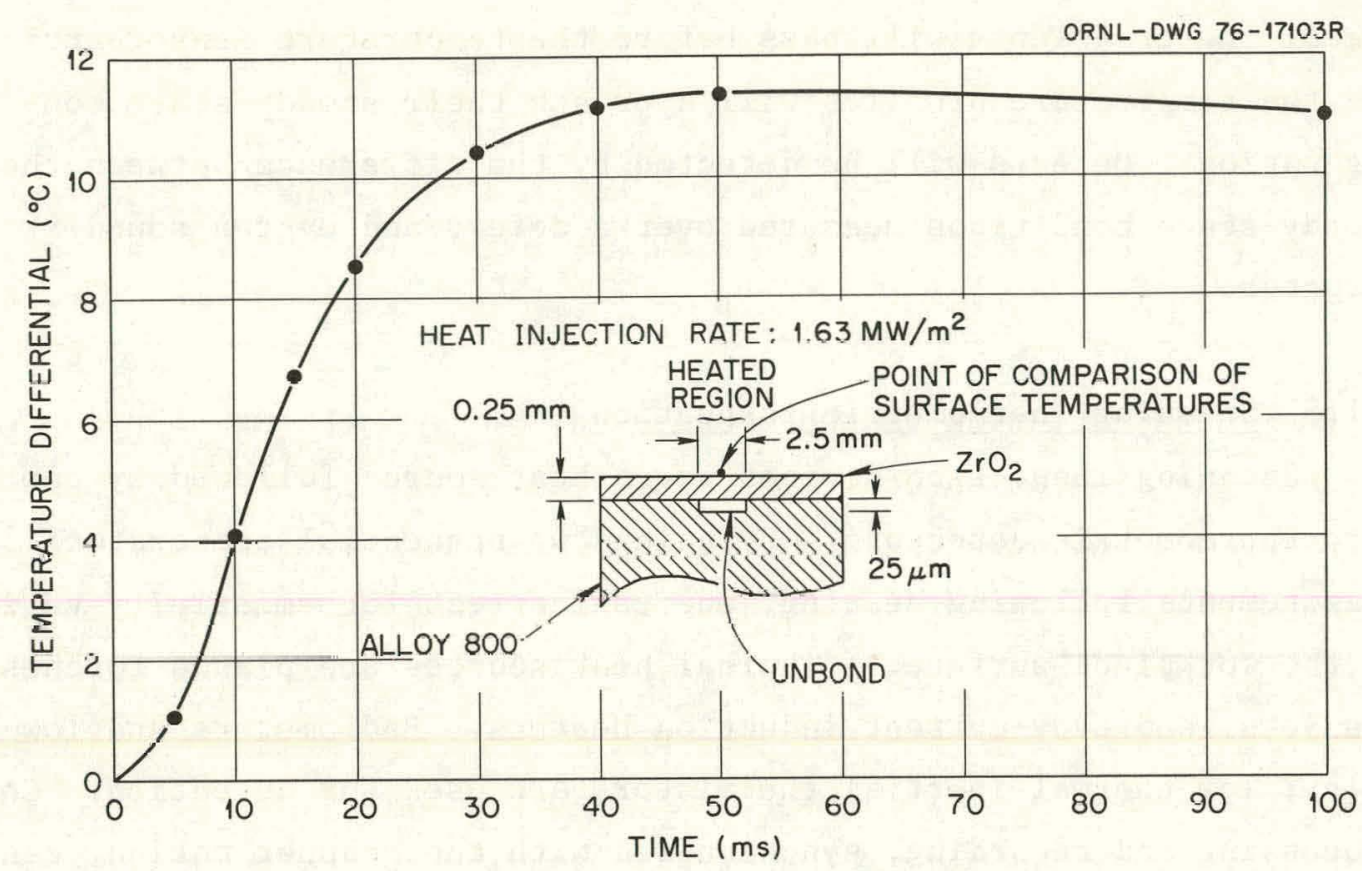

Fig. 8.1. Computed Surface Temperature Differential Between Coated Specimens With and Without Unbond Flaws.

between flawed and nonflawed sections on a heat-up transient in $\mathrm{ZrO}_{2}$ coated on alloy 800. For the assumed parameters, the data show adequate thermal contrast for flaw detection, and the scanning speed for the heat source can be estimated. The other half of the computation will be the cool-down transient, from which the temperature sensor spacing can be calculated.

Future computations at ORNL will use HEATING5, a newer program, ${ }^{4}$ which calculates the same solutions as HEATING3 but has additional features to improve its efficiency.

\subsubsection{Video Thermographic Tests}

Expcriments ware performed ${ }^{5}$ with existing laboratory equipment to quickly demonstrate feasibility of thermal methods for $\mathrm{ZrO}_{2}$ coatings.

\footnotetext{
${ }^{4}$ W. D. Turner et a1., HEATING5 - An IBM 360 Heat Conduction Program, ORNL/CSD/'I'M-15 (March 1977).

${ }^{5}$ W. A. Simpson, Jr., "Thermal Testing," Coal Technology Program Quart. Prog. Rep. Mar. 31, 1977, ORNL-5282, pp. 91-93.
} 
The same heat transfer parameters govern the appearance and persistence of a thermographic image that govern the situation described in Sect. 8.2.1, except no scanning is involved.

A specimen similar to that shown in Fig. 8.1 was made by machining a void space $3.2 \mathrm{~mm}$ ( $0.12 \mathrm{in.)}$ diam by $0.25 \mathrm{~mm}$ (0.010 in.) deep in the substrate, filling it with a mica disk, and then spraying the coating over it. Two heating methods were used, a hot gas jet blowing on the ceramic surface and an eddy-current induction coil placed next to the metal side of the specimen.

Figure 8.2 shows the thermographs of the gas-heating and inductionheating experiments. The artificial flaw produced a slightly elongated thermal indication; two views show two orientations $90^{\circ}$ apart.

The preceding work was done with an imaging infrared camera. The drawbacks to this approach are: (1) The time spent interrogating the nonbond region is only a small fraction of the time required to produce the entire picture, hence the time between successive interrogations of the nonbond region is relatively large. (2) Neither the relative nor absolute temperatures of features in the thermal display can be determined easily because of the transient nature of the temperature distribution and because temperature is represented by image intensity. Both these difficulties can be ameliorated by substituting a line-scanning camera for the imaging system. Temperature is then represented by the analog voltage output of the camera, and the time spent scanning the nonbond is a much larger fraction of the total scan time. This approach was adopted on the sample of Fig. 8.2 with an induction source uscd to heat the metal substrate.

Figure 8.3(a) shows the thermal profile obtained in a bonded region just above the intentional nonbond. The decrease in temperature at the left edge of the figure is caused by the edge of the induction coil; this region is outside the heated area. The sharp rise in temperature to the right of center is caused by the sample boundary. The crowding together of the induction field lines at the sample edge produces stronger heating in this region. This scan was made after heating for $0.5 \mathrm{~s}$.

In Fig. 8.3(b) the scan has been adjusted to pass across the center of the nonbond area. After $0.5 \mathrm{~s}$ of heating the effect of the nonbond 

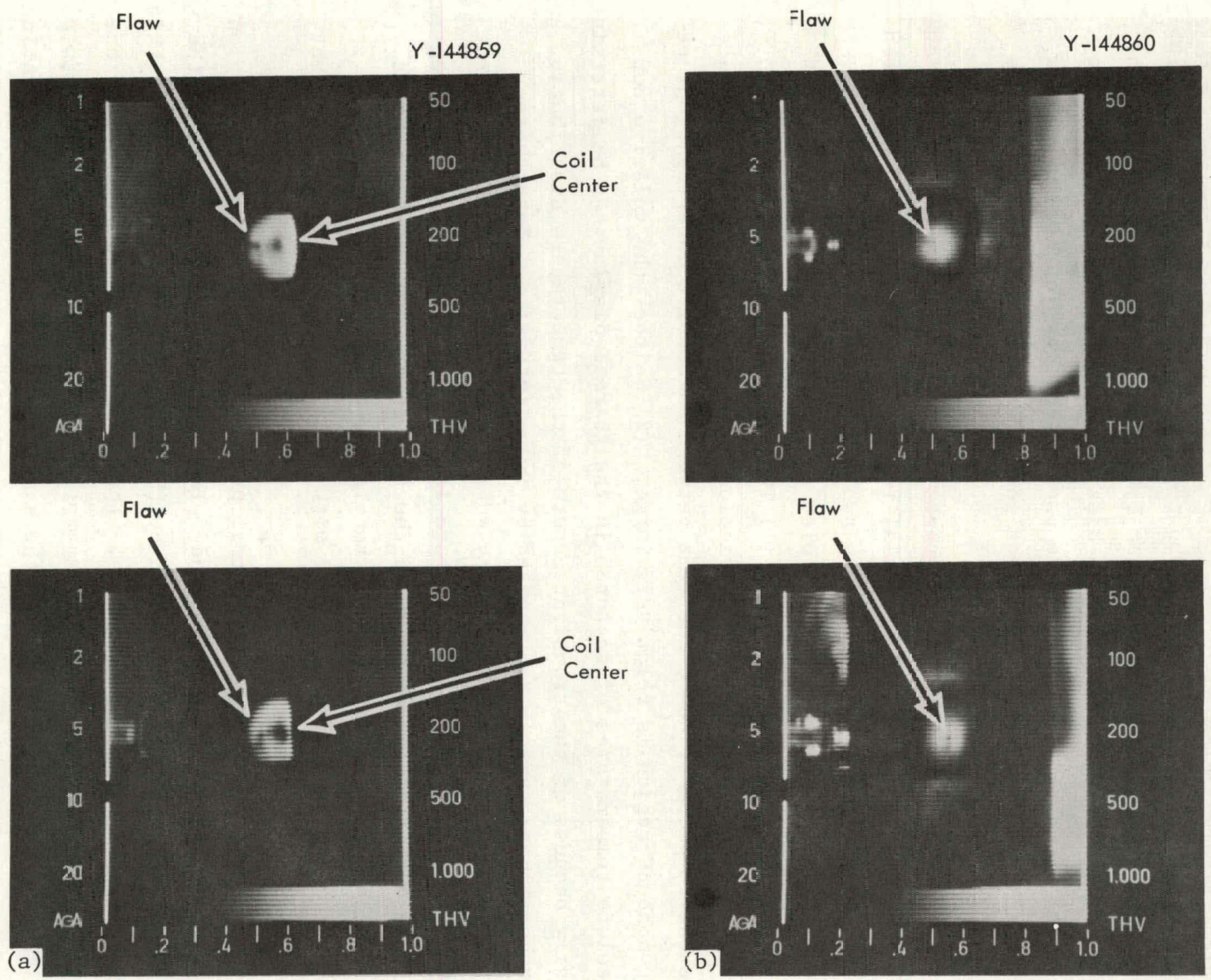

Fig. 8.2. Therrographs of an Unbond Flaw in a Specimen cf $\mathrm{ZrO}_{2}$ Coated on $\mathrm{Alloy} 800$. For each heating method, two crientations $90^{\circ}$ apart are shown. Left: Hot-gas-jet-heated coating surface. Right: Induction-heated substrate. 

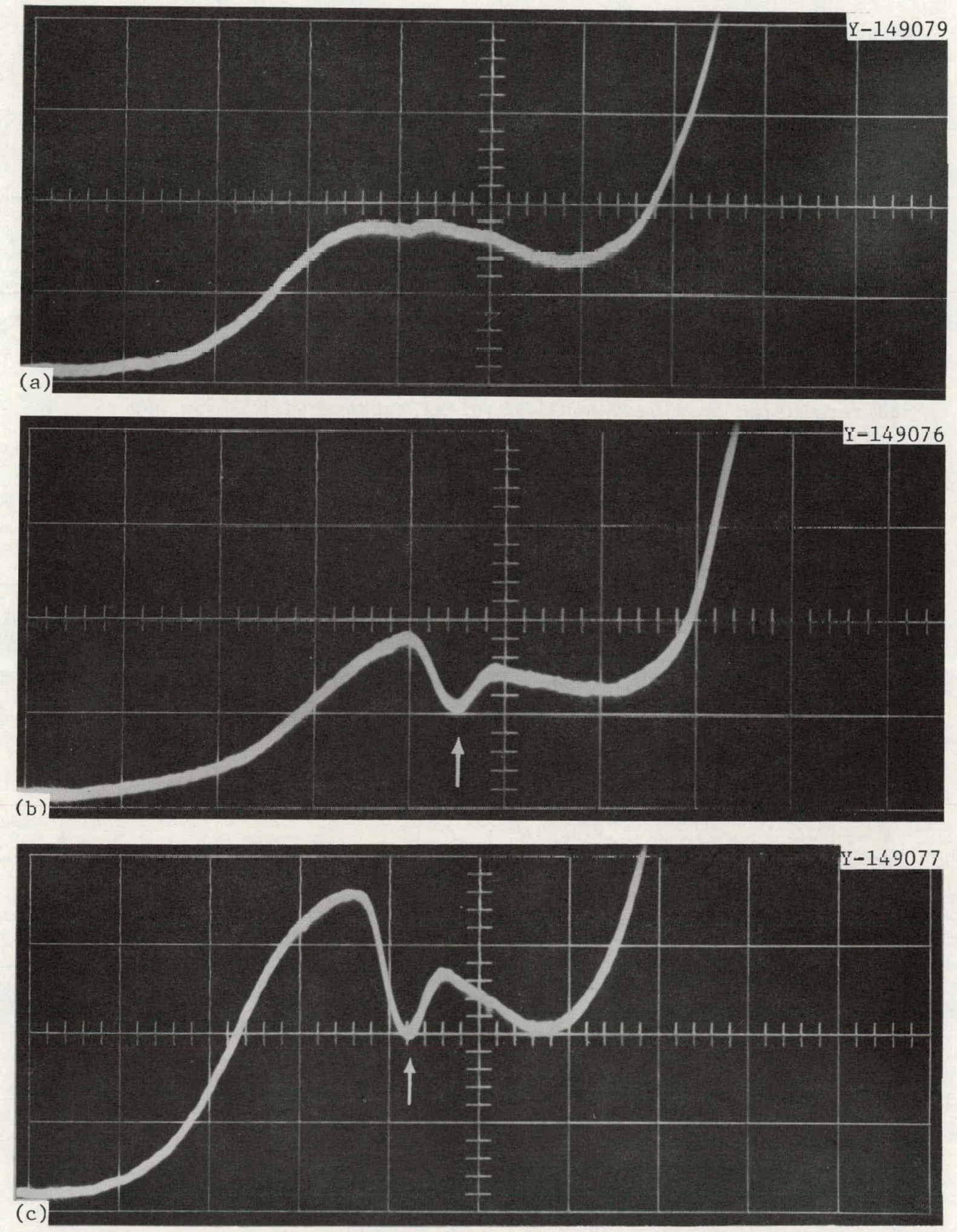

Fig. 8.3. Line Thermographs of a $\mathrm{ZrO}_{2}$ Coating Specimen on an Induction-Heated Alloy 800 Substrate. Vertical scale is about $1^{\circ} \mathrm{C}$ per major division. (a) $5 \mathrm{~mm}$ ( $0.2 \mathrm{in.)}$ from defect center after $0.5 \mathrm{~s}$ heating. (b) Unbond flaw after $0.5 \mathrm{~s}$ heating. (c) Same unbond flaw after $1.0 \mathrm{~s}$ heating. 
is obvious. A temperature differential of approximately $0.75^{\circ} \mathrm{C}$ exists between the nonbond area and the adjacent bonded regions. Figure 8.3(c) shows the thermal profile after heating $1.0 \mathrm{~s}$. The temperature differential is more than $1.0^{\circ} \mathrm{C}$.

Having established the efficacy of thermal techniques to detect nonbonds in ceramic coatings, we designed a thermistor probe. The active element is a 0.13 -mm-diam (0.005-in.) thermistor with a response time of $0.12 \mathrm{~s}$. The difficulty in mounting such a small sensor can be appreciated from the wire size of approximately $15 \mu \mathrm{m}$ (0.0006 ill.). However, once mounted, the probe should provide adequate sensitivity and resolution in a very small physical package with a low power consumption suitable for field service.

\subsection{BIBLIOGRAPHY}

R. E. Engelhardt and W. A. Hewgley, "Thermal and Infrared Testing," Nondestructive Testing, A Survey, NASA-SP-5113 (1973), Chap. 6.

F. E. Alzofon, "Retardation and Diffraction Aspects of the Conduction of Heat in Solids," Am. J. Phys. 30: 285 (1962). 


\section{ULTRASONIC INSPECTION METHODS}

All ultrasonic inspection methods interrogate the workpiece with high-frequency sound, most of ten in the range 1-30 $\mathrm{MHz}$. Characteristics of sound emissions from the workpiece are analyzed to detect a condition or measure a property. Ultrasonic methods are nearly always described by the characteristics of the sound used. Often, the description must include the inspection equipment, its design, and its physical arrangement relative to the workpiece.

Sound is characterized by its frequency and its mode of vibration (e.g., longitudinal, shear) in the material it traverses. For inspection, sound is generated as a beam, either unfocussed ("straight") or focussed. The beam source may emit a single frequency, which must be a continuouswave signal, or a pulse, which always contains a mixture of frequencies. Interrogating sound incident on the workpiece may be reflected, transmitted, refracted, scattered, or converted to another vibration mode, or it may undergo any combination of these processes to produce the emission that is received and analyzed. Analysis of emissions in the time domain may yield such information as time of arrival of or intervals between pulses, duration, amplitude, and evidence of interference. Analysis of multifrequency emissions in the frequency domain yields the frequency content and relative phase information. The data retrieved by analysis may be output as an oscilloscope display, as a single-channel recording, or as a plan view recording depicting part of the workpiece.

U1trasound has been used to detect flaws, to measure acoustic properties of materials, and to measure dimensions. Other properties or conditions, such as cold work, that correlate with an acoustic property can be determined indirectly.

The acoustic properties of plasma-sprayed coatings present some difficulties to the application of simple methods, so a long search and evaluation period is likely. Because of the diversity and sophistication of ultrasonic technology, the discovery of an adequate inspection method also appears likely. 


\subsection{APPLICATIONS TO COATING INSPECTION}

\subsubsection{Acoustic Properties of Coating-Substrate Structures}

All the coating layers are thin, so the transit times for waves traveling across the layers are short and time resolution of the two surfaces of the layer requires high-resolution equipment. The ceramics have higher acoustic wave velocities than most metals. Values of the acoustic impedance (the product of velocity and density) for all the coatings are close to those of the substrates, so it is difficult to get reflections from the coating-substrate interfaces. The porosity of the sprayed coatings scatters sound, so any wave propagating through the coating attenuates rapidly and may become disturted if the path in the coating is more than a few wavelengths.

Most austenitic stainless steels are highly attenuating. The alloy 800 specimens examined have been somewhat attenuative; thick sections used in other work have been unpredictable in their properties. The as-milled thickness and surface finish of industrial materials will vary somewhat, so compensation will be required in any test design.

\subsubsection{Design of Coating Inspections}

Although systematic trials will ultimately demonstrate capabilities, the repertoire of applicable methods can be narrowed by considering the limitations of the workpiece and its environment. Closed systems will require inspection from the outside by a pulse-echo (single-transducer) or pitch-catch (two-transducer) method. Immersion coupling of focussed transducers may be desirable to achieve resolution, but inspection of hot, operating systems will require contact coupling through cooled delay lines. On the other hand, contact coupling would be unsuitable for sliding coupling on the rough (coated) inside surfaces.

Because of the acoustic properties of the coatings, applicable methods are likely to exploit the effects of the coating on the propagation of sound waves in the substrate. Reflections at normal incidence or at angles from the coated surface of the substrate show promise. Waves propagating in the coating layer or surface-type waves in the substrate along the interface should also be investigated. Any method relying on 
the effects of the coating's presence may be adversely affected by the deposit of process material on the surface of the coating, so a way to compensate for such effects will also be required.

\subsection{EXPERIMENTAL WORK}

\subsubsection{Thickness Gaging}

We have tried a number of commercial ultrasonic thickness gages on various specimens and at frequencies of 5, 10, and $15 \mathrm{MHz}$. Thus far, none of the instruments has successfully differentiated between coated and uncoated areas on a specimen. The instruments read the same on coated and uncoated areas, which suggests that either the sound does not penetrate the coating or penetrating the coating does not produce a significantly different echo. Additional studies on acoustical effects in the coating may provide a better explanation of these observations.

Waveforms from a Panametrics ${ }^{1}$ thickness gage showed a phase shift of about $180^{\circ}$ upon reflection from the coating interface of the ANL-C5 specimen $^{2}$ described in Sect. 3.2.2. This effect has not been observed on any other specimen. It can be caused by the presence of a layer of material with a higher acoustic impedance, but we have no corroborative data indicating the impedance of the coating.

\subsubsection{Critical Angle and Surface Wave Studies}

Various coated specimens have been examined ${ }^{3}$ with two different schlieren sound visualizalion systems, one at URNL and the other at the University of Tennessee, Knoxville. Visualization allows direct observation of sound beams entering and leaving the workpiece (specimens) and rough measurement of the angular relationships between them. These observations showed no Rayleigh-angle phenomena for $\mathrm{ZrO}_{2}$-coated specimens, which suggests that the coating layer does not transmit surface waves we11. Considering the porosity of the coatings examined, this difficulty in transmitting sound is not surprising.

\footnotetext{
${ }^{1}$ Model 5221, Parametrics, Inc., Waltham, Mass.

${ }^{2}$ Provided by Argonne National Laboratory.

${ }^{3}$ G. W. Scott, "U1trasonic Testing," Coal Technology Program Quart. Prog. Rep. March 31, 1976, ORNL-5159, pp. 97-98.
} 


\subsubsection{Norma1-Incidence Pulse-Echo Unbond Detection}

We used immersion-coupled, focussed transducers of various frequencies to determine if unbonds or areas of missing coating could be detected by loss of energy in the rear-surface reflection of normally incident pulses. ${ }^{4}$ A sound pulse that has made several round trips between the front (uncoated) and rear (coated) surfaces of a specimen suffers a measurable loss of amplitude. Figure 9.1 shows a drawing of the specimen used; scans were made along the centerline of this specimen. The results obtained at various frequencies are shown in Fig. 9.2. The unbond and missing-coating defects were buth delectable at all frcquencies with approximately

${ }^{4}$ G. W. Scott, "U1trasonics," Coal Technology Program Quart. Prog. Rep. December 31, 1976, ORNL-5252, pp. 91-94.

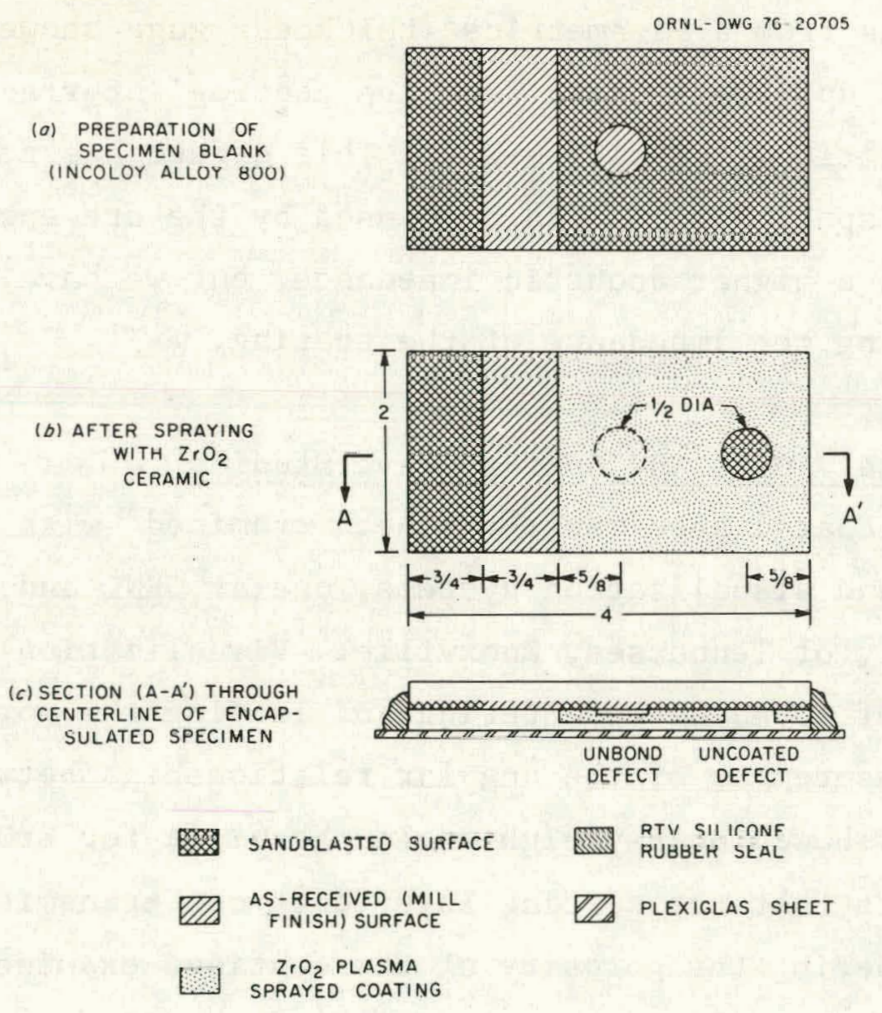

Fig. 9.1. Fabrication Steps and Description of the Immersible U1trasonic Specimen. Multiply dimensions indicated by 25.4 to get values in millimeters. 


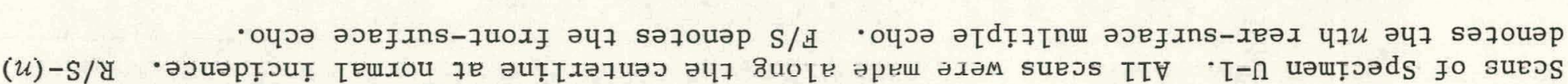

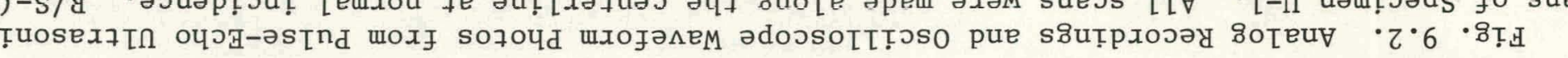
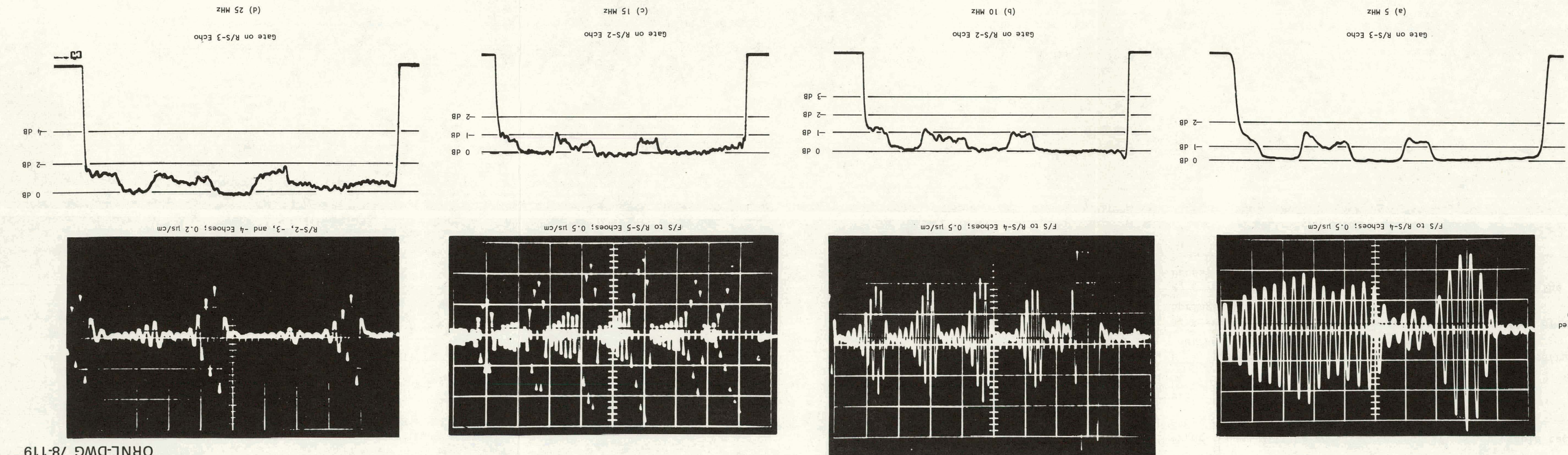
the same sensitivity. As Fig. 9.2(a) indicates, the echoes are more difficult for an operator to distinguish at lower frequencies. This technique can be used on workpieces with parallel surfaces, such as pipe, plate, and vessel walls.

Variations of this technique using solid-wedge contact couplers and dual transducers are being developed. A systematic trial-anderror scheme will be required to identify other usable techniques.

\subsection{BIBLIOGRAPHY}

B. E. Leonard and C. G. Gardiner, "Ultrasonics," Nondestmuctive Testing, A sumey, NASA-SP-5113 (1973), Chap. 3.

J. Krautkramer and H. Krautkrämer, ULtrasonic Testing of Materials, Springer-Verlag, New York, 1969.

R. C. McMaster, ed., Nondestructive Testing Handbook, The Ronald Press, New York, 1959, Sects. 43-50. 
10. SUMMARY AND TECHNICAL ASSESSMENT OF INSPECTION

The program planner, the potential equipment manufacturer, and others need the latest available guidance on inspection capability for plasma-sprayed ceramic and cermet coatings. Our evaluation of the present state of the art with restrictions and qualifications is given below.

\subsection{LIMITATIONS OF CURRENT WORK}

The work completed thus far has been directed toward an assumed set of flaws or defect conditions. Other conditions of interest may not be known until materials are selected and additional studies on those materials are completed. Also, at this time, there is very little indication of the significant sizes of flaws or severity of defect conditions.

The experimental work at ORNL has used a small number of selected materials, applied under laboratory or small-shop operating conditions. Our materials represent the general coating types of interest, but are not likely to be the exact types used. Materials applied in the industrial environment may show greater variability than the small specimens we have used.

Part of the evaluations included here are based on our interpretation and evaluation of published literature rather than firsthand laboratory experience on project-related materials. We do not have firsthand experience or expertise will all the methods examined.

\subsection{ASSESSMENT OF CURRENTLY AVAILABLE INSPECTION CAPABILITY}

\subsubsection{Thickness Measurement}

The best candidate method for ceramic coatings is a lift-offsensing eddy-current technique. It requires contact with the coating, it integrates over the finite coil area, and it averages over rough surfaces with some error, usually positive (i.e., indicating greater thickness), based on the quality of the contact and the accuracy of 
probe orientation. For ceramic coatings, it is the only activesensing method that is unaffected by other properties of the coating, such as dielectric constant or porosity. A capacitance system should be examined further, and a suitably equipped laboratory should look at microwave methods, especially for production applications.

\subsubsection{Detection of Cracks and Holes}

Flaw or defect conditions related to this type of abnormality may require better definition before a reliable assessment. For example, large areas where the complete coating layer has spalled or where one or more outer layers in a mileflayer scruccure have spalled llay be apprnpriate1y detected by methods applicable to unbonds or delaminations.

Methods using surface inspection materials appear to offer the most efficient and economical evaluation of small defects located in large surface areas. Some development of procedures is still necessary and some new materials with less sensitivity to porosity may be required.

The high-voltage method can provide good detection of defects that pass through a ceramic layer. Desirable improvements in resolution can probably be achieved with some additional development. The method should be adaptable to automation, including rapid scanning and planview recording.

The electrochemical differential capacitance method has some novel features, which may be advantageous for some inspections. It will require considerable development before industrial application. We have not yet determined all the types of coatings to which it may apply.

\subsubsection{Detection of Unbonds and Delaminations}

Ultrasonies appcars to have the greatcot potontial for detecting missing cuallug alteds. Il is lie vily method thus far demonstratcd as feasible for inspecting any coating property through the containment wall of a closed system. Inspection techniques may require significant dcvelopment times because of the variety of 111 trasnnir methods that will have to be screened.

Thermal methods offer a potential alternative to ultrasonics. Thermal equipment is bulkier than ultrasonic equipment and may be more 
difficult to adapt to some workpiece geometries and to the industrial environment. It will also require access to the coated side of the workpiece. If the various disadvantages can be overcome, thermal methods may achieve sensitivity and resolution comparable to those of ultrasonics. The development time is also probably comparable to that of ultrasonics.

\subsubsection{Detection or Measurement of Inhomogeneity}

No method appears suitable to detect or measure inhomogeneity with a single measurement (assuming that the measurement is repeated at a number of points). The special case of inhomogeneity in composition may be detectable with $x$-ray fluorescence by a single counting period at a point. Several characteristic $x$-ray lines can be measured simultaneously, and the relation between them shows the variation in composition. Those methods that respond to inhomogeneities, such as porosity, also respond to other variables, such as thickness, so that the source of variation cannot be identified. This aspect of the inspection problem reflects the least progress among those discussed, because most of the methods examined only detect or measure conditions characterized by a single variable.

For ceramic coatings, it may be possible to develop a microwave technique that makes two measurements simultaneously, either amplitude and phase, or phase and loss: A capacitance probe combined with another device, such as an eddy-current lift-off sensor, could detect variations in dielectric properties or porosity.

Inhomogeneity in cermet coatings that affects electrical or magnetic properties may be detectable by multiple-frequency eddy-current methods. However, these methods will also likely sense crack-, hole-, and voidtype defects, making computer-controlled signal analysis necessary.

\subsection{RECOMMENDATIONS}

At this stage of the coal technology program, we do not feel that specific methods should be singled out for each of the above abnormal or defect conditions and developed to a high degree of performance. Each method having potential should be pursued until it is well understood 
technologically, but preparation of specific procedures and fabrication of prototype industrial standards should be deferred. The more tools there are available, the more likely will be the solution of unexpected problems in the inspection of coal equipment when they arise. As long as the plasma-sprayed materials remain viable candidates for coal equipment applications, some level of effort should be directed toward characterizing them and developing a technology base for application to their inspection.

\section{ACKNNOWLEDGMENTS}

The aulluss wish Lu Lliank F. A. Pusey of the ORNL Clıeinlstry Division for suggesting the investigation of differential electrode capacitance effects on ceramic coatings. J. D. Hudson and D. P. Edmonds of the ORNL Welding and Brazing Laboratory fabricated most of the specimens used and assisted in designing many of them. H. T. Murrin and C. Ruffner fabricated prototype equipment for various experiments. D. P. Edmonds and R. T. King reviewed the manuscript. S. Peterson edited the report and Connie Harrison prepared it for reproduction. 
ORNL/TM-6210

\section{INTERNAL DISTRIBUTION}

1-2. Central Research Library

3. Document Reference Section

4-6. Laboratory Records Department

7. Laboratory Records, ORNL RC

8. ORNL Patent Office

9. M. Bender

10. N. K. Bernander $(Y-12)$

11. H. D. Cochran, Jr.

12. K. V. Cook

13. K. E. Cowser

14. E. V. Davis

15. V. A. DeCarlo

16. C. V. Dodd

17. W. P. Eatherly

18. D. P. Edmonds

19. D. E. Ferguson

20. L. M. Ferris

21. B. E. Foster

22. W. Fulkerson

23. J. W. Garber $(\mathrm{K}-25)$

24. T. G. Godfrey

25. G. M. Goodwin

26. R. J. Gray

27. W. L. Greenstreet

28. J. R. Hightower

29-31. M. R. Hill

32. R. S. Holcomb

33. J. M. Holmes

34. J. K. Huffstetler

35. V. C. Jackson $(Y-12)$

36. G. R. Jasny $(Y-12)$

37. J. E. Jones, Jr.

38. R. T. King

39. W. J. Lackey

40. W. R. Laing

41. J. S. Lin

42. R. S. Livingston

43. $P . L$. Long $(Y-12)$

44. R. E. MacPherson
45. W. R. Martin (Y-12)

46. D. L. Mason $(Y-12)$

47. W. J. Mason

48. R. W. McClung

49. R. E. McDonald

50. J. R. McGuffey

51. L. E. McNeese

52. J. R. McWherter

53. H. J. Metz

54. C. S. Morgan

55. F. D. Mundt $(\mathrm{K}-25)$

56. J. P. Nichols

57. L. C. Oakes

58. T. W. Pickel

59. H. Postma

60. C. R. Richmond

61. M. W. Rosenthal

62. T. H. Row

63. R. Salmon

64. G. Samuels

65. C. D. Scott

66-70. G. W. Scott

71. W. A. Simpson, Jr.

72. G. M. Slaughter

73. J. H. Smith

74. R. F. Smith (K-25)

75. S. D. Snyder

76. I. Spiewak

77. V. J. Tennery

78. H. E. Trammell

79. D. B. 'l'rauger

80. G. D. Whitman

81. L. V. Wilson

82. C. S. Yust

83. L. Adler (Consultant)

84. S. Alpert (Consultant)

85. H. Beuther (Consultant)

86. M. Semchyshen (Consultant)

87. H. W. Sternberg (Consultant)

88. C. Streed (Consultant) 


\section{EXTERNAL DISTRIBUTION}

89. Ames Laboratory, 205 Met. Dev. Bldg. Iowa State University, Ames, IA 50011

T. E. $S \cot t$

90. Argonne National Laboratory, 9700 S. Cass Avenue, Argonne, IL 60439
0. K. Chopra.
Steven Danyluk
W. A. Ellingson
K. Natesan
J. Y. Park
W. J. Sháck
D. Stah1
R. Swaruup

91. Babcock \& Wilcox Company, P. O. Box 1260, Lynchburg, VA 24505

E. M. Anderson

92. Battelle Columbus Laboratories, 505 King Avenue, Columbus, $\mathrm{OH}$ 43201
A. M. Hall
J. J. Mueller
J. R. Schorr
I. F. Wright

93. Battelle Pacific Northwest Laboratory, P. O. Box 999, Richland, WA 99.352

$$
\text { J. J. Bates }
$$

94. Cabot Corporation, Stel1ite Division, 1,020 Park Avenue, Kokomo, IN 46901

R. B. Herchenroeder

95. Combustion Engineering, Inc., 1000 Prospect Hill Road, Windsor, CT 06095
A. L. Plumley

96. Combustion Engineering Power Systems, 911 West Main Street, Chattannnga, TN 37402

E. C. Lewis

97. Electric Power Research Institute, 3412 H1llview Ave., Palo Alto, CA 94304

F. L. Culler

R. I. Jaffee

I. Stringer 
98. Exxon Research and Engineering Company, P. 0. Box 51, Linden, NJ 07036

M. S. Nutkis

99. Fluidyne Engineering Corp., P. 0. Box Drawer 1465, Springfield, VA 22151

L. R. White

100. Foster Wheeler Development Corporation, 12 Peach Tree Hill Road, Livingston, NJ 07039

I. M. Rehn

101. General Electric Company, 1 River Road, Schenectady, NY 12019

M. B. Cutrone

H. V. Doering

R. M. Goldhoff

R. L. McCarron

102. International Nickel Company, Sterling Forest, Suffern, NY 10901

E. P. Sadowski

103. Lockheed Palo Alto Research Laboratories, 3251 Hanover Street, Palo Alto, CA 94304

R. A. Perkins

104. Metal Properties Council, Inc., 1351 Butler Pike, Blue Bell, PA 19422

A. D. Srhaefer

105. National Bureau of Standards, Washington, DC 20234

J. H. Smith

106. Pratt \& Whitney Aircraft, Aircraft Road, Middletown, CT 06457

T. S. Pettit

107. Sandia Laboratories, Livermore, CA 94550

R. Bradshaw

108. Solar Turbines International, 2200 Pacific Highway, P. 0. Box 80966, San Diego, CA 92122
A. G. Metcalfe
M. E. Ward

109. University of Notre Dame, Box E, Met. Eng. and Materials Science, Notre Dame, IN 46556

N. F. Fiore

110. U. S. Bureau of Mines, P. O. Box 70, Albany, OR 97321

F. W. Wood 
1:1. Westinghouse Electric Corporation, 1310 Beulah, Pittsburg, PA 15235

R. J. Bratton

T. J. Harvey

J. D. Landes

D. Moon

T. Vojnovich

112. DOE, Office of Fossil Energy, 20 Massachusetts Avenue, N.W., Washington, DC 20545

W. T. Bakker

John Fairbank.s

H. E. Franke1

113. DOE, Oak Ridge Operations Office, P. O. Box E, Oak Ridge, TN 37830

Reséarch and Technical Support Division

114-140. DOE, Technical Information Center, Office of Information Services, P. O. Box 62 , Oak Ridge, TN 37830

मU.S. GOVERNMENT PRINTING OFFICE: $1978-740-190 / 7$ 